\title{
INFLUENCE OF ORAL CONTRACEPTIVES ON BONE ADAPTATIONS TO ISOKINETIC STRENGTH TRAINING IN YOUNG WOMEN
}

\author{
BY \\ Serah Elizabeth Selmon \\ Thesis submitted to the faculty of Virginia Polytechnic Institute and State \\ University in partial fulfillment of the requirements for the degree of \\ MASTER OF SCIENCE \\ IN \\ CLINICAL EXERCISE PHYSIOLOGY \\ Dr. William G. Herbert, Chair \\ Dr. Warren K. Ramp \\ Dr. Sharon M. Nickols-Richardson
}

Date: $12 / 05 / 03$

Blacksburg, Virginia

Keywords: Oral Contraceptive, MRTA, DXA, Bone, Young Women 


\title{
INFLUENCE OF ORAL CONTRACEPTIVES ON BONE ADAPTATIONS TO ISOKINETIC STRENGTH TRAINING IN YOUNG WOMEN
}

\author{
Serah Elizabeth Selmon \\ Committee Chair: William G. Herbert, Ph.D. \\ Department of Human Nutrition, Foods, and Exercise \\ Clinical Exercise Physiology
}

\begin{abstract}
Osteoporosis is a debilitating and costly disease of the skeleton characterized by low bone mass and structural deterioration of bone tissue leading to bone fragility and an increased susceptibility to fractures of the hip, spine, and wrist. Current data suggest that at present time, 7.8 and 21.8 million women have osteoporosis and osteopenia respectively. The development of osteoporosis and related fracture in later life depends not only on the rate of bone loss in adulthood, but also on the amount of bone present at skeletal maturity. Oral contraceptives (OC), because of their capacity to diminish concentrations of free testosterone and estrogen, have been purported to affect bone mass in young adult women, but results have proven inconsistent. Further, positive skeletal effects of exercise training are thought to be compromised by use of OCs in skeletally immature females. PURPOSE: To assess the independent and synergistic effects of OC use on bone mineral density (BMD) and long bone mechanical bending stiffness (EI) in college-aged females after unilateral isokinetic resistance training. METHODS: Forty six females (age $20 \pm 1.4 \mathrm{yr}$, height $163.8 \pm 6.2 \mathrm{~cm}$, weight $58.9 \pm 8.6 \mathrm{~kg}$, fat $27.9 \pm 4.8 \%$ ) were categorized as $\mathrm{OC}$ users $(\mathrm{OC}, \mathrm{N}=22$ ) or non-users $(\mathrm{NOC}, \mathrm{N}=24)$. Subjects participated in 32 weeks ( $3 \mathrm{~d} / \mathrm{wk})$ of unilateral arm and leg training at an angular velocity of $60 \% \mathrm{~s}$ using isokinetic dynamometers. BMD and $\mathrm{EI}_{\mathrm{MRTA}}$ were assessed using dual-energy x-ray absorptiometry (DXA) and mechanical response tissue analysis (MRTA), respectively. RESULTS: Total leg and arm muscular strength of the trained limb increased by $16 \%$ and $15 \%$, respectively $(\mathrm{p}<0.001)$, beyond changes observed in the control limbs. Total body BMD increased from baseline for NOC subjects $(\mathrm{p}<0.05)$, but not for OC users. This difference failed to show significance $(\mathrm{p}=$ 0.069) when comparisons were run between NOC and OC groups. Increases in ulnar BMD (p < 0.01 for all limbs) and BMD of the trained total hip (OC, $p<0.001$; NOC, $p<0.05$ ) occurred irrespective of contraceptive status. Positive changes in EI were conflicting, occurring in the trained ulna for the NOC group $(p<0.05)$, and trained tibia for OC users $(p<0.05)$. Tibial BMD increased only for the untrained leg in NOC subjects $(\mathrm{p}<0.01)$. No between group differences were found to be significant, nor were differences between trained vs. untrained, and weight bearing (tibia) vs. non-weight-bearing (ulna) limbs found to be significant. CONCLUSION: These results suggest that oral contraceptives may limit attainment of total body peak bone mass in young adult females. Skeletal maturation in the ulna appeared to be unaffected by exercise training and OC use. Positive effects of exercise training on the total hip were seen in both groups, irrespective of OC status. Conversely, exercise training and use of OCs use may limit the attainment of bone mass in the tibia. Further studies are needed to determine the interactive effects of OC use and isokinetic resistance training on measures of total body and site-specific bone status.
\end{abstract}




\section{DEDICATION}

I dedicate this thesis to my husband Tim, my brother Nathan, and my late grandmother Gladys. Without your love and support through all of my endeavors, I would not be the woman I am today. I also dedicate this work to my mom Gemmah, whose strength and perseverance have shown me that it is possible to overcome any hurdle. 


\section{ACKNOWLEDGMENTS}

I would like to thank my advisor Dr. William G. Herbert who has shown faith in me and my abilities as a student from day one. Without your assistance, this document would not have been possible. I am also grateful to each of my committee members: Dr. Sharon Nickols-

Richardson, and Dr. Warren Ramp, who have assisted with the design of this study, and preparation of this document: your input and suggestions have been invaluable. Dr. Robert

Schulman and Zhengrong Li, your assistance with the statistical analysis used in this document are greatly appreciated. Thank you both for taking the time to explain things to me every step of the way. Dr. Kathleen Poole, your guidance as an undergraduate advisor, and your friendship and assistance throughout my graduate degree have meant more to me than you could ever imagine. Lastly, I would like to thank all others who were more than willing to assist me with my research: Larry Miller, Lee Pierson, Chris Callaghan, Jeannemarie Beiseigel, and everyone who assisted with data collection for the TiBIAL study. I couldn't have completed this project without any of you! 


\section{TABLE OF CONTENTS}

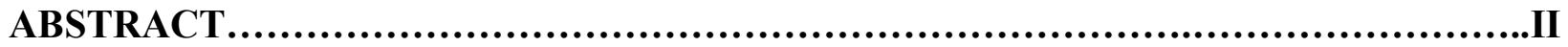

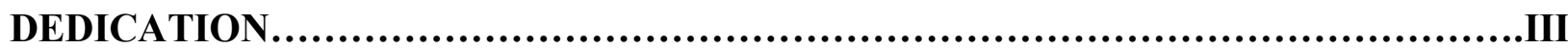

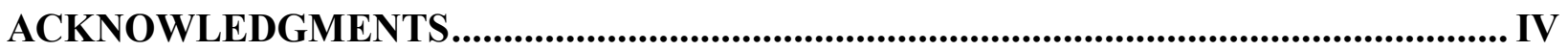

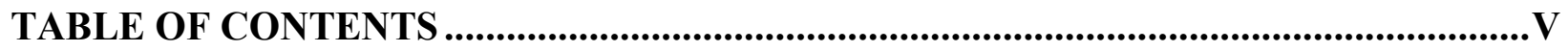

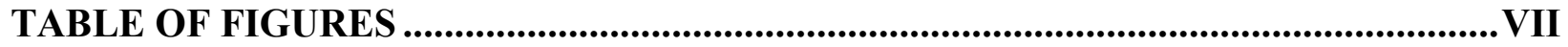

TABLE OF TABLES ...................................................................................................... VII

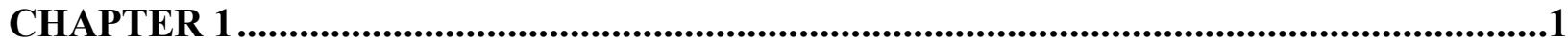

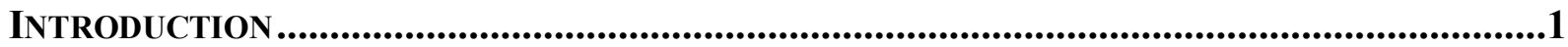

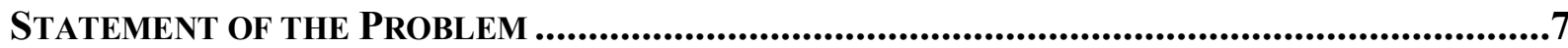

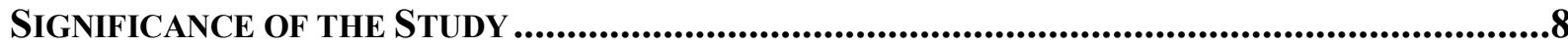

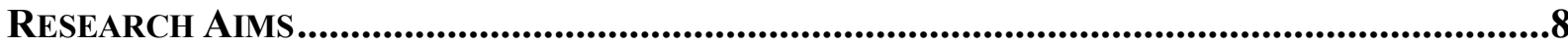

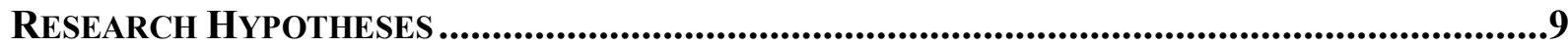

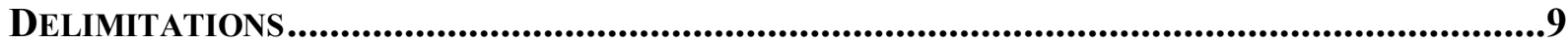

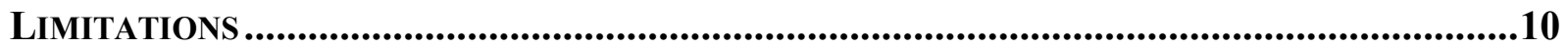

BASIC ASSUMPTIONS .................................................................................................................

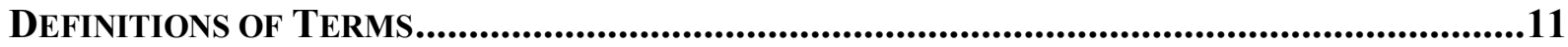

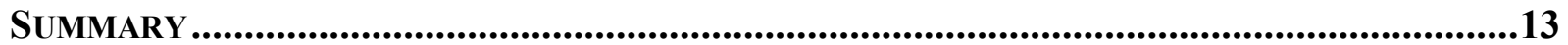

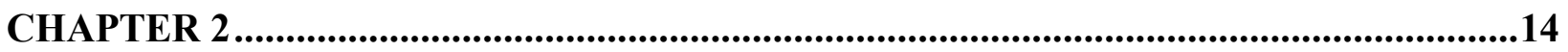

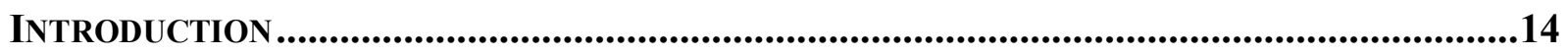

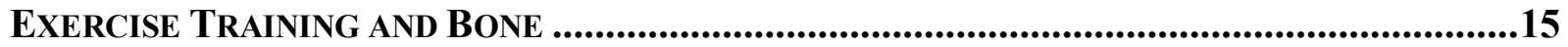

EFFECTS OF ORAL CONTRACEPTIVE USE ON BONE.................................................................17

SKELETAL EFFECTS OF ORAL CONTRACEPTIVE USE COMBINED WITH .................................22

EXERCISE TRAINING IN YOUNG WOMEN..........................................................................22

DUAL ENERGY X-RAY ABSORPTIOMETRY AS THE CURRENT GOLD STANDARD FOR

Measurement Of Bone Mineral Density, AND THE EMERGENCE OF MeChaniCal

RESPONSE TISSUE ANALYSIS AS A MEASURE OF BONE STRUCTURAL INTEGRITY .................27

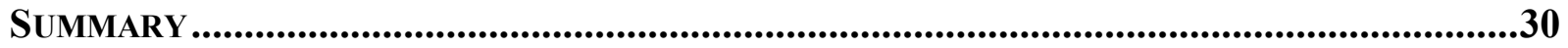

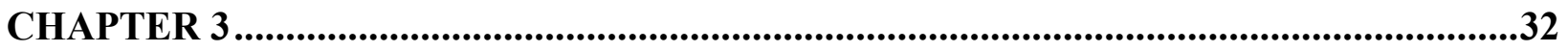

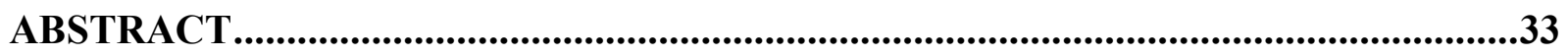

INTRODUCTION ................................................................................................................34

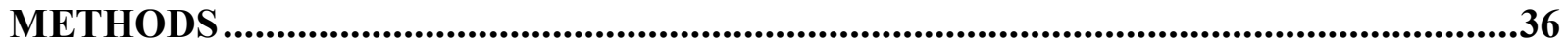

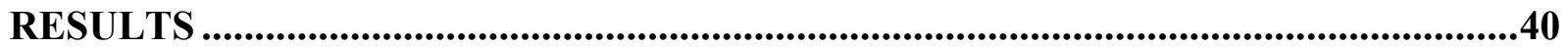

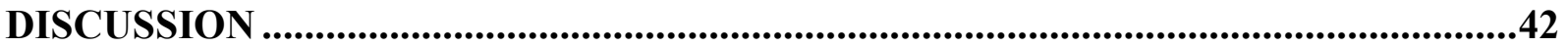

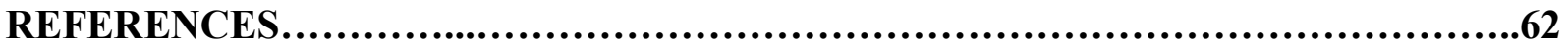

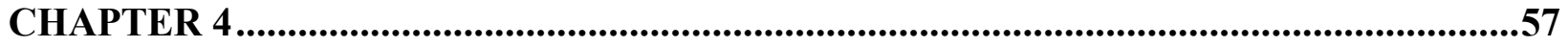

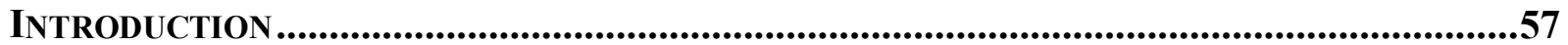

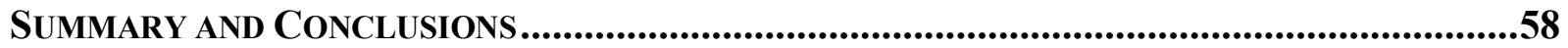

PRACTICAL AND CLINICAL IMPLICATIONS............................................................................59 
RECOMMENDATIONS FOR FUTURE RESEARCH ..........................................................60

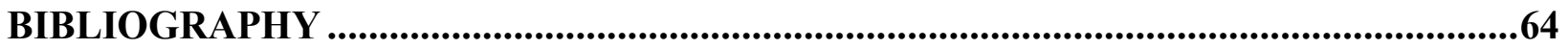

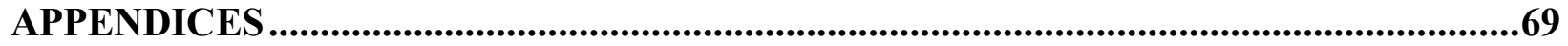

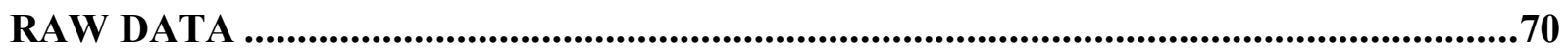

SUBJECT INCLUSION CRITERIA FOR THE TIBIAL STUDY ...................................................81

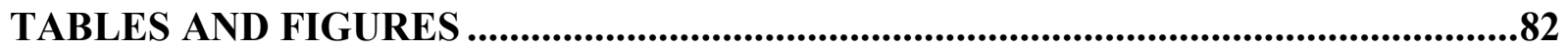

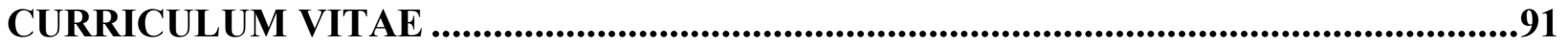




\section{TABLE OF FIGURES}

FIGURE 1: Total body, and site specific increases in BMD seen in NOC and OC subjects

FIGURE 2: Site specific changes in BMD over time for OC and NOC groups

53,88

FIGURE 3- Trends seen in total body BMD (OC vs. NOC)

FIGURE 4- Diagram of skeletal maturation occurring in the ulna irrespective of exercise training, or oral contraceptive status 


\section{TABLE OF TABLES}

TABLE 1: Hormonal Contraceptive Concentrations- Use at Baseline

TABLE 2: Baseline Characteristics for Oral Contraceptive Users and Non-users

TABLE 3: Changes in Strength over Time for Oral Contraceptive Users and Non-users

TABLE 4: Changes in BMD and EI from baseline to post-training for OC users and nonusers

TABLE 5: Subject Inclusion Criteria for the TiBIAL study 


\section{Chapter 1}

\section{Introduction}

Osteoporosis is a debilitating and costly disease of the skeleton characterized by low bone mass and structural deterioration of bone tissue leading to bone fragility and an increased susceptibility to fractures of the hip, spine, and wrist (NOF 2000). Current data suggest that at present time, 7.8 and 21.8 million women have osteoporosis and osteopenia, respectively (NOF 2000). The development of osteoporosis and related fracture in later life depends not only on the rate of bone loss in adulthood, but also on the amount of bone present at skeletal maturity (Golden, Lanzkowsky et al. 2002). Several investigators have suggested that interventions to ensure maximal skeletal mineralization during adolescent bone growth may decrease the risk of osteoporosis later in life (Cromer, Blair et al. 1996). Individuals with the highest peak bone mass after adolescence have the greatest protective advantage when the inexorable declines in bone density associated with increasing age, illness, and diminished sex-steroid production take their toll (NOF 2000). One effective strategy to reduce fracture risk is to find mechanisms to build bone mass in younger women (Burr, Yoshikawa et al. 2000). In general, three classes of factors are thought to influence bone mineral density (BMD): alterations in hormone concentration (reproductive, calciotropic, other), bone-loading (weight, strength, mobility), and lifestyle (nutrition, alcohol, tobacco) (Hawker, Forsmo et al. 2002).

Oral contraceptives (OCs) are the most popular form of reversible contraception today (Abma, Chandra et al. 1997). Based on the 1995 Survey of Family Growth, OCs were used by $13 \%$ and $33.1 \%$ of the U.S. population ages $15-19$, and $20-24$, respectively. With the increasing popularity of OCs as a method of contraception, as well as a prevention measure for endometrial adenocarcinoma, ovarian and colon or rectal cancers and so on (Kaunitz 2002), current statistics 
are undoubtedly higher. Contained in OC pills is a form of estrogen and a form of progesterone, which are both female hormones involved in conception. Bone density has a biological relationship to estrogen that is easily observed during menopause. At menopause, loss of endogenous estrogen promotes an increase in daily calcium loss from $20 \mathrm{mg}$ to about $60 \mathrm{mg}$, reflecting a relative increase in bone resorption over formation activity (Greenspan and Gardner 2001). Women who receive hormone replacement therapy as they enter menopause, however, show calcium balance and rates of mineral turnover similar to those of premenopausal women (Greenspan and Gardner 2001; Perrotti, Bahamondes et al. 2001). The role of estrogen deficiency in the genesis of bone loss and osteoporosis provides a basis for investigating a possible association between bone metabolism and the use of esteroid hormone contraceptives. It can then be speculated that OCs protect against loss of bone because they contain estrogen (Perrotti, Bahamondes et al. 2001). Estrogens are known to increase calcium absorption, decrease calcium loss, and have a direct effect on the reduction of bone resorption (KritzSilverstein and Barrett-Connor 1993). This positive effect on bone formation is caused by stimulation of osteoblastic activities and suppression of osteoclastic activities. Progestin is said to affect bone metabolism by an unknown mechanism (Tharnprisarn and Taneepanichskul 2002), and some studies show no additional benefits of progestin in women taking estrogen either premenopausally (Hergenroeder, Smith et al. 1997; Prior, Vigna et al. 1997), or postmenopausally (Nand, Wren et al. 1999). Women in a reduced state of bone turnover, such as the situation brought about by OC use, are therefore not expected to lose bone (Weaver, Teegarden et al. 2001).

The effect of OC use in young adult females who have not yet achieved peak bone mass is not well established. Prior to the attainment of peak bone mass, young adult women experience a 
net gain in bone mass from year to year as the skeleton matures and develops. Therefore, one might assume that a reduced state of bone turnover in this age group may interfere with normal age-related bone growth. In postmenopausal women, use of OCs has led to suppression of bone turnover, and increased BMD in various sites including the lumbar spine (Taechakraichana, Limpaphayom et al. 2000), hip (Kritz-Silverstein and Barrett-Connor 1993; Taechakraichana, Limpaphayom et al. 2000), and femoral neck (Kritz-Silverstein and Barrett-Connor 1993). Administration of OCs during the years immediately preceding menopause may help women to avoid the increase in bone turnover and decrease in femoral bone density due to perimenopausal impairment of ovarian function (Gambacciani, Ciaponi et al. 2000). Although many studies have seen a positive effect of OC administration on bone in older women, similar studies involving adolescent and young women show different results. Hawker et al (2002) found OC use to have no significant association with BMD in a sample size of 963 women aged 19-35 (Hawker, Forsmo et al. 2002). These results are in agreement with other research concluding that OC has no significant effect on BMD (Fortney, Feldblum et al. 1994; Cromer, Blair et al. 1996; Berenson, Radecki et al. 2001; Cobb, Kelsey et al. 2002; Golden, Lanzkowsky et al. 2002). Although the effect of OCs seems to have either a positive or no effect on bone in the adult skeleton, the concern of many researchers lies in the possible interference of OC use with the achievement of peak bone mass in young women, especially in the presence of exercise training.

The suppression of bone turnover brought about by esteroid contraceptives could reduce the osteogenic effect of an exercise program by preventing the normal increase in bone formation that would occur in response to mechanical loading (Burr, Yoshikawa et al. 2000). In a study by Burr et al (2000), it was hypothesized that although women who exercise during their second and third decades may increase their peak bone mass thus reducing their eventual risk for 
postmenopausal fracture, the effects of exercise in younger women can be modulated by the use of OCs, possibly preventing the accretion of bone mass that would otherwise occur (Burr, Yoshikawa et al. 2000). The conclusions of this study were that either exercise or OC use is associated with a suppression of the normal increase in bone mass and mechanical strength in the femoral neck in women 18-35 years old, but the combination of exercise and OC use appears to have a less suppressive effect (Burr, Yoshikawa et al. 2000). The results of a study by Hartard et al (1997) found the highest BMD (L2-4: $0.858 \mathrm{~g} / \mathrm{cm}^{2}$, femoral neck: right-0.971 g/ $/ \mathrm{cm}^{2}$, left-0.984 $\mathrm{g} / \mathrm{cm}^{2}$ ) in a group classified as long-term exercise/short-term OC use, while no beneficial effect of exercise on BMD was found in the long-term exercise/long-term OC group. There were also no differences in BMD found in the groups with short-term exercise but long or brief histories of OC use. This suggests that use of low dose OCs might counteract the beneficial influence of physical activity on bone formation (Hartard, Bottermann et al. 1997). Research by Polatti et al (1995) measured BMD after 5 years of treatment in healthy women between 19 and 22 years of age and found similar results. BMD in the OC treated group did not show any significant change over 5 years, whereas BMD in the untreated group increased significantly thus showing that OCs did not have a negative effect on bone, but rather prevented the normal physiological increase related to peak bone mass (Polatti, Perotti et al. 1995).

In a non-exercise intervention study by Cromer et al (1996) researchers set out to examine bone density in adolescent girls receiving depot medroxyprogesterone acetate (Depo-Provera), levonorgestrel (Norplant), or OCs (30 mcg ethinyl estradiol, $0.15 \mathrm{mg}$ desogestrel) along with that of control subjects. Depo-Provera was found to, at least temporarily, suppress the expected skeletal bone mineralization in adolescents, whereas Norplant and oral contraceptives were associated with the expected increase in bone density in this age group (Cromer, Blair et al. 
1996). Findings from Lloyd et al (2000) are also encouraging and suggest that teenage women who initiate $\mathrm{OC}$ use during adolescence will not be different from nonusers in their peak bone mass, weight, or body fat distribution (Lloyd, Taylor et al. 2000). Further research by Petitti et al suggests that hormonal contraceptive use by young adult women is associated with small positive changes in BMD that occur early after initiation of use and is reversible (Petitti, Piaggio et al. 2000). It becomes evident when reviewing the research surrounding this topic, that further study is imperative.

To adequately determine the effects of $\mathrm{OC}$ use and isokinetic resistance training on bone strength in young females, all aspects of bone strength must be considered. Bone strength reflects the integration of two main features: bone density and bone quality. Bone density is expressed as grams of mineral per area or volume and in any given individual is determined by peak bone mass and amount of bone loss. Bone quality refers to the architecture, turnover, damage accumulation, and mineralization of bone (2000). Dual energy x-ray absorptiometry (DXA) is the current gold standard measure of BMD which accounts for no more than 70 percent of overall bone strength (2000). Measurements of BMD and bone mineral content (BMC) have been relied upon as the primary methods of evaluating bone strength in vivo (Mazess 1983). Although these measurements relate well to bone composition, they are not adequate predictors of fracture risk (Wasnich, Ross et al. 1985). It has been shown that even routine bone density testing in postmenopausal women may mask structural damage occurring within (Mazess 1983). Fracture risk is largely determined by the bone's geometry and fundamental material properties such as the distribution of bone around its bending axis or cross sectional moment of inertia (I), and the elastic modulus of the bone (E), as well as an index of bone sufficiency (a ratio of axial load capability to body weight). The $\mathrm{EI}_{\mathrm{MRTA}}$ (E x I) yields a measure of long bone structural 
integrity which is related to the composition, geometry, and internal architecture of bone (Steele CR 1988; McCabe Frances 1991; Myburgh Kathryn 1992; Myburgh Kathryn H 1993; Roberts S. G. 1995). The MRTA was designed to assess, in vivo, the mechanical properties of the constituents of the long bones in humans. This is done by measuring the impedance response curve of a long bone to a low frequency vibration set between 60 and 1,600 $\mathrm{Hz}$.

A review by Turner et al. 2003 mentions a recently conducted experiment in which mechanical loading was applied to the right ulna of adult female rats three times a week for sixteen weeks. When the whole ulnae were scanned, the load-induced increases in BMD and BMC were modest $(5.4 \%$ and $6.9 \%$, respectively), whereas mechanical testing (axial compression using a materials testing machine) revealed a $64 \%$ increase in ultimate force (explained as the maximum amount of force the bone could support before failing) and a $90 \%$ increase in energy to failure. The explanation for why such dramatic changes in bone strength were noted, was that the new bone formation, although small, was localized to the medial and lateral periosteal surfaces where mechanical strains (stresses) were greatest (Turner and Robling 2003). It is then suggested that if confirmed in human populations, areal BMD may not be the best parameter for the assessment of the effectiveness of exercise. It then seems that the most accurate assessment of bone strength should include some measure of bone shape and size in addition to BMD measurements.

Although peripheral quantitative computed tomography (pQCT) measured in $\mathrm{g} / \mathrm{cm}^{3}$ is emerging in the field as a valuable measure of bone "strength" (de Bruin, Herzog et al. 2000; Kontulainen, Sievanen et al. 2003), currently there is no accurate and widely used measure of overall bone quality (2000). Therefore, in the proposed study, both measures of BMD (DXA) 
and EI (MRTA) will be assessed to gain insight to the possible modifying effects of OCs on both the mass and mechanical strength of bone as a function of muscular strength training.

Exercise training has been well documented throughout the years as an effective method of improving bone integrity. In a study by Scerpella et al, a dose-dependant relationship between BMD and hours/week of impact activity was observed in pre-pubescent girls with even moderate doses of impact activity shown to be associated with increased BMD (Scerpella, Davenport et al. 2003). Another study by Proctor et al (2002) illustrates the apparent effect of gymnastics training resulting in augmented BMD and BMC values throughout the body, and that these elevations appeared to be due to the high-load nature of the gymnastics training itself, rather than selection bias (Proctor, Adams et al. 2002).

Isokinetic resistance exercise provides a unique situation where muscles involved are able to produce high joint forces over the entire range of motion. This has a definite advantage over an isotonic resistance exercise situation such as lifting with free-weights, where the same degree of control is not available. Isokinetic exercises may be performed concentrically (where muscles shorten as they contract), or eccentrically (muscles lengthen during contraction, due to being overcome by external forces applied to the limb). Both training methods are utilized in the current study. It is unclear whether there are any added muscular strength and morphology gains attributable to isokinetic resistance training, when performed eccentrically vs. concentrically. Therefore, subjects have been randomly assigned to either concentric or eccentric training groups.

\section{Statement of the Problem}

Osteoporosis, the most common disease of the skeleton, currently affects 7.8 million women (NOF 2000). The rate of bone loss in adulthood, as well as the amount of bone present at 
skeletal maturity are critical determinants of the risk of osteoporosis and related fractures in later life (Golden, Lanzkowsky et al. 2002). No consensus exists as to the interactive effects of isokinetic resistance training and $\mathrm{OC}$ use on bone in young women. However, any insight that can be gained regarding the independent and synergistic effects of these two stimuli on the attainment of peak bone mass in young women could have major implications in the field of osteoporosis prevention.

\section{Significance of the Study}

Findings of this study will give further insight into the effects of $\mathrm{OC}$ use and isokinetic resistance training on measures of bone strength in women who have yet to achieve peak bone mass. By assessing both BMD and EI, the density of bone as well as its long bone bending stiffness, are explored to gain a more complete understanding of bone adaptations to isokinetic resistance training both in the presence of, and without the use of OCs. Further, differences will be noted between the tibia (a weight bearing bone) and the ulna (a non-weight bearing bone). The ability to determine what changes these stimuli yield on bone strength may help to develop osteoporosis prevention strategies for young women in preparation for later life.

\section{Research Aims}

This study will further explore past research claims stating that OC use in combination with isokinetic resistance training will have a collective effect on measures of bone strength that is different than the effects of each treatment individually. Previous studies have explored effects of OC use and resistance training on measures of BMD, but currently none have examined this question using a set of measures that simultaneously assess effects on bone mass (DXA) and mechanical strength (MRTA) of bone in response to high-load muscular strength training. Isokinetic resistance training has not been previously explored in OC studies. The stimulus 
provided by this mode of training may prove to be more osteogenic than more popularly used isotonic resistance programs. It is also important to take advantage of the available comparison between a weight bearing bone (tibia), and non-weight bearing bone (ulna) to see if the effects of OC use and isokinetic resistance training have dissimilar effects on these sites.

\section{Research Hypotheses}

1. Isokinetic resistance training will increase trained limb BMD to a greater extent in the NOC group than the OC group.

2. Isokinetic resistance training will positively effect measures of bone stiffness (EI) in the trained limbs for both NOC and OC groups.

3. Effects seen in measures of BMD, and EI for the trained limb will be significantly greater than in the untrained limb.

4. Effects seen in measures of BMD and EI in the tibia, a weight bearing bone, will differ from the effects seen in the ulna, a non-weight bearing bone.

\section{Delimitations}

1. All subjects were volunteer women aged 18-25 years attending Virginia Polytechnic Institute and State University and were already involved in the Trial in Bone Injury Abatement for Ladies (TiBIAL) study.

2. Subjects were on no prescribed medications and had no medical problems known to affect bone metabolism.

3. No subjects were using oral contraceptives prescribed specifically to treat menstrual irregularities. 
4. OC users were classified as those subjects who had been using OCs for 12 months or longer at the end of the study and the NOC group were those subjects who did not use OCs for the duration of the study.

5. Subjects had not participated in any structured exercise program or athletic training during the 12 months preceding the study.

6. Loading cycles and training time were held constant between subjects training by the two modes under investigation (CON vs ECC) for the duration of the study.

7. All DXA measurements were analyzed by the same technician to ensure inter-tester variation.

8. Strength training and testing sessions were supervised to ensure proper set-up, positioning, and technique.

9. Subjects performed, on alternate days when they were away from campus during recesses, a prescribed group of concentric or eccentric (depending on their assignment to training mode) exercises designed to prevent deconditioning effects during these periods.

\section{Limitations}

1. OC information was based on self-report.

2. OC concentrations were not held constant for all OC subjects.

3. Subjects were volunteers and were not representative of the entire female student body attending Virginia Polytechnic Institute and State University.

4. Subject adherence to additional exercise guidelines were based on subject self-report.

5. Use of the untrained limb as a control measure may not account for possible crosstraining effects occurring in that limb.

\section{Basic Assumptions}


1. Subjects accurately answered the general health questionnaire and correctly reported their duration and type of oral contraceptive use.

2. Subjects complied with all pre-testing instructions regarding DXA and MRTA measurements.

3. The MRTA was mechanically zeroed before each subject was tested to achieve accurate testing throughout the study period.

4. Quality control for BMD and BMC was ensured by daily scans of an anthropomorphic phantom lumbar spine prior to any subject testing.

5. Subjects were positioned correctly and accurately for measurements with the MRTA and DXA when compared with previous measurements.

6. Each subject relaxed their limbs for all MRTA measurements and did not move after the probe/shaker was positioned on the tibia or ulna.

7. Subjects put forth a maximal effort during each resistance training session.

\section{Definitions of Terms}

1. Bending stiffness: Product of Young's Modulus of elasticity (E, N/m²) and crosssectional moment of inertia $\left(\mathrm{I}, \mathrm{m}^{4}\right)$; EI is expressed in Newton meters squared $\left(\mathrm{N} \cdot \mathrm{m}^{2}\right)$.

2. Bone mass: The amount of bone tissue contained in a bone, usually the volume minus the marrow cavity

3. Bone Mineral Density (BMD): expressed as grams of mineral per area or volume $\left(\mathrm{g} / \mathrm{cm}^{2}\right)$ and in any given individual is determined by peak bone mass and amount of bone loss.

4. Cross-sectional area moment of inertia: The cross sectional area of bone and the distribution of the bone tissue around its natural axis. 
5. Dual x-ray absorptiometry (DXA): A two-dimensional x-ray that measures bone mineral density, bone mineral content, body composition, and bone width. Is the current gold standard measure of BMD and accounts for no more than 70 percent of overall bone strength.

6. Load: any mechanical force placed upon a bone

7. Oral Contraceptive (OC): The most popular form of reversible contraception today. OC pills contain a form of estrogen and a form of progesterone, which are both female hormones involved in conception.

8. Osteoblast: a connective tissue cell that builds bone

9. Osteoclasts: a large multinuclear cell of hematopoitic origin that degrades and resorbs bone. This is important to the development, growth, maintenance, and repair of bone.

10. Quality (of bone): refers to the architecture, turnover, damage accumulation, and mineralization of bone.

11. Remodeling period: The length of time between resorption of old bone and formation of new lamellar bone. This entire process usually takes place in about 3 months in healthy bone

12. Resorption: The loss of bone by osteoclastic degradation

13. Stiffness: the resistance of bone to strain under a load. The ability of an object to be elastic or flexible. Stress/Strain.

14. Strain: the deformation or change in shape caused by a load or stress on structural material, e.g. bone. Strain can include compressive, torsional, stretching, and/or bending forces. 
15. Stress: the elastic resistance of the bone (specifically trabeculae) to be stretched by strains. Loads placed on the bone initially cause strain, which in turn causes stress. Types of strain and stress applied to bone include tension and compression.

16. Sufficiency: the load capability divided by body weight, i.e. the number of body weights the bone can support in axial load: $\mathrm{S}=\mathrm{P}_{\mathrm{cr}} / \mathrm{BW}$

17. Vibrating shaker/probe: contains both the vibration source and the impedance head. Emits the frequencies ranging from $60-1600 \mathrm{~Hz}$ to the midpoint of the long bone.

18. Wolff's Law: States that bone will adapt to the loads placed upon it by alteration of mass and distribution of mass.

19. Young's Modulus of elasticity: The stiffness of a material. Found by dividing the load or stress by the corresponding strain; $E=\sigma / €$, where $\sigma$ is stress and $\epsilon$ is strain.

\section{Summary}

The use of OCs in the young adult female population is widespread. Determination of the effects of OC use and isokinetic resistance training on bone response in this age group may have implications in the prevention of osteoporosis in our aging population. While most research on this topic focuses on measures of BMD, this study will explore not only the density of bone, but also EI as a measure of bone quality. Further, isokinetic resistance training provides a unique osteogenic stimulus to bone unlike that of conventional isotonic training presented in previous research on this topic. Thus, this study sought to explore the influence of OCs on bone adaptations to isokinetic strength training in healthy young women. 


\section{Chapter 2}

\section{Review of Literature}

\section{Introduction}

Attainment of an optimal peak bone mass is considered a pivotal preventive strategy against osteoporosis and future fractures (Genant, Cooper et al. 1999). Primary prevention strategies for young women should focus on factors that positively influence peak bone mass, as well as examine lifestyle factors that either negatively or positively affect quality of bone and attainment of bone mass at maturation. Physical activity, both as weight-bearing cardiovascular exercise and muscular strength training, has shown an association with the attainment and maintenance of optimal peak bone mass. Oral contraceptives have also been suspected of modifying bone health in skeletally immature females and have been examined as an intervention for the rapid loss of bone seen in women during menopause, despite conflicting results. Both topics have been examined individually in detail, but there is a paucity of published research on the interactive effects of both $\mathrm{OC}$ use and exercise training on bone health in young women. This study set out to determine if oral contraceptive (OC) use will modify the adaptive response to isokinetic resistance training on $\mathrm{BMD}$, and bone strength in young women. This chapter presents background information needed to understand the issues most relevant to this investigation, including literature on the effects of: a) Exercise training on measures of bone strength, b) OC use on bone in women of all ages; and c) OC use combined with exercise training in young women. In addition, a section is presented to discuss the role of dual energy xray absorptiometry (DXA) as the current gold standard for measurement of BMD, and the emergence of mechanical response tissue analysis (MRTA) as a measure of bone structural integrity. 


\section{Exercise Training and Bone}

Exercise training is well documented as an effective method of improving bone density, size, and shape. Exercise related increases in BMD during skeletal growth may have a further positive effect due to increased bone mineral deposition prior to the attainment of peak bone mass. Incidence rates for osteoporotic fracture and associated morbidity and mortality have prompted many physicians and public health officials to recommend that individuals engage in daily exercise due to the positive association between exercise and bone mass (Turner and Robling 2003). However, exercise prescription is made complex by uncertainties regarding which mode and duration of activity is the most effective for optimum skeletal health.

The goals of exercise training should adapt as a person ages to coincide with the distinct stages of skeletal maturation. Exercise during early childhood has been shown to have a more substantial positive effect on bone than exercise performed by the older adult and may lead to permanent biomechanically advantageous changes in bone geometry (Marcus 2002). Physical activity during childhood and young adulthood must focus on the development and maturation of a mechanically sound adult skeleton whereas after the attainment of peak bone mass, efforts should be made to conserve bone and prevent bone loss.

As stated by Julius Wolff, bones adapt by changing shape, form and architecture when mechanically stressed. Various modes of exercise have proven to be more effective than others for achieving maximal skeletal mineralization. Frost's threshold theory states that bone must be exposed to some minimal level of strain in order to adapt, and that only when this threshold strain is exceeded will gains in bone (mass and quality) occur. Gymnastics training is known to impose a level of skeletal stress sufficient to increase BMD and BMC throughout the body. This 
gain in bone mass appears to be due to this type of activity, rather than selection bias (Proctor, Adams et al. 2002). The high-magnitude forces, impact loading, and initiation of gymnastics training early in life, are thought to contribute to its effectiveness as a highly osteogenic training method. Other studies have explored sports involving dominant and non-dominant limbs. Squash or tennis players who initiate their respective sport before puberty have shown $11-24 \%$ higher bone mass in their playing arm, compared with their non-playing arm (Kannus, Haapasalo et al. 1995), and female tennis players aged 14-34 years of age displayed a cortical thickness of the dominant humerus that was $28 \%$ higher than in the non-playing arm (Jones, Priest et al. 1977). Resistance training has also proven effective for increasing bone strength and density. There is evidence of a linear relationship between positive change in BMD, and total and exercisespecific weight lifted in a 1-year strength-training program for postmenopausal women (Cussler, Lohman et al. 2003). With regards to resistance training, dynamic loading is more osteogenic than static loading. This is thought to be largely due to the hydrostatic pressure gradients created within bone's fluid-filled lacunar-canalicular network by this type of activity (Turner and Robling 2003). It is also said that activities associated with high load intensity at low number of cycles are associated with substantial increases in bone mass (Marcus 2002). The effects of exercise on bone are also realized in the absence of physical activity where immobilization leads to decreases in bone mass, and situations such as injury and prolonged spaceflight lead to skeletal atrophy (Bikle, Halloran et al. 1997; Turner 2000; Zerath, Grynpas et al. 2002).

The respective dose and duration of physical activity plays a major role in the effectiveness of the exercise prescription. Dose dependant relationships between BMD and hours/week of impact activity have been observed in pre-pubescent girls with even moderate doses of impact activity showing an association with increased BMD (Scerpella, Davenport et al. 
2003). Strength programs initiated during the years of skeletal growth which include activities that apply loads in an unusual manner or direction with higher than customary impact are shown to be most effective for those who wish to increase bone mass and strength (Marcus 2002). Isokinetic resistance training provides a unique mode of strength training and research has indicated that eccentric muscle training may be more osteogenic than concentric muscle training. Eccentric training may also be more efficient by attaining higher force production with lower integrated electromyographic signaling (Hawkins, Schroeder et al. 1999). Given that skeletal gains are maximized when exercise training occurs during skeletal growth, any supplementary treatment that may compromise this window of opportunity could substantially raise the risk of osteoporosis and fracture in later life by hindering the attainment of peak bone mass.

\section{Effects of Oral Contraceptive Use on Bone}

One in three women between the ages of 45 and 64 use hormone replacement therapy (HRT) to combat the biological effects of menopause, namely, age-related bone loss and postmenopausal osteoporosis (Collins, Schoen et al. 1999). It is estimated that half of all postmenopausal women will have an osteoporosis related fracture during their lives, including $25 \%$ who will develop a vertebral deformity, and $15 \%$ who will suffer a hip fracture (Nelson,

Rizzo et al. 2002). In addition to the great deal of research on HRT as an effective method of preventing or retarding this loss of bone (Kritz-Silverstein and Barrett-Connor 1993; Gambacciani, Ciaponi et al. 2000; Taechakraichana, Limpaphayom et al. 2000), there are many studies exploring the implications of OC treatment in postmenopausal women (Kaunitz 2001). Administration of both hormone replacement therapy and OCs have been shown to increase BMD of the lumbar spine and hip in this age group over a period of 12 months 
(Taechakraichana, Limpaphayom et al. 2000). However, it is less clear whether exogenous estrogens administered as OCs can modify premenopausal BMD (Cobb, Kelsey et al. 2002).

Estrogen is the major sex steroid affecting skeletal growth, remodeling, and homeostasis and is known to regulate the processes of osteoblast-mediated bone formation and osteoclastmediated bone resorption at multiple levels including progenitor cell recruitment, proliferation, differentiation, and programmed cell death (Rickard, Harris et al. 2002). Bone gained in adolescence accounts for approximately sixty percent of final adult bone mass. The amount of bone mineral present at any time in adult life is said to be a representation of that which has been gained at skeletal maturity (peak bone mass) minus that which has been subsequently lost. Therefore, any treatment that may affect the amount of bone present at skeletal maturity could have large scale effects on the risk of osteoporosis and related fracture in later life.

Thirteen articles published prior to 1999 on the topic of OC use and bone in pre-, peri-, and postmenopausal women were reviewed, and found that nine studies showed a positive effect of low-dose OC use on BMD, four found no association, and no studies found a negative association (Kuohung, Borgatta et al. 2000). More recently, protective effects of OCs on the femur, the site most relevant for osteoporotic fracture have been witnessed through a significant reduction in urinary hydroxyproline excretion in women who use OCs late in reproductive life, and after the age of 40 years (Gambacciani, Ciaponi et al. 2000). Significantly greater spine and femoral neck densities have also been realized in postmenopausal women with 6 years of prior OC use compared with women who have never used OCs (Kritz-Silverstein and Barrett-Connor 1993). A longitudinal study by Gambacciani et al, found that OC administration during the perimenopausal years helped women to avoid the increase in bone turnover and decrease in femoral bone density due to the perimenopausal impairment of ovarian function (Gambacciani, 
Ciaponi et al. 2000). Although the majority of research presents an alleged positive effect of OCs on bone, premenopausal women have been described through National population based data to present lower BMD values for the trochanter and spine in women who have used OCs, compared with those who have never used OCs (Prior, Kirkland et al. 2001). In a great deal of current research published using skeletally mature women and "past use" of OCs, the estrogen concentration in past prescriptions has the potential to differ greatly from that of the more current lower-dosed OCs. Past research has stated that based on results seen in older women, OC use in young adulthood could potentially delay or prevent the decline in bone that begins between 3040 years of age. However, OC preparations now used by young women are different than those used years ago, as are physical activity patterns, dietary considerations, and many other lifestyle related factors that play a vital role in bone health.

Concerns regarding optimization of peak bone mass in young women using OCs are eminent given that bone gained in adolescence accounts for the majority of final adult bone mass. Contraceptive treated female cynomolgus monkeys gained less spinal BMC and BMD and less whole body BMC than controls over a 20 month treatment period in a study by Register et al, 1997. In the same subject group there was a subsequent decrease in serum osteocalcin and alkaline phosphatase levels as well as moderate reductions in serum acid phosphatase and calcium suggesting that $\mathrm{OC}$ treatment of young adult female monkeys that have not reached peak bone mass inhibits the net bone accretion and/or growth by reducing bone metabolism (Register, Jayo et al. 1997). In contrast, a comparison study between adolescent girls using either no hormonal contraception, OC's, Norplant, or Depot Medroxyprogesterone Acetate (DMPA) found DMPA to at least temporarily, suppress expected skeletal bone mineralization, whereas Norplant and OCs were associated with the expected increase in bone density in this population (Cromer, 
Blair et al. 1996). However, although OCs were associated with an increase in BMD in this age group of $1.5 \%$, the control group experienced a greater increase in BMD of $2.9 \%$ after one year. Other contraceptive comparison studies have found no association between use of combined OCs and BMD values, while DMPA shows an association with decreased BMD only at the lumbar spine in women aged 30-34 (Wanichsetakul, Kamudhamas et al. 2002). Consistently, DMPA is shown to suppress the expected skeletal bone mineralization in adolescents (Cundy, Farquhar et al. 1996; Cundy, Cornish et al. 1998), whereas research on OCs in young women is conflicting. Positive effects of OC use on bone mass have been noted through a decreased risk of low BMD at the spine, hip, and total body in 216 white women aged 25-37 and this effect on BMD was proportional to the cumulative estrogen exposure (Cobb, Kelsey et al. 2002). However, small positive changes in BMD that occur early after the initiation of OC use in young adult women are seemingly reversible (Petitti, Piaggio et al. 2000).

A large subset of research shows a lack of association between OC use and measures of bone strength. No differences in BMD have been found between combined oral contraceptive pill users and menstruating women who are adequately estrogenized by their own ovaries (MacDougall, Davies et al. 1999). There was seemingly no effect of OCs on bone health in a study by Cobb et al that found no significant differences between OC users (ever) and never users ( $<1$ year) for all variables examined (Cobb, Kelsey et al. 2002). Similarly, no substantial differences in BMD at any site were noted by Fortney et al between OC ever and never users (Fortney, Feldblum et al. 1994), and Hawker et al found OC use to have no significant association with BMD in a sample size of 963 women aged 19-35 (Hawker, Forsmo et al. 2002). A prospective study followed a cohort of reproductive-aged women for 36 months and found no significant differences between OC users and comparison women for measures of percent 
change, or BMD of the total hip $\left(0.952 \mathrm{~g} / \mathrm{cm}^{2}(0.48 \%), 0.949 \mathrm{~g} / \mathrm{cm}^{2}(0.12 \%)\right)$, spine $\left(1.062 \mathrm{~g} / \mathrm{cm}^{2}\right.$ $\left.(1.61 \%), 1.059 \mathrm{~g} / \mathrm{cm}^{2}(1.34 \%)\right)$, or total body $\left(1.100 \mathrm{~g} / \mathrm{cm}^{2}(0.68 \%), 1.099 \mathrm{~g} / \mathrm{cm}^{2}(0.66 \%)\right)$ in OC and Non-OC subjects respectively (Reed, Scholes et al. 2003). Further, teenage women who initiate $\mathrm{OC}$ use during adolescence have not shown to be different from nonusers in their peak bone mass, weight, or body fat distribution in a subject group that was indistinguishable in terms of body composition, anthropometric, total body, and hip bone measures, age of menarche, and sports exercise scores (Lloyd, Taylor et al. 2000).

Anorexic females are known to be malnourished, hypoestrogenemic, and have reduced bone mass at presentation. Estrogen regulation through the use of OCs has been purported to be effective in restoring bone density to normal levels with this disorder. However, the effectiveness of OC use for the improvement of bone health in women with eating disorders is not welldocumented. In a study by Golden et al, 50 anorexic females showed no significant differences in absolute values or in net change of lumbar spine or femoral neck BMD between those who received estrogen-progestin and those who received the standard treatment for anorexia nervosa (combination of medical, nutritional, and psychiatric intervention) at one year follow-up (Golden, Lanzkowsky et al. 2002). It seems that in hypoestrogenic females, the possible positive effect of OC use on bone is not realized and that nutritional, and medical interventions may provide the greatest benefit for restoring skeletal health. This has led various researchers to think that estrogen supplementation may only have the ability to regulate bone metabolism in individuals who have an adequate nutritional intake.

Inconclusive findings in current $\mathrm{OC}$ research can be tied to inconsistencies in the age of subjects, estrogen/progestin concentrations used, study/intervention duration, and anatomical sites evaluated. Although OC research is inconsistent, the majority of studies point out that low 
dose OC's help in decreasing menopausal bone loss, and depending on the time of initiation can even induce an increase in bone density (Karck and Breckwoldt 2001). However, low dose OCs may impede the formation of a physiologic peak bone mass in young women by a reduction in bone metabolism (Fait, Novakova et al. 2001; Karck and Breckwoldt 2001). This reduction is thought to be due to the increases in production and serum concentrations of sex hormone binding globulin seen with $\mathrm{OC}$ use that subsequently result in diminished concentrations of free testosterone and estrogen, an inhibition of gonadotropin secretion, and a further decrease in ovarian androgen secretion (Burkman 1995; Greenspan and Gardner 2001; Reed, Scholes et al. 2003). Research by Polatti et al (1995) measured BMD after 5 years of treatment in healthy women between 19 and 22 years of age and found that BMD in the OC treated group did not show any significant change over 5 years, whereas BMD in the untreated group increased significantly thus showing that OCs did not have a negative effect on bone, but rather prevented the normal physiological increase related to peak bone mass (Polatti, Perotti et al. 1995). This potential negative interaction between OCs and bone health may be a partial explanation for the greater fracture rates reported among OC users in two large epidemiological studies of premenopausal women (Cooper, Hannaford et al. 1993; Vessey, Mant et al. 1998). If prolonged continuous OC use in skeletally immature females is shown to definitively lead to a lower peak bone mass in females, the risk of developing osteoporosis in later life would increase substantially.

\section{Skeletal Effects of Oral Contraceptive Use Combined with Exercise Training in Young Women}


Young women who use OCs have shown lower bone formation and resorption rates than women not using hormonal contraception, but this has not consistently resulted in higher bone densities (Ott, Scholes et al. 2001). Suppression of bone turnover, such as that caused by OC use, could reduce the osteogenic effect of an exercise program by preventing the normal increase in bone formation that would occur in response to mechanical loading (Burr, Yoshikawa et al. 2000). However, research has raised the concern that during puberty, vigorous exercise may interrupt hormone cyclicity, delay the progression of puberty, and result in the attainment of a lower peak bone mass (Frisch, Gotz-Welbergen et al. 1981). Following puberty, exercise has been suspected to result in amenorrhea, bone loss, and reduced BMD (Drinkwater, Nilson et al. 1984). Hormonal regulation through OCs in young adult women may then help to optimize the positive effects of exercise on the developing skeleton. In the third decade of life, both physical activity and dietary calcium intake have been shown to exert a positive effect on BMD, and use of OCs has been shown to exert a further independent positive effect (Recker, Davies et al. 1992). It is of primary importance to explore these phenomena in young women who have not yet achieved peak bone mass to ensure optimal skeletal growth for the prevention of osteoporosis in later life.

To date, there are only four experiments designed to assess the combined effects of exercise and OC use on measures of bone health. In 1992, Recker et al examined whether bone mass increases in healthy non-pregnant white women during early adult life after the cessation of linear growth. They also assessed whether various self-chosen levels of physical activity and nutrient intake or use of oral contraceptives influence this increase in bone mass. Healthy college-aged women $(\mathrm{N}=156)$ were screened at 6 month intervals for a total of nine visits to determine spine BMD (dual photon absorptiometry), forearm BMD (single photon 
absorptiometry), nutrient intake (7-day diary), physical activity level (4-day recording with a CALTRAC personal activity monitor), and use of OCs. Total body BMD was assessed by dual photon absorptiometry early in the study, and then again during the last visit. Over the course of the study it was found that bone gain did in fact occur in the spine, total body, and forearm, and further that the gain in bone mass in these women ended at a point close to the age of 30 years. Physical activity, nutrition, and use of oral contraceptives were all shown to have an additional positive effect on BMD, making this one of the pioneer studies in this body of research.

Hartard et al initiated research specifically on the topic of BMD responses to OC use compared to and combined with physical activity to examine what effects these two activities may have on the proper attainment of peak bone mass (Hartard, Bottermann et al. 1997). Young women $(\mathrm{N}=128)$ aged 20-35 years, were assigned to four groups with respect to years of exercise and OC use. Physical activity and OC use was determined by a detailed questionnaire and interview. An effect of exercise on bone metabolism was assumed after at least three years of regular exercise ( $\geq 2$ hours/week) or for more than half the years since turning 20 , and an effect of OC use was assumed after at least three years of intake or at least half the years since turning 20. Subject groupings were determined as follows: group A was characterized by long-term exercise $(9.45 \pm 4.32$ years $)$ and short-term OC use (1.6 \pm 1.69 years), group B underwent longterm exercise (10.4 \pm 4.14 years) and long-term OC use ( $8.2 \pm 4.14$ years), group C reported only a few years of years of exercise $(3.26 \pm 3.69)$ and a long intake of OCs $(7.9 \pm 2.88$ years $)$, and group D there was brief history of exercise $(3.5 \pm 3.5$ years $)$ and OC use ( $1.5 \pm 1.73$ years). Right and left femoral neck and L2-4 BMD was assessed by DXA. Statistical analysis for within-group differences were based on ANOVA. The highest BMD values in all regions assessed were found in group A (long-term exercise/short term OC use). Less beneficial effects of exercise on BMD 
(namely in L2-4) were found in group B (long-term exercise/long-term OC use). Differences in mean BMD values between groups A and B became significant $(p<0.05)$ in most regions assessed. No significant BMD differences were observed between groups B and C, B and D, or $\mathrm{C}$ and $\mathrm{D}$. The results of this study suggest that use of low-dose OCs may counteract the beneficial influence of physical activity on bone formation, and led to further research in this area.

Weaver et al, set out to determine the effect of quantified resistance plus high-impact exercise training on BMD or BMC as modified by age and OC use in a randomized intervention trial in healthy, non-athletic women $(\mathrm{N}=179)$ aged 18-31 years (Weaver, Teegarden et al. 2001). The exercise training consisted of a "super circuit" consisting of eight lower, and eight upper body weight stations with cycle ergometry located between each station, and an accumulation of 60 minutes of jump rope per week. All OC users in this study were taking low dose estrogen compounds (50 $\mu \mathrm{g}$ or less ethinyl estradiol) and all subjects were characterized by age (18-23, and 24-31 years) and OC use totaling four groups. Each of the four groups was then randomized into an exercise or non-exercise subset. Exercise compliance was assessed at six-month intervals by changes in lean mass. Spine and hip (femoral neck, greater trochanter, and Ward's area) $\mathrm{BMD}$, and total body and spine BMC were measured via DXA, and radial BMD and BMC were measured using a single photon absorptiometer. Biochemical markers for bone formation (serum osteocalcin and alkaline phosphatase) and resorption (serum tartrate resistant acid phosphatase (TRAP) and urinary hydroxyapatite/creatinine) were assessed at baseline and six month intervals. Primary outcome variables were analyzed using a three-way analysis of variance with independent factors age, exercise, and OC use, each at two levels. Multivariate analysis of variance was used to compare the profiles of the subjects who dropped out with those who did 
not. This study established that exercise resulted in a positive effect on total body BMC, which was greater in the younger than older women. On the other hand, exercise had a negative effect on femoral neck BMD. An unexpected interaction between exercise and OC use was observed such that spine $\mathrm{BMC}$ and $\mathrm{BMD}$ decreased during the first six months and remained lower for the two year intervention. Use of OCs had a negative impact on total body BMC compared with no OC use. However, there was no interaction between exercise and OC use in terms of total body BMC. This study states its most surprising finding as the negative interaction found between exercise and $\mathrm{OC}$ use in spine $\mathrm{BMC}$ and $\mathrm{BMD}$, which became apparent during the first six months of the intervention and suggests that exercising young women who use OCs compromise the attainment of spinal peak BMC and BMD. Conclusions drawn from these results are that individuals in a state of reduced bone turnover such as that caused by OC use are not expected to loose bone. The authors suggest two explanations for this occurrence: 1) that an imbalance of resorption and formation occurred, and 2) that newly formed bone was not well mineralized. No consistent changes in biochemical markers were detected.

Burr et al then submitted a publication on the same subject sample used by Weaver (although accepted for publication at an earlier date), but this time in regards to strength and geometry of the femoral neck in response to moderate exercise (Burr, Yoshikawa et al. 2000). It was hypothesized that exercise intervention in young adult women would significantly increase both bone mass and the bending rigidity of the femoral neck and also that exercise intervention in the presence of $\mathrm{OC}$ use would have a negative effect on bone mass and bending rigidity. This article explains bending rigidity as a means of gathering geometric information about a bone contained in the absorption curves generated by DXA measurements. The authors used these measurements to derive the cross sectional moment of inertia (CSMI) as well as the estimated 
rigidity of the femoral neck. Exercise protocol is described above in the review of Weaver et al. Women who neither exercised or used OCs demonstrated the greatest percent increases in bone structure and geometry while OC users, whether they exercised or not, had greater percentage increases than those who exercised but did not use OCs. Overall, the combination of exercise and OC use produced more positive changes than OC use or exercise alone. The conclusions of this study were that either exercise or OC use depresses the normal increase of bone mass and mechanical strength in the femoral neck of women 18-31 years of age, but the combination of exercise and $\mathrm{OC}$ use seems to be less detrimental than either treatment alone.

Use of OCs and initiation of various fitness programs are common practices of young women and it is essential to gain insight into their potential interactions with respect to bone health and skeletal maturation. The present study will use an unexplored exercise stimulus and measure of bone geometry so that it may be possible to gain further insight regarding the interactions of these two stimuli on the young adult skeleton.

\section{Dual Energy X-ray Absorptiometry as the Current Gold Standard for Measurement of Bone Mineral Density, and the Emergence of Mechanical Response Tissue Analysis as a Measure of Bone Structural Integrity}

The skeleton is an intricately designed system assisting in locomotion, mineral metabolism, protection of the internal organs, and permission of organisms to withstand gravitational and mechanical stresses. To withstand these stresses in a manner that optimizes bone strength without adding substantial weight, bones accommodate the loads that are placed on them by undergoing alterations in mass, external geometry, and internal microarchitecture (Marcus 2002). Measurements of BMD and BMC have been relied upon as the primary methods of evaluating 
bone strength in vivo (Mazess 1983). Although these measurements relate well to bone composition, they are not adequate predictors of fracture risk (Wasnich, Ross et al. 1985). Dual energy x-ray absorptiometry (DXA) is the current gold standard measure of BMD, but accounts for no more than 70 percent of overall bone strength (2000). A World Health Organization panel offered an absolute BMD standard to make the diagnosis of osteoporosis. By definition, a person whose BMD value falls more than 2.5 SD below the average value for a 25 -year-old Caucasian woman is stated to have osteoporosis and an individual whose BMD falls between -1.0 and -2.5 SD below the standard is said to have osteopenia. Absolute reliance on a BMD standard, although useful for diagnosis, fails to account for the fact that BMD predicts fracture risk along a continuous, progressive relationship and ignores other contributors to bone fragility such as bone size and geometry, as well as qualitative abnormalities of the matrix and mineral of osteoporotic bone (Greenspan and Gardner 2001). The widely accepted definition of osteoporosis is "a systematic skeletal disease characterized by low bone mass and microarchitectural deterioration of bone tissue with a consequent increase in bone fragility and susceptibility to fractures"(Anonymous 1993). However, bone mass is only a small piece of this definition; and other contributing factors towards osteoporosis not accounted for by use of DXA, such as bone's geometry and fundamental material properties, are often ignored.

To illustrate this line of reasoning, research from Riggs et al demonstrated that sodium fluoride treatment has been shown to increase spinal bone density without significantly decreasing the risk of vertebral fracture (Riggs, Hodgson et al. 1990). This study found that because of the lack of change in the extent of horizontal cross-tie stabilization in bone, the bone mass and density of a sodium fluoride treated subject group increased measurably, whereas the ability of the bone to withstand mechanical loads had been only minimally altered (Riggs, 
Hodgson et al. 1990). Supporting the evidence that measures beyond BMD and BMC are needed to assess the "strength" of bone, is a review by Turner et al, 2003 that mentions a recently conducted experiment in which mechanical loading was applied to the right ulna of adult female rats three times a week for sixteen weeks. When the whole ulnae were scanned, the load-induced increases in BMD and BMC were modest (5.4\% and 6.9\% respectively), whereas mechanical testing (axial compression using a materials testing machine) revealed a $64 \%$ increase in ultimate force (explained as the maximum amount of force the bone could support before failing) and a $90 \%$ increase in energy to failure. The explanation for why such dramatic changes in bone strength were noted, was that the new bone formation, although small, was localized to the medial and lateral periosteal surfaces where mechanical strains (stresses) were greatest (Turner and Robling 2003). It is then suggested that if confirmed in human populations, areal BMD may not be the best parameter for the assessment of the effectiveness of exercise. Instead, assessment should include some measure of bone shape and size.

Where DXA proves useful in the measurement of BMD, an additional measure of bone strength is available. Mechanical response tissue analysis (MRTA) is a useful measurement of cross-sectional bending stiffness of long bones in vivo. The $\mathrm{EI}_{\mathrm{MRTA}}$ (E x I) yields a measure of long bone structural integrity which is related to the composition, geometry, and internal architecture of bone in the ulna and tibia (Steele CR 1988; Arnaud, Steele et al. 1991; McCabe Frances 1991; Myburgh Kathryn 1992; Myburgh Kathryn H 1993; Roberts S. G. 1995). Bone stiffness is the product of a material property known as the elastic modulus, specifically Young's modulus of elasticity (E) and the cross-sectional moment of inertia (I), which is a geometric property of bone determined by the distribution of mineral around the bone's central axis. Bending stiffness ( $\left.\mathrm{EI}_{\mathrm{MRTA}}\right)$ is suggested to be a better predictor of bone failure strength than 
BMD because of consistently high correlations found with fracture properties and is said to have greater physical significance than does BMD for quantifying long-bone structural integrity (Roberts, Hutchinson et al. 1996). Physical activity sufficient to increase arm, namely biceps, strength has been shown to influence ulnar bending stiffness showing that a long-term exercise program should be effective in increasing this measure of bone quality (Myburgh, Charette et al. 1993). It should be noted that MRTA offers a global estimate of bending stiffness, which correlates highly with bone strength, but does not distinguish between individual contributions of material properties and geometry (McCabe, Zhou et al. 1991). A validation study comparing MRTA to the same property (EI) measured by three-point bending in a static ex vivo test, was performed using monkey tibiae showing a correlation of $\left(\mathrm{R}^{2}=.95\right)$ (Roberts, Hutchinson et al. 1996). Typical values for ulnar EI have been published as $26.6 \pm 1.20 \mathrm{Nm}^{2}$ in young adult women (McCabe, Zhou et al. 1991), 45.2 $\pm 7.5 \mathrm{Nm}^{2}$ in moderately active men (Myburgh, Zhou et al. 1992), and a range of 8-12 $\mathrm{Nm}^{2}$ as a minimum score associated with osteoporosis to $120 \mathrm{Nm}^{2}$ for a $240 \mathrm{lb}$. retired butcher (Steele, Zhou et al. 1988), tibial values in non-primate subjects are reported less often. Use of MRTA is said to be complementary to photon absorptiometry, since a different physical property of bone is being measured, and has advantages in terms of speed, cost, and lack of radiation exposure (Steele, Zhou et al. 1988). Although this complementary approach to bone analysis is idealistically sound, it is important to note that recent dissertation work using the newer MRTA prototype has found the new hardware to be less reliable, and outside of the acceptable range used in clinical research (Callaghan 2003; Miller 2003).

\section{Summary}


More research is necessary to determine the effects of OC use in combination with exercise training on measures of bone strength. Results regarding the effect of hormonal contraception on the aging skeleton are conflicting, but remain of utmost importance in the primary prevention of osteoporosis. The goal of the current study is to offer further insight into potential interactions of $\mathrm{OC}$ use and exercise training in young women using an unexplored mode of muscular strength training and an additional measure of bone quality. It is expected that with unilateral high load isokinetic training, skeletal strain will be sufficient to cause increases in bone measures of the trained, but not the untrained limb. The design of the current study allows comparisons between a trained and untrained limb in the same subject, as well as the effect of OC use on measures of bone (density and quality) in the separate limbs. To date, there has been no published literature looking specifically at the effect of isokinetic exercise and OC use on bone, nor has there been literature on OC use using MRTA as a measure of bone "quality." Exercise training and use of OCs are common practices of college-aged females and may play an important role in the development of a structurally sound skeleton. It is important to realize that BMD during old age is largely determined by factors operating during skeletal maturation, and that any treatment options that either maximize or hinder skeletal growth warrant further research. 


\section{Chapter 3}

\section{JOURNAL MANUSCRIPT}

Influence of oral contraceptives on bone adaptations to isokinetic strength training in young women

Serah E. Selmon, M.S. ${ }^{1}$, Sharon M. Nickols-Richardson, Ph.D., R.D. ${ }^{1}$, Warren K. Ramp, Ph.D. ${ }^{1,2}$, William G. Herbert, Ph.D. ${ }^{1,2}$

${ }^{1}$ Department of Human Nutrition, Foods and Exercise, Virginia Polytechnic Institute and State University, Blacksburg, VA

${ }^{2}$ Health Research Group, Blacksburg, VA

Prepared for submission to: Medicine and Science in Sports and Exercise 
ABSTRACT

\section{INFLUENCE OF ORAL CONTRACEPTIVES ON BONE ADAPTATIONS TO ISOKINETIC STRENGTH TRAINING IN YOUNG WOMEN}

Serah E. Selmon, ${ }^{1}$ William G. Herbert, FACSM, ${ }^{1,2}$ Sharon M. Nickols-Richardson, ${ }^{1}$ Warren K. Ramp ${ }^{1,2}$ Laboratory for Health and Exercise Sciences, Virginia Polytechnic Institute and State University, Blacksburg, VA' ${ }^{1}$; and Health Research Group, Blacksburg, VA ${ }^{2}$

PURPOSE: To assess the independent and synergistic effects of oral contraceptive (OC) use on bone mineral density (BMD) and bone mechanical stiffness (EI) in college-aged females after unilateral isokinetic resistance training in weight bearing vs. non-weight bearing limbs, i.e. tibia vs. ulna. METHODS: Forty six females (age $20 \pm 1.4$ yrs, height $163.8 \pm 6.2$ in., weight $58.9 \pm 8.6$ kg., $\%$ fat 27.9 \pm 4.8 ) were categorized as oral contraceptive users (OC, $\mathrm{N}=22$ ) or not (NOC, $\mathrm{N}=24)$ and randomized to eccentric (ECC) or concentric (CON) training. Subjects completed 32 weeks ( $3 \mathrm{~d} / \mathrm{wk})$ of unilateral arm and leg training, angular velocity $60^{\circ} / \mathrm{s}$, using isokinetic dynamometers. Measurement of BMD, and $\mathrm{EI}_{\mathrm{MRTA}}$ were assessed via dual-energy x-ray absorptiometry (DXA) and mechanical response tissue analysis (MRTA) respectively. RESULTS: Total leg and arm muscular strength of the trained limb increased by $16 \%$ and $15 \%$, respectively $(\mathrm{p}<0.001)$, beyond the control limbs. Total body BMD increased for NOC $(\mathrm{p}<0.05)$, but not for OC users. This difference failed to show significance $(\mathrm{p}=0.069)$ when comparisons were run between NOC and OC groups. Increases in ulnar ( $p<0.01$ for all limbs) and trained total hip BMD (OC, $\mathrm{p}<0.001$; NOC, $\mathrm{p}<0.05$ ) occurred irrespective of contraceptive status. Positive changes in EI were conflicting, occurring in the trained ulna for the NOC group $(\mathrm{p}<0.05)$, and trained tibia for OC users $(\mathrm{p}<0.05)$. Tibial BMD increased only for the untrained leg in NOC subjects $(p<0.01)$. No between group differences were significant, nor were differences between trained vs. untrained, and weight bearing (tibia) vs. non-weight-bearing (ulna) limbs found to be significant. CONCLUSION: These results suggest that oral contraceptives may limit attainment of total body peak bone mass in young adult females. Skeletal maturation in the ulna appeared to be unaffected by exercise training and $\mathrm{OC}$ use. Positive effects of exercise training on the total hip were seen in both groups, irrespective of OC status. Conversely, exercise training and OC use may limit the attainment of bone mass in the tibia. Further studies are needed to determine the interactive skeletal effects of OC use and isokinetic resistance training. Key Words: Oral Contraceptive, MRTA, DXA, Bone, Young Women

Supporting agency: United States Army Medical Research and Materiel Command, Grant \#DAMD17-00-1-0114 


\section{INTRODUCTION}

The achievement of optimal peak bone mass during adulthood is conceivably the most important factor for the primary prevention of osteoporosis in later life. Osteogenic physical activity, manifested through weight-bearing cardiovascular (Jones, Priest et al. 1977; Kannus, Haapasalo et al. 1995; Proctor, Adams et al. 2002; Scerpella, Davenport et al. 2003) and muscular strength exercise training (Marcus 2002) increases both the mass and mechanical strength of bone, and most notably, when initiated during the years of skeletal growth. However, use of oral contraceptives (OCs) may modify the osteogenic effects of exercise in young adult females. (Recker, Davies et al. 1992; Hartard, Bottermann et al. 1997; Burr, Yoshikawa et al. 2000; Weaver, Teegarden et al. 2001) Estrogen is the major sex steroid affecting skeletal growth, remodeling, and homeostasis and is known to regulate the processes of osteoblast-mediated bone formation and osteoclast-mediated bone resorption at multiple levels including progenitor cell recruitment, proliferation, differentiation, and programmed cell death.(Rickard, Harris et al. 2002) Young women who use combined (estrogen + progesterone) OCs have shown lower bone formation and resorption rates than women not using hormonal contraception.(Ott, Scholes et al. 2001) Endogenous production of estrogen and testosterone is negatively affected through an increase in the production and serum concentrations of sex hormone binding globulin brought about by use of OCs.(Burkman 1995) Suppression of bone turnover, such as that caused by OC use, could reduce the osteogenic effects of an exercise program by preventing the normal increase in bone formation that would otherwise occur in response to mechanical loading.(Burr, Yoshikawa et al. 2000) Although exercise training is well established as an effective means of increasing bone size and strength, research has raised the concern that during puberty, vigorous exercise may interrupt hormone cyclicity, resulting in a lower peak bone mass at skeletal 
maturation.(Frisch, Gotz-Welbergen et al. 1981) Certain types of exercise (namely distance running and gymnastics training) following puberty have been suspected to result in amenorrhea, bone loss, and reduced bone mineral density (BMD).(Drinkwater, Nilson et al. 1984) Alternatively, it might be postulated that the enhancing uniformity of hormonal regulation through the use of OCs in young adult women may then help to optimize the positive effects of exercise on the developing skeleton. Previous research on this topic has proven inconclusive,(Recker, Davies et al. 1992; Hartard, Bottermann et al. 1997; Burr, Yoshikawa et al. 2000; Weaver, Teegarden et al. 2001) and further studies are necessary. Use of OCs and participation in various forms of physical activity are common practices of young women. Consequently, information regarding the independent and synergistic effects of these two stimuli on the attainment of peak bone mass in young women could have major implications in the field of osteoporosis prevention.

Measures of BMD are often used as the sole determinant of bone status and may not be the best indicator of the overall effect of exercise on the geometry of bone and its mechanical strength. Small, and often insignificant, increases in BMD have led to large increases in the mechanical strength of bone in animal studies.(Turner and Robling 2003) A measure of long bone structural integrity and strength, termed mechanical response tissue analysis (MRTA), has been validated against three point bending stiffness tests to yield an accurate measure of the composition, geometry, and internal architecture of bone.(Roberts, Hutchinson et al. 1996) In combining MRTA with the current gold standard measure of bone quality in the clinical setting (BMD), it may be possible to gain a better understanding of the overall quality of bone in response to an exercise regimen. 
To date, few studies have examined how OCs may alter the bone response to osteogenic exercise training in young women.(Hartard, Bottermann et al. 1997; Burr, Yoshikawa et al. 2000; Weaver, Teegarden et al. 2001) Concentric and eccentric isokinetic resistance training provide unique means for generating high bending and compressive mechanical loads on specific regions of bones via the high torques generated by contracting skeletal muscles that attach to them. The purpose of this study was to use these particular strength training modalities to explore the effects of a 32-week unilateral isokinetic resistance training program on BMD and EI in females either using, or not using OCs as a form of contraception. Changes in BMD and EI in the trained versus the untrained limb were also examined. Finally, this study set out to compare the training effects on BMD and EI in the tibia, a weight bearing bone, to the effects seen in the ulna, a non-weight bearing bone.

\section{METHODS}

Subjects. The 46 female volunteers were categorized as oral contraceptive users ( $\mathrm{OC}, \mathrm{N}=22)$ or non-users (NOC, $\mathrm{N}=24$ ) based on subject response to a standard questionnaire given prior to each DXA scan and had been previously randomized into either eccentric $\left(\mathrm{OC}_{\mathrm{ECC}}, \mathrm{N}=10\right.$, $\left.\mathrm{NOC}_{\mathrm{ECC}}, \mathrm{N}=10\right)$ or concentric $\left(\mathrm{NOC}_{\mathrm{CON}}, \mathrm{N}=14 \mathrm{OC}_{\mathrm{CON}}, \mathrm{N}=12\right)$ isokinetic resistance training groups. Oral contraceptive users were classified as subjects using OCs continuously for 12 months or longer by the end of the training period; non-users were classified by never use of OCs throughout the duration of the study. All short-term $(<12$ months $)$ OC users and subjects with incomplete questionnaires were excluded. Reproductive hormone concentrations for the

OCs used at baseline are listed in Table 1 where all subjects were using low dose oral contraceptives with an ethinyl estradiol concentration of $40 \mathrm{mg}$ or less. Subjects underwent 
baseline testing to determine ulnar and tibial bending stiffness, BMD, and flexor and extensor strength of the knee and elbow joints.

Isokinetic Strength Training and Testing. Both concentric and eccentric peak torque values were recorded for all subjects using a Biodex ${ }^{\circledR}$ System III isokinetic dynamometer (Shirley, NY) at a constant speed of $60^{\circ} / \mathrm{sec}$. Strength values for the current study were obtained by summing the peak torque values for the elbow and knee flexors (concentric flexion + eccentric extension) and extensors (concentric extension + eccentric flexion). Upon completion of baseline testing, participants were randomly assigned to either concentric or eccentric training groups. The subjects then participated in a 32-week training period in which they trained the non-dominant elbow (flexion/extension) and knee (flexion/extension) at an angular velocity of $60^{\circ} / \mathrm{sec}$ on three nonconsecutive days per week. Non-dominant limbs were identified by asking each subject to identify her "writing hand" and "kicking leg" (dominant body side). Initially subjects completed non-dominant elbow and knee flexion/extension for two sets of six repetitions. Then, an additional set of six repetitions was added weekly until the final volume of five sets of six repetitions was achieved for each exercise. All testing and training sessions were supervised to ensure proper set-up, positioning, and technique, as well as to promote compliance. Upon completion of the 32-week training period, subjects were admitted for post-training testing. Posttraining tests were conducted in the same manner as baseline testing.

Mechanical Response Tissue Analysis (MRTA). MRTA was performed at baseline and 32 weeks to assess changes in long bone bending stiffness. Tibial length was measured with an anthropometer from the medial condyle proximally to the inferior edge of the medial malleolus distally. The mid-shaft of the tibia, which served as the location for MRTA probe placement, was determined by measuring one-half the tibia length from the inferior edge of the medial malleolus. 
Ulnar length was assessed similarly from the proximal edge of the olecranon, to the distal ulnar styloid process with the elbow flexed to 90 degrees. The mid-shaft of the ulna, again serving for the location for MRTA probe placement, was determined by measuring one-half of the ulnar length from the bottom of the olecranon process. Mid-points for both the tibia and ulna were marked with permanent marker. Subject data was recorded into the computer and the MRTA components were activated and calibrated. A successful calibration was defined by an impedance response of $8 \pm 1 \mathrm{~g}$ across a frequency range of 70-500 Hz. After calibration, for measurement of the tibia, the MRTA probe was positioned on the anterior border, equidistant from the medial condyle and the inferior edge of the medial malleolus. Tibial assessment was performed with the subject seated in a position where the femur was positioned parallel to the floor with approximately $90^{\circ}$ of knee flexion. Ulnar measurements were taken with subjects seated on a stable platform with shoulders perpendicular to the MRTA stand. The humerus was positioned parallel to the floor, with approximately $90^{\circ}$ of elbow flexion. Nine consecutive measures were performed without repositioning over a 2 minute period and results were analyzed using a 12parameter model. The 12-parameter model takes into account the mass, distributed stiffness, and damping of the bone and skin, as well as at the proximal and distal bone ends. The average value $\left(\mathrm{EI}_{\mathrm{ave}}\right)$ for the nine measures obtained at each site was used in the statistical analysis.

Reproductive Health Questionnaire. Prior to each DXA measurement, subjects were asked to complete a standard questionnaire describing current type and duration of OC use, family history of osteoporosis, smoking, and other topics relative to bone and reproductive health. Subjects were included in the current study based on response to OC type and duration questions and were assigned accordingly to an OC user, or control group. 
Dual X-ray Absorptiometry (DXA). DXA scans were performed using the QDR 4500A Elite Fan Beam X-Ray Bone Densitometer (Hologic, Bedford, MA) which received FDA approval in 1995 for bone densitometry measurements. Measurements were performed with subjects lying supine on the DXA platform for one total body scan to determine BMD and percentage body fat. Each subject then had both dominant and non-dominant forearms, total proximal femurs, and lower legs scanned to determine BMD of the ulna, femoral neck, total hip, and tibia. Standard total body, forearm, and hip protocols were used during scans. Total body (version 8.25), forearm (version 8.25), and total proximal femur (version 8.23) scans were analyzed with Hologic software. Lower leg scans were analyzed with user-defined adaptations to the forearm software. All scans were performed and analyzed by the same technician to eliminate inter-tester variation. Quality control for BMD was ensured by daily scans of an anthropomorphic phantom lumbar spine prior to any subject testing. Precision for total body BMD measurements was $<1.0 \%$ and for the femoral neck was $<2.0 \%$; thus, it was anticipated that expected changes for BMD values in the range of $5-7 \%$ with slow velocity isokinetic resistance training would be detected. Quality control for soft tissue mass was ensured by weekly scans of an external soft tissue bar comprised of aluminum and leucite calibrated against stearic acid and water (Hologic, Bedford, MA). To assess the effects of isokinetic strength training with or without the use of OCs on BMD and percent fat, DXA scans were performed at baseline and after 32 weeks of subject training.

Statistical analyses. All statistical analyses were performed using SPSS version 11.0 statistical software (Chicago, IL), and significance was set at $\mathrm{p}<0.05$ for all comparisons. Independent ttests were performed to compare OC-users with non-users at baseline for all measures. Upon completion of the training period, changes in muscular strength were used as verification of a 
training effect using paired t-tests. For assessment of all bone strength measures, a two way analysis of variance was performed to allow consideration of OC and NOC groups, as well as the different $\mathrm{CON}$ and ECC training methods. Changes in BMD and EI were determined by subtracting baseline values from post-training measurements for non-dominant and dominant limbs and then subtracting this change in the dominant (untrained) limb from the change in the non-dominant (trained) limb to discern any effects of training on bone that were not due to normal age-related growth. Changes between the trained and untrained limbs, and also differences between the tibia (weight bearing bone) and ulna (non-weight bearing bone) were explored with paired t-tests to compare potential differences for each of the four groups (OC/ECC, OC/CON, NOC/ECC, NOC/CON). Paired t-tests were also used to make posttraining comparisons between OC and NOC groups for all measures. Finally, Pearson product moment correlations were run to determine if the changes in BMD and $\mathrm{EI}_{\mathrm{MRTA}}$ were occurring in the same direction, and to what degree.

\section{RESULTS}

Baseline characteristics. No significant differences were found at baseline between OC (age $20.1 \pm 1.2 \mathrm{yrs}$, height $164.8 \pm 6.4$ in, weight $60 \pm 9.7 \mathrm{~kg}$, body fat $\% 29.2 \pm 4.9$, total body BMD $1.1 \pm 0.1$ ) and NOC (age $20 \pm 1.5 \mathrm{yrs}$, height $162.9 \pm 5.9 \mathrm{in}$, weight $57.9 \pm 7.6 \mathrm{~kg}$, body fat $\% 26.8$ \pm 4.5 , total body BMD $1.1 \pm 0.1$ ) groups for all clinical measures assessed (see Table 2). Strength measures. Changes in strength values from baseline to post-training were used as confirmation of exercise compliance (see Table 3). In the OC group, there were significant ( $p<$ 0.05) strength improvements from baseline for all movements of the trained limbs, and for the untrained elbow extensors. Similarly, in the NOC group, there were significant $(\mathrm{p}<0.05)$ 
changes from baseline for all movements of the trained limb, untrained knee flexors and extensors, and untrained elbow extensors. Comparisons at baseline showed no significant differences in strength of the dominant and non-dominant limbs with the exception of significantly $(\mathrm{p}<0.05)$ higher strength found in the dominant knee extensors and flexors in OCusers, and elbow extensors in the NOC group.

\section{Responses to exercise intervention}

OC-users compared with NOC users. No consistent contraceptive effects on appendicular bone sites were seen in response to exercise training. Total body BMD increased from baseline for NOC subjects $(\mathrm{p}<0.05)$, but not for OC users, suggesting a potential suppressive effect of OCs on total body bone mass accumulation in skeletally immature females. This difference failed to show significance $(\mathrm{p}=0.069)$ when comparisons were run between NOC and OC groups. There was a positive effect of exercise training seen in total hip BMD for both groups, irrespective of contraceptive status (OC, $p<0.001$; NOC, $p<0.05)$. Skeletal maturation effects were seen in the ulna and seemed to be unaffected by both exercise training and contraceptive use ( $p<0.01$ for trained and untrained limbs, in OC and NOC groups). Positive changes in EI were conflicting, occurring in the trained ulna for the NOC group $(\mathrm{p}<0.05)$, and trained tibia for OC users $(p<0.05)$. Lastly, the only positive change in tibial BMD from baseline occurred in the untrained leg for the NOC group, suggesting that exercise training and use of OCs may have a negative effect on BMD in the tibia. Results from baseline to post-training irrespective of training groups for OC users and NOC users can be seen in Table 4. No between group differences were found to be significant. Measures of BMD and EI were weakly correlated and inconsistent in direction for both the ulna (0.08), and tibia (-0.11). 
Isokinetic training mode dependent analysis. No between-group interactions were noted between NOC and OC-users, and the ECC and CON training groups. With regards to the different training modes, a significantly greater gain in ulnar BMD was seen with concentric vs. eccentric training $(\mathrm{p}<0.05)$.

Trained limb comparisons with the untrained limb. Significant increases in the trained limb compared to the untrained limb were seen in femoral neck BMD $(\mathrm{p}<0.05)$ in concentrically trained subjects not using OCs. No significant differences were seen in concentrically trained subjects using OCs or for any measures in the eccentrically trained groups regardless of contraceptive status.

Weight bearing compared with non-weight bearing limbs. No significant differences between the tibia and ulna were found for any measures of BMD or EI.

\section{DISCUSSION}

It is expected that with the normally positive balance between formation and resorption at various skeletal sites seen in young women a reduction in bone turnover caused by either increased exercise or by OC use will suppress the age-related addition in bone mass and increased bone strength that would normally occur. Despite the lack of significant between group interactions for OC use and non-use and the different $\mathrm{CON}$ and ECC modes of isokinetic training found in this study, further investigation is warranted regarding apparent positive changes from baseline seen in total body BMD (NOC group), total hip BMD (trained limb, both groups), ulnar BMD (both groups, both limbs), untrained tibial BMD and trained ulnar EI (NOC group), and trained tibial EI (OC group). A summary of BMD results in NOC and OC users is shown in 
Figure 1. This study utilizes a training stimulus that is unique from any training study performed on OC users thus far and incorporates a novel measurement of long bone bending stiffness.

The significant increase in strength found in all movements of the trained limbs is evidence of training compliance and provides reassurance that a training effect did occur. Although there were baseline differences reported between dominant and non-dominant limbs, the differences were in favor of the untrained limb illustrating that the trained limb movements had to overcome an existing strength deficit in order to approach significance post-training. Increases in strength were also noted in untrained limb movements as a result of a potential cross-education effect. These findings concur with previous isokinetic training studies(Housh and Housh 1993; Housh, Housh et al. 1996; Weir, Housh et al. 1997; Farthing and Chilibeck 2003) where significant increases in untrained limb strength (trained leg: 29\%, untrained leg: 17\%),(Housh, Housh et al. 1996) (trained leg: 42\%, untrained leg: 15\%)(Housh, Housh et al. 1996) have been reported.

Despite the effect of exercise on measures of muscular strength, no distinct changes were seen for measures of BMD or EI as a function of oral contraceptive use. Ulnar BMD increased significantly from baseline regardless of training or OC status $(\mathrm{p}<0.01)$, as did total hip BMD in the trained leg regardless of OC status $(\mathrm{p}<0.05)$. Changes in the ulna may be a factor of normal age-related growth in this age group and remain unaffected by OC use, or isokinetic training. Remaining regions of interest did not change significantly from baseline and remained consistent between groups with the exception of significant increases in total body BMD, untrained tibial BMD, trained ulnar EI in NOC subjects, and trained tibial EI in OC users. There were no significant differences found between OC and NOC subjects for any measures of BMD or EI from baseline to post-training which is in agreement with other research on this topic finding no 
significance between OC users and non-users.(Fortney, Feldblum et al. 1994; MacDougall, Davies et al. 1999; Lloyd, Taylor et al. 2000; Cobb, Kelsey et al. 2002; Hawker, Forsmo et al. 2002; Reed, Scholes et al. 2003)

As stated above, subjects not using OCs experienced a significant increase in total body BMD from baseline, whereas the OC group decreased slightly. This change in total body BMD approached significance $(\mathrm{p}<0.07)$ comparing the NOC with the OC group suggesting a delay in the progression towards peak bone mass in subjects using OCs. These findings are in agreement with previous research on combined $\mathrm{OC}$ use and exercise finding that use of low dose OCs might counteract the beneficial influence of physical activity on bone formation.(Hartard, Bottermann et al. 1997) In past studies without an exercise component, no increase in BMD was found in young women using OCs for five years, whereas BMD in untreated subjects increased significantly.(Polatti, Perotti et al. 1995) Additionally, a study comparing OCs with other forms of hormonal contraception found that although OCs were associated with normal age related increases in $\mathrm{BMD}$, greater increases were seen in subjects not using hormonal contraception.(Cromer, Blair et al. 1996)

Comparisons to show increases in the trained limb beyond that of the untrained limb showed significance only for femoral neck BMD in concentrically trained subjects using OCs. In a previous study from Burr et al., either exercise or OC use was associated with a suppression of the normal increase in bone mass and mechanical strength in the femoral neck in women 18-35 years old.(Burr, Yoshikawa et al. 2000) However, in the same study, subjects using OCs as well as participating in an exercise program experienced a less suppressive effect on cross-sectional moment of inertia of the femoral neck,(Burr, Yoshikawa et al. 2000) supporting the slight but significant increases in BMD seen in the femoral neck of concentrically trained OC-users in the 
current study. This trend has also been recognized in postmenopausal women where use of OCs has led to suppression of bone turnover and increased BMD in the femoral neck.(KritzSilverstein and Barrett-Connor 1993)

Concentric isokinetic strength training resulted in greater increases in ulnar BMD than did eccentric training. However, without consistent trends in the data showing concentric training to be more osteogenic than eccentric training, it is difficult to draw conclusions regarding the effectiveness of this mode of isokinetic training on improving the quality of bone. Eccentric training has repeatedly shown in past research to produce greater muscular strength gains than with concentric training.(Hortobagyi, Devita et al. 2001; Hiliard-Robertson, Schneider et al. 2003) However, to date no studies have found significant associations between concentric vs. eccentric isokinetic strength training and measures of BMD or EI.

This study presents several limitations. To reach peak bone mass, factors other than estrogen are needed, such as calcium, vitamin D, lack of smoking, and so on.(Karck and Breckwoldt 2001) Measures of these various lifestyle factors were poorly reported, and could not be controlled for through statistical analysis. Further studies are urged to incorporate additional countermeasures to determine if effects seen in BMD and EI are in fact due to exercise and/or $\mathrm{OC}$ use, or if there is a separate factor impacting bone quality measures. Secondly, it is difficult to draw definitive conclusions from a small subject number. When separating subjects into their respective modes of isokinetic training and use or non-use of OCs, we were left with only 10-14 subjects in each group leading the investigators to question if significance found in various bone strength measures were due to chance, or treatment effect. Third, the MRTA device used as a measure of EI has been validated $\left(\mathrm{r}^{2}=.95\right)$ against three-point bending in a static ex vivo test using monkey tibias.(Roberts, Hutchinson et al. 1996) Mean values found for ulnar EI in this 
study $\left(16.8-23.2 \mathrm{Nm}^{2}\right)$ are similar to results from a previous study in young adult women (26.6 $\pm 1.20 \mathrm{Nm}^{2}$ ), (McCabe, Zhou et al. 1991) but are near values described as indicative of osteoporosis $\left(8-12 \mathrm{Nm}^{2}\right)$ in past research.(Steele, Zhou et al. 1988) Further, recent dissertation work using the newer MRTA prototype has found the new hardware to be less reliable, and of an unacceptable range for use in clinical research.(Callaghan 2003; Miller 2003) The immense variability $\left(0-58.5 \mathrm{Nm}^{2}\right)$ found in EI measures in this study suggest that improvements in the MRTA device need to be made before it can be used as a reliable and valid assessment of bone quality. Finally, differing hormonal concentrations in the OCs used in this study could be viewed as a limitation. However, all OCs used by the subjects in this study contained between 30-40 mg ethinyl estradiol and can be considered low-dose OCs. Being combined OCs, differing forms and concentrations of progestins were used. Nevertheless, studies have shown no additional skeletal benefits of progestin in women taking estrogen either premenopausally,(Hergenroeder, Smith et al. 1997; Prior, Vigna et al. 1997) or postmenopausally.(Nand, Wren et al. 1999) Using varying prescriptions of OCs help generalize the results of this study to all methods of combined lowdose OCs rather than isolating the effects to only one hormonal concentration.

The results of this study suggest that oral contraceptives may limit attainment of total body peak bone mass in young adult females. Skeletal maturation continued in the ulna regardless of exercise training or contraceptive status, and exercise training had a positive effect on total hip BMD regardless of contraceptive status. Changes found in the untrained tibia for the NOC group suggest a potential negative effect of both exercise training and $\mathrm{OC}$ use on this skeletal site. Correlations between BMD and EI differences over time were weakly related and inconsistent in terms of direction, suggesting that the MRTA device may require improvements to various hardware and software components before it can be used as a reliable and valid 
assessment of bone quality. Issues of bone health in OC users are important to address so that we may formulate a set of recommendations for use and guarantee that this form of contraception will not lead to serious skeletal consequences in later life. Further studies are needed to determine the interactive effects of $\mathrm{OC}$ use and isokinetic resistance training on measures of BMD and geometry. 
TABLE 1:

Table 1: Hormonal Contraceptive Concentrations - Use at Baseline

\begin{tabular}{|c|c|c|c|}
\hline & Estrogen (mg) & Progestin (mg)2 & Subjects \\
\hline Ortho-Tri-Cyclen & & & 11 \\
\hline days $1-7$ & Ethinyl estradiol 35 & Norgestimate 0.18 & \\
\hline days $8-14$ & Ethinyl estradiol 35 & Norgestimate 0.215 & \\
\hline Days $15-21$ & Ethinyl estradiol 35 & Norgestimate 0.25 & \\
\hline Ortho-Cyclen & Ethinyl estradiol 35 & Norgestimate 0.25 & 2 \\
\hline Desogen & Ethinyl estradiol 30 & Desogestrel 0.15 & 3 \\
\hline Triphasil & & & 2 \\
\hline days 1-6 & Ethinyl estradiol 30 & L-Norgestrel 0.05 & \\
\hline days $7-11$ & Ethinyl estradiol 40 & L-Norgestrel 0.075 & \\
\hline Days12-21 & Ethinyl estradiol 30 & L-Norgestrel 0.125 & \\
\hline Demulen 1/35 & Ethinyl estradiol 35 & Ethynodiol Diacetate 1.0 & 1 \\
\hline Loestrin $1.5 / 30$ & Ethinyl estradiol 30 & Norethindrone acetate 1.5 & 1 \\
\hline Nordette & Ethinyl estradiol 30 & L-Norgestrel 0.15 & 1 \\
\hline Ortho-Novum 1/35 & Ethinyl estradiol 35 & Norethindrone 1.0 & 1 \\
\hline None & 0 & 0 & 24 \\
\hline
\end{tabular}


TABLE 2:

Table 2: Baseline characteristics for oral contraceptive users and non-users

\begin{tabular}{|c|c|c|c|c|c|c|c|c|}
\hline \multirow[b]{2}{*}{ Measure } & \multirow[b]{2}{*}{ Unit } & \multicolumn{3}{|c|}{$\mathrm{NC}$} & \multicolumn{3}{|c|}{$\mathrm{OC}$} & \multirow[b]{2}{*}{$\mathbf{P}$} \\
\hline & & Mean & & SD & Mean & & SD & \\
\hline Age & $\mathrm{yr}$ & 20.0 & \pm & 1.5 & 20.1 & \pm & 1.2 & 0.83 \\
\hline Height & $\mathrm{m}$ & 1.6 & \pm & 5.9 & 1.6 & \pm & 6.4 & 0.30 \\
\hline Weight & $\mathrm{kg}$ & 57.9 & \pm & 7.6 & 60.0 & \pm & 9.7 & 0.42 \\
\hline Total Body Fat & $\%$ & 26.8 & \pm & 4.5 & 29.2 & \pm & 4.9 & 0.09 \\
\hline Total Body BMD & $\mathrm{g} / \mathrm{cm}^{2}$ & 1.114 & \pm & 0.070 & 1.109 & \pm & 0.090 & 0.81 \\
\hline \multicolumn{9}{|l|}{ Femoral Neck BMD } \\
\hline trained & $\mathrm{g} / \mathrm{cm}^{2}$ & 0.832 & \pm & 0.090 & 0.862 & \pm & 0.130 & 0.37 \\
\hline untrained & $\mathrm{g} / \mathrm{cm}^{2}$ & 0.837 & \pm & 0.090 & 0.859 & \pm & 0.120 & 0.49 \\
\hline \multicolumn{9}{|l|}{ Total Hip BMD } \\
\hline trained & $\mathrm{g} / \mathrm{cm}^{2}$ & 0.929 & \pm & 0.090 & 0.956 & \pm & 0.140 & 0.40 \\
\hline untrained & $\mathrm{g} / \mathrm{cm}^{2}$ & 0.917 & \pm & 0.080 & 0.955 & \pm & 0.130 & 0.25 \\
\hline \multicolumn{9}{|l|}{ Tibial BMD } \\
\hline trained & $\mathrm{g} / \mathrm{cm}^{2}$ & 1.002 & \pm & 0.090 & 0.917 & \pm & 0.110 & 0.34 \\
\hline untrained & $\mathrm{g} / \mathrm{cm}^{2}$ & 0.998 & \pm & 0.080 & 0.994 & \pm & 0.110 & 0.90 \\
\hline \multicolumn{9}{|l|}{ Tibial EI } \\
\hline trained & $\mathrm{N} \cdot \mathrm{m}^{2}$ & 111.9 & \pm & 70.9 & 106.6 & \pm & 50.3 & 0.78 \\
\hline untrained & $\mathrm{N} \cdot \mathrm{m}^{2}$ & 109.7 & \pm & 57.0 & 109.8 & \pm & 43.0 & 1.00 \\
\hline \multicolumn{9}{|l|}{ Ulnar BMD } \\
\hline trained & $\mathrm{g} / \mathrm{cm}^{2}$ & 0.522 & \pm & 0.030 & 0.527 & \pm & 0.050 & 0.64 \\
\hline untrained & $\mathrm{g} / \mathrm{cm}^{2}$ & 0.540 & \pm & 0.030 & 0.533 & \pm & 0.050 & 0.58 \\
\hline \multicolumn{9}{|l|}{ Ulnar EI } \\
\hline trained & $\mathrm{N} \cdot \mathrm{m}^{2}$ & 16.1 & \pm & 13.4 & 17.6 & \pm & 13.4 & 0.72 \\
\hline untrained & $\mathrm{N} \cdot \mathrm{m}^{2}$ & 16.9 & \pm & 11.0 & 18.9 & \pm & 16.3 & 0.63 \\
\hline
\end{tabular}


TABLE 3:

Table 3: Changes in strength over time for oral contraceptive users compared with non-users

\begin{tabular}{|c|c|c|c|c|c|c|c|}
\hline & & \multicolumn{3}{|c|}{$\mathrm{OC}$} & \multicolumn{3}{|c|}{ NOC } \\
\hline & & 0 & 32 & $p$ & 0 & 32 & $p$ \\
\hline \multicolumn{8}{|l|}{ Arm } \\
\hline \multirow{2}{*}{$\begin{array}{l}\text { flexors } \\
(\mathrm{Nm})\end{array}$} & trained & 46.3 & 50.8 & 0.026 * & 43.94 & 49.60 & 0.002 * \\
\hline & untrained & 47.5 & 48.9 & 0.432 & 45.97 & 47.57 & 0.428 \\
\hline \multirow{2}{*}{$\begin{array}{l}\text { extensors } \\
(\mathrm{Nm})\end{array}$} & trained & 63.3 & 69.9 & 0.041 * & 57.77 & 77.10 & 0.001 * \\
\hline & untrained & 63.1 & 74.5 & 0.002 * & 61.87 & 69.21 & 0.042 * \\
\hline \multicolumn{8}{|l|}{ Leg } \\
\hline \multirow{2}{*}{$\begin{array}{l}\text { flexors } \\
(\mathrm{Nm})\end{array}$} & trained & 130.0 & 147.0 & 0.003 * & 118.35 & 140.91 & 0.001 * \\
\hline & untrained & 142.1 & 136.5 & 0.332 & 119.66 & 132.71 & 0.003 * \\
\hline \multirow{2}{*}{$\begin{array}{l}\text { extensors } \\
(\mathrm{Nm})\end{array}$} & trained & 213.1 & 261.4 & 0.000 * & 200.86 & 261.11 & 0.000 * \\
\hline & untrained & 226.3 & 237.8 & 0.132 & 205.48 & 232.37 & 0.004 * \\
\hline
\end{tabular}

${ }^{*}$ statistically significant at $p<0.05$

All values are reported as peak torque 
TABLE 4:

Table 4: Changes in BMD and EI from baseline to post-training for OC users and nonusers

\begin{tabular}{|c|c|c|c|c|c|c|c|c|c|}
\hline \multirow[b]{2}{*}{ Region } & \multirow[b]{2}{*}{ Measure } & \multirow[b]{2}{*}{ Status } & \multirow[b]{2}{*}{ Units } & \multicolumn{3}{|c|}{ OC } & \multicolumn{3}{|c|}{ NOC } \\
\hline & & & & 0 & 32 & $p$ & 0 & 32 & $p$ \\
\hline Total Body & BMD & & $\mathrm{g} / \mathrm{cm}^{2}$ & 1.109 & 1.107 & 0.700 & 1.114 & 1.119 & $0.020^{*}$ \\
\hline \multirow{2}{*}{ Total Hip } & \multirow{2}{*}{ BMD } & trained & $\mathrm{g} / \mathrm{cm}^{2}$ & 0.956 & 0.972 & $0.000^{*}$ & 0.929 & 0.935 & $0.023^{*}$ \\
\hline & & untrained & $\mathrm{g} / \mathrm{cm}^{2}$ & 0.862 & 0.866 & 0.355 & 0.832 & 0.832 & 0.738 \\
\hline \multirow{2}{*}{ Femoral Neck } & \multirow{2}{*}{ BMD } & trained & $\mathrm{g} / \mathrm{cm}^{2}$ & 0.859 & 0.866 & 0.391 & 0.837 & 0.853 & 0.107 \\
\hline & & untrained & $\mathrm{g} / \mathrm{cm}^{2}$ & 0.955 & 0.963 & 0.146 & 0.917 & 0.922 & 0.196 \\
\hline \multirow{4}{*}{ Ulna } & \multirow{2}{*}{ BMD } & trained & $\mathrm{g} / \mathrm{cm}^{2}$ & 0.527 & 0.540 & $0.000^{*}$ & 0.522 & 0.534 & $0.000^{*}$ \\
\hline & & untrained & $\mathrm{g} / \mathrm{cm}^{2}$ & 0.53 & 0.54 & $0.003^{*}$ & 0.54 & 0.55 & $0.004^{*}$ \\
\hline & \multirow{2}{*}{ El } & trained & $\mathrm{N} \cdot \mathrm{m}^{2}$ & 18.8 & 23.2 & 0.181 & 16.8 & 22.2 & $0.048^{*}$ \\
\hline & & untrained & $\mathrm{N} \cdot \mathrm{m}^{2}$ & 18.0 & 20.7 & 0.506 & 16.9 & 21.4 & 0.092 \\
\hline \multirow{4}{*}{ Tibia } & \multirow{2}{*}{ BMD } & trained & $\mathrm{g} / \mathrm{cm}^{2}$ & 0.972 & 0.979 & 0.298 & 1.002 & 1.008 & 0.151 \\
\hline & & untrained & $\mathrm{g} / \mathrm{cm}^{2}$ & 0.994 & 1.003 & 0.308 & 0.998 & 1.012 & $0.002^{*}$ \\
\hline & \multirow{2}{*}{ El } & trained & $\mathrm{N} \cdot \mathrm{m}^{2}$ & 107.1 & 139.0 & $0.046^{*}$ & 111.9 & 119.9 & 0.662 \\
\hline & & untrained & $\mathrm{N} \cdot \mathrm{m}^{2}$ & 108.1 & 125.6 & 0.158 & 109.7 & 141.9 & 0.063 \\
\hline
\end{tabular}

* statistically significant at $p<0.05$, no significance was found for time by group interactions, significant values reflect only time effects within groups 
Figure 1: Total body, and site specific increases in BMD seen in NOC and OC subjects

\section{OC Subjects}

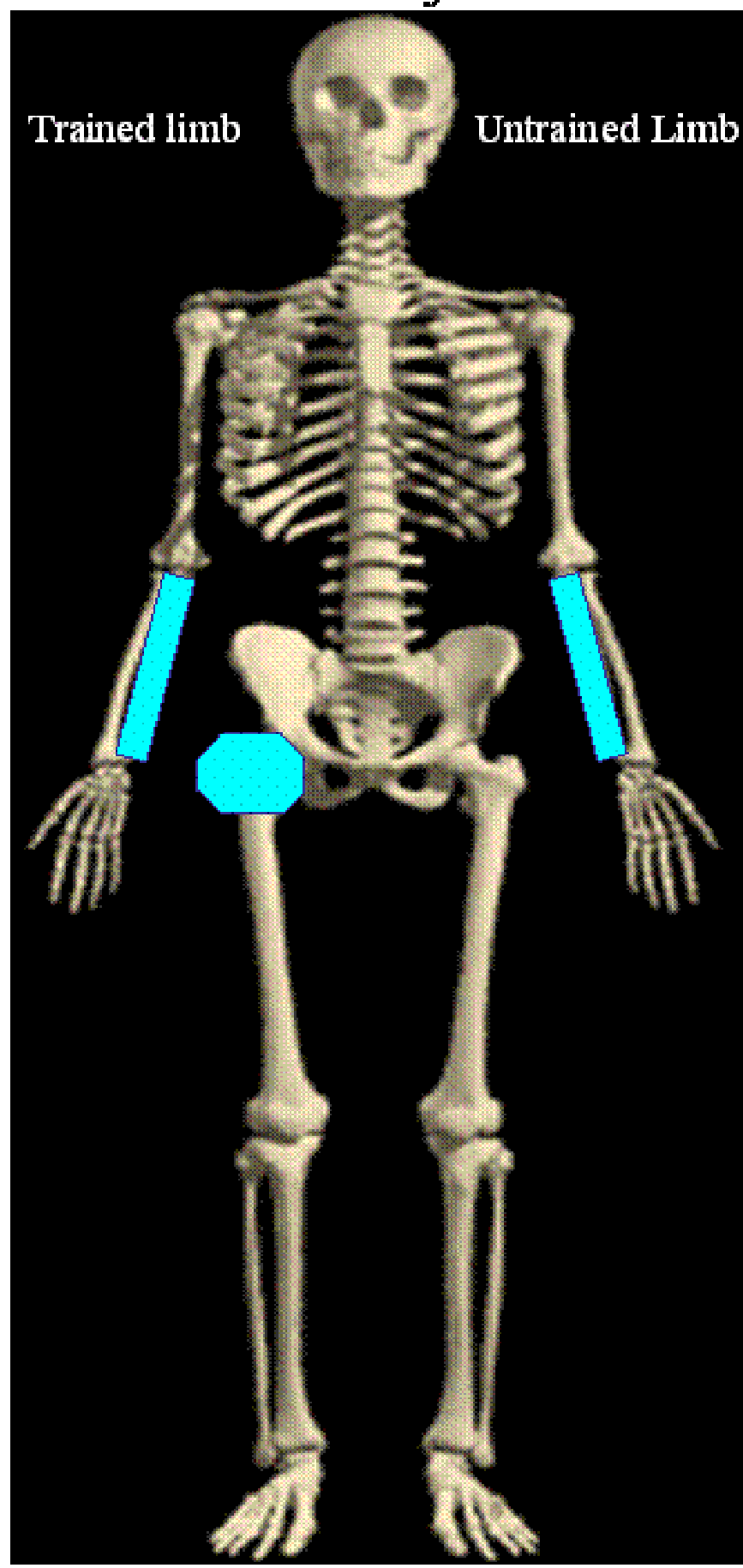

Total Ulna (Both limbs, p <0.01), Total Hip $\uparrow$ (Untrained limb, $\mathrm{p}<0.01$ )

\section{NOC Subjects}

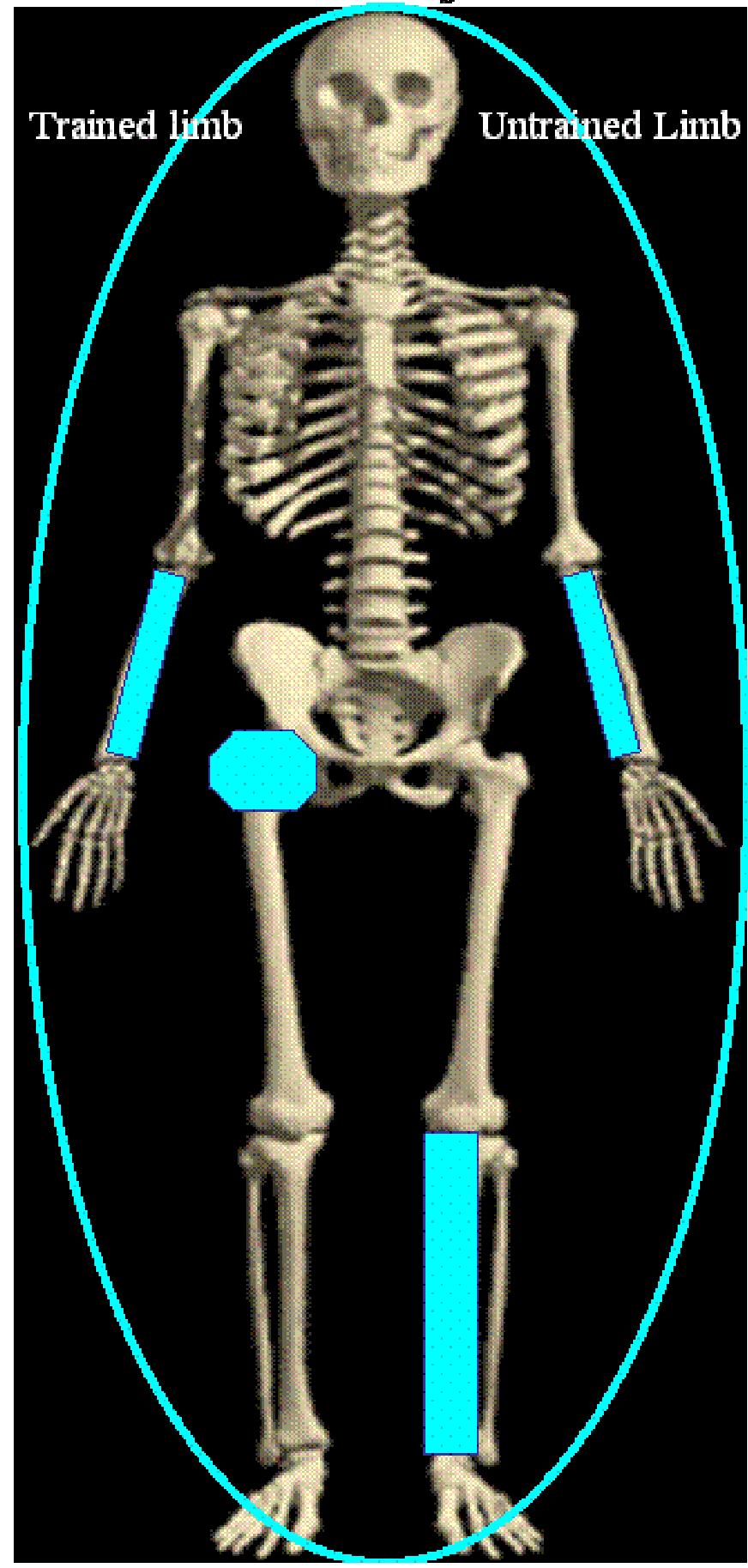

Total Body $\uparrow(p<005)$, Total Ulna $\uparrow$ (Both limbs, $\mathrm{p}<0.01$ ) Total Hip $\uparrow$ (Untraned limb, $\mathrm{p}<005$ ), Total Tibia (Traned limb, $\mathrm{p}<001$ ) 
Figure 2: Site specific changes in BMD over time for OC and NOC groups

\section{Changes in BMD over time (OC)}

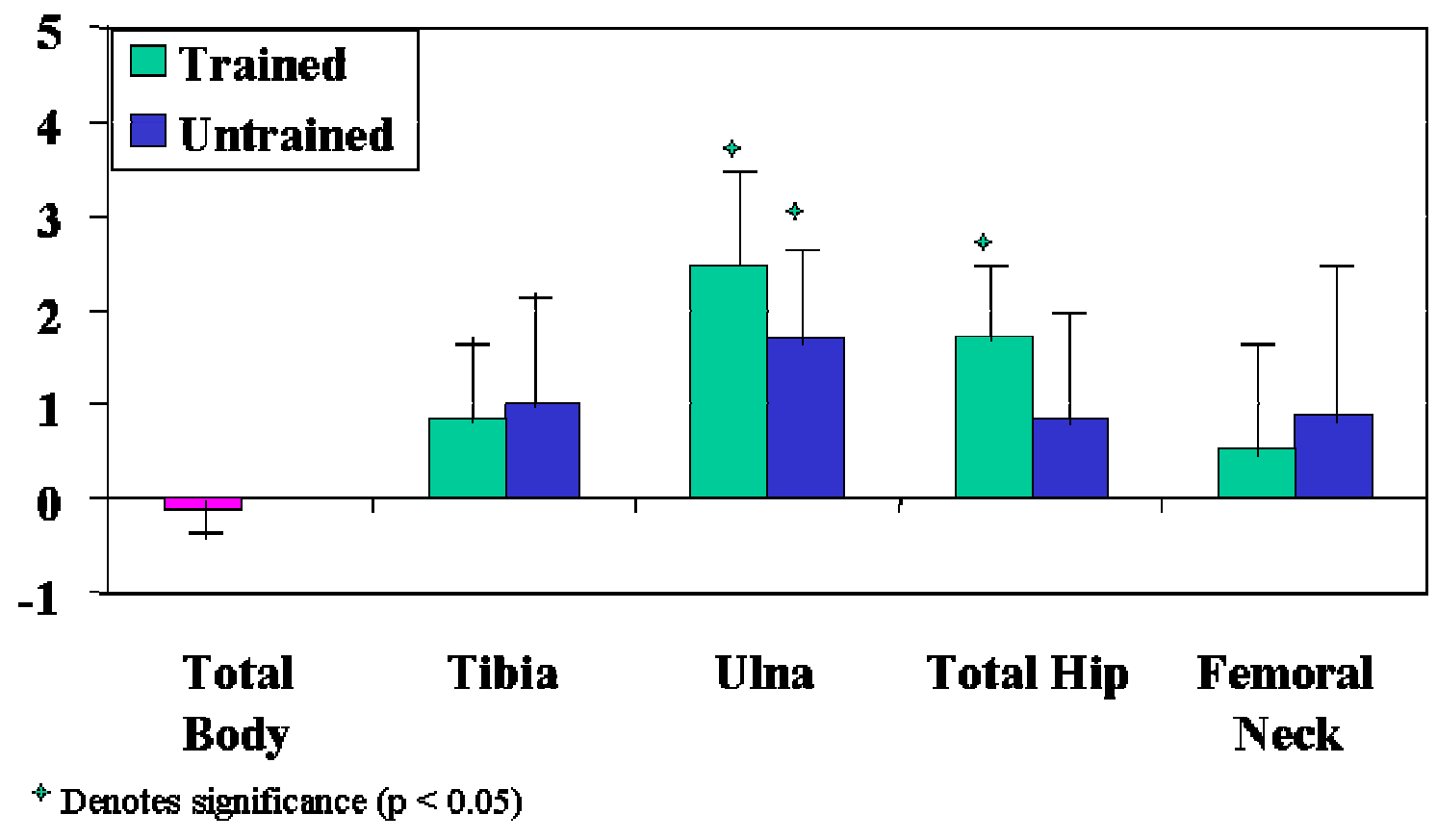

Changes in BMD over time (NOC)

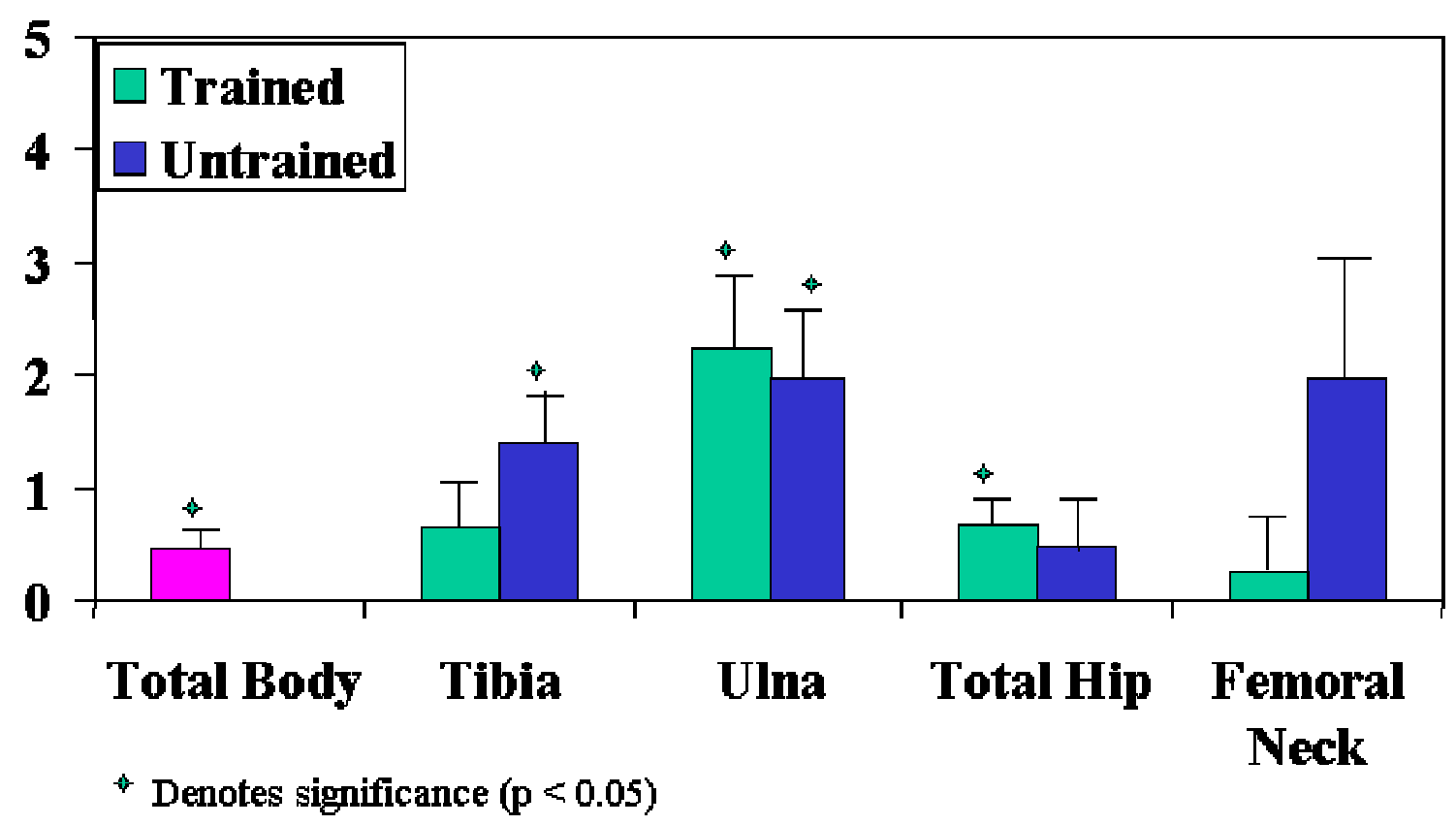




\section{REFERENCES}

1. Burkman, R. The role of oral contraceptives in the treatment of hyperandrogenic disorders. Am J Med. 98:130S-136S, 1995.

2. Burr, D. B., T. Yoshikawa, D. Teegarden, R. Lyle, G. McCabe, L. D. McCabe, and C. M. Weaver. Exercise and oral contraceptive use suppress the normal age-related increase in bone mass and strength of the femoral neck in women 18-31 years of age. Bone. 27:855863., 2000.

3. Callaghan, C. E. Reliability of Tibial Measurement with Mechanical Response Tissue Analysis. Dissertation. Virginia Polytechnic Institute and State University, Human Nutrition, Foods and Exercise, Blacksburg, 2003.

4. Cobb, K. L., J. L. Kelsey, S. Sidney, B. Ettinger, and C. E. Lewis. Oral contraceptives and bone mineral density in white and black women in CARDIA. Coronary Risk Development in Young Adults. Osteoporos Int. 13:893-900., 2002.

5. Cromer, B. A., J. M. Blair, J. D. Mahan, L. Zibners, and Z. Naumovski. A prospective comparison of bone density in adolescent girls receiving depot medroxyprogesterone acetate (Depo-Provera), levonorgestrel (Norplant), or oral contraceptives. J Pediatr. 129:671-676., 1996.

6. Drinkwater, B., K. Nilson, C. Chestnut, W. Bremner, S. Shainholtz, and M. Southworth. Bone mineral content of amenorrheic and eumenorrheic athletes. $N$ Engl J Med. 311:277281, 1984.

7. Farthing, J. and P. Chilibeck. The effect of eccentric training at different velocities on cross-education. Eur J Appl Physiol. 89:570-577, 2003.

8. Fortney, J. A., P. J. Feldblum, R. V. Talmage, J. Zhang, and S. E. Godwin. Bone mineral density and history of oral contraceptive use. J Reprod Med. 39:105-109., 1994.

9. Frisch, R. E., A. V. Gotz-Welbergen, J. W. McArthur, T. Albright, J. Witschi, B. Bullen, J. Birnholz, R. B. Reed, and H. Herman. Delayed menarche and amenorrhea of college athletes in relation to to age of onset of training. JAMA. 246:1559-1563, 1981.

10. Hartard, M., P. Bottermann, P. Bartenstein, D. Jeschke, and M. Schwaiger. Effects on bone mineral density of low-dosed oral contraceptives compared to and combined with physical activity. Contraception. 55:87-90., 1997.

11. Hawker, G. A., S. Forsmo, S. M. Cadarette, B. Schei, S. B. Jaglal, L. Forsen, and A. Langhammer. Correlates of Forearm Bone Mineral Density in Young Norwegian Women, The Nord-Trondelag Health Study. Am J Epidemiol. 156:418-427, 2002.

12. Hergenroeder, A. C., E. O. Smith, R. Shypailo, L. A. Jones, W. J. Klish, and K. Ellis. Bone mineral changes in young women with hypothalamic amenorrhea treated with oral contraceptives, medroxyprogesterone, or placebo over 12 months. Am J Obstet Gynecol. 176:1017-1025., 1997.

13. Hiliard-Robertson, P., S. Schneider, S. Bishop, and M. Guilliams. Strength gains following different combined concentric and eccentric exercise regimens. Aviat Space Environ Med. 74:342-347, 2003.

14. Hortobagyi, T., P. Devita, J. Money, and J. Barrier. Effects of standard and eccentric overload strength training in young women. Med Sci Sports Exerc. 33:1206-1212, 2001.

15. Housh, D. and T. Housh. The effects of unilateral velocity-specific concentric strength training. J Orthop Sports Phys Ther. 17:252-256, 1993. 
16. Housh, T., D. Housh, J. Weir, and L. Weir. Effects of eccentric-only resistance training and detraining. Int J Sports Med. 17:145-148, 1996.

17. Housh, T., D. Housh, J. Weir, and L. Weir. Effects of unilateral concentric-only dynamic constant external resistance training. Int J Sports Med. 17:338-343, 1996.

18. Jones, H. H., J. D. Priest, W. C. Hayes, C. C. Tichenor, and D. A. Nagel. Humeral hypertrophy in response to exercise. J Bone Joint Surg. 59-A:204-208, 1977.

19. Kannus, P., H. Haapasalo, M. Sankelo, H. Sievanen, M. Pasanen, A. Heinonen, P. Oja, and I. Vuori. Effect of starting age of physical activity on bone mass in the dominant arm of tennis and squash players. Ann Intern Med. 123:27-31, 1995.

20. Karck, U. and M. Breckwoldt. [Low-dose oral contraception and bone density]. Ther Umsch. 58:547-551., 2001.

21. Kritz-Silverstein, D. and E. Barrett-Connor. Bone mineral density in postmenopausal women as determined by prior oral contraceptive use. Am J Public Health. 83:100-102., 1993.

22. Lloyd, T., D. S. Taylor, H. M. Lin, A. E. Matthews, D. F. Eggli, and R. S. Legro. Oral contraceptive use by teenage women does not affect peak bone mass: a longitudinal study. Fertil Steril. 74:734-738., 2000.

23. MacDougall, J., M. C. Davies, C. E. Overton, B. Gulekli, M. Hall, W. Bounds, H. S. Jacobs, and J. G. Guillebaud. Bone density in a population of long term oral contraceptive pill users does not differ from that in menstruating women. Br J Fam Plann. 25:96-100., 1999.

24. Marcus, R. Mechanisms of Exercise Effects on Bone. In: Principles of Bone Biology: Academic Press, 2002, pp. 1477-1488.

25. McCabe, F., L. J. Zhou, C. R. Steele, and R. Marcus. Noninvasive assessment of ulnar bending stiffness in women. J Bone Miner Res. 6:53-59., 1991.

26. Miller, L. E. Reliability and Validity of Mechanical Response Tissue Analysis in Composite and Human Tibia. Dissertation. Virginia Polytechnic Institute and State University, Human Nutrition, Foods and Exercise, Blacksburg, 2003.

27. Nand, S. L., B. G. Wren, B. A. Gross, and B. G. Heller. Bone density effects of continuous estrone sulfate and varying doses of medroxyprogesterone acetate. Ogen/Provera Study Group. Obstet Gynecol. 93:1009-1013, 1999.

28. Ott, S. M., D. Scholes, A. Z. LaCroix, L. E. Ichikawa, C. K. Yoshida, and W. E. Barlow. Effects of contraceptive use on bone biochemical markers in young women. J Clin Endocrinol Metab. 86:179-185., 2001.

29. Polatti, F., F. Perotti, N. Filippa, D. Gallina, and R. E. Nappi. Bone mass and long-term monophasic oral contraceptive treatment in young women. Contraception. 51:221-224., 1995.

30. Prior, J. C., Y. M. Vigna, J. D. Wark, D. R. Eyre, B. C. Lentle, D. K. Li, P. R. Ebeling, and L. Atley. Premenopausal ovariectomy-related bone loss: a randomized, double- blind, one-year trial of conjugated estrogen or medroxyprogesterone acetate. J Bone Miner Res. 12:1851-1863., 1997.

31. Proctor, K. L., W. C. Adams, J. D. Shaffrath, and M. D. Van Loan. Upper-limb bone mineral density of female collegiate gymnasts versus controls. Med Sci Sports Exerc. 34:1830-1835, 2002.

32. Recker, R. R., K. M. Davies, S. M. Hinders, R. P. Heaney, M. R. Stegman, and D. B. Kimmel. Bone gain in young adult women. Jama. 268:2403-2408., 1992. 
33. Reed, S. D., D. Scholes, A. Z. LaCroix, L. E. Ichikawa, W. E. Barlow, and S. M. Ott. Longitudinal changes in bone density in relation to oral contraceptive use. Contraception. 68:177-182, 2003.

34. Rickard, D., S. Harris, R. Turner, S. Khosla, and T. Spelsberg. Estrogens and Progestins. In: Principles of Bone Biology. G. Rodan (Ed.) San Diego, CA: Academic Press, 2002, pp. 655-675.

35. Roberts, S. G., T. M. Hutchinson, S. B. Arnaud, B. J. Kiratli, R. B. Martin, and C. R. Steele. Noninvasive determination of bone mechanical properties using vibration response: a refined model and validation in vivo. J Biomech. 29:91-98, 1996.

36. Scerpella, T. A., M. Davenport, C. M. Morganti, J. A. Kanaley, and L. M. Johnson. Dose Related Association of Impact Activity and Bone Mineral Density in Pre-pubertal Girls. Calcif Tissue Int. 72:24-31, 2003.

37. Steele, C. R., L. J. Zhou, D. Guido, R. Marcus, W. L. Heinrichs, and C. Cheema. Noninvasive determination of ulnar stiffness from mechanical response-- in vivo comparison of stiffness and bone mineral content in humans. J Biomech Eng. 110:87-96., 1988.

38. Turner, C. H. and A. G. Robling. Designing Exercise Regimens to Increase Bone Strength. Exercise and Sport Sciences Reviews. 31:45-50, 2003.

39. Weaver, C. M., D. Teegarden, R. M. Lyle, G. P. McCabe, L. D. McCabe, W. Proulx, M. Kern, D. Sedlock, D. D. Anderson, B. M. Hillberry, M. Peacock, and C. C. Johnston. Impact of exercise on bone health and contraindication of oral contraceptive use in young women. Med Sci Sports Exerc. 33:873-880., 2001.

40. Weir, J., D. Housh, T. Housh, and L. Weir. The effect of unilateral concentric weight training and detraining on joint angle specificity, cross-training, and the bilateral deficit. $J$ Orthop Sports Phys Ther. 25:264-270, 1997. 


\section{Chapter 4}

\section{Introduction}

Osteoporosis is a disease characterized by low bone mass and structural deterioration of bone tissue leading to increased bone fragility and greater risk of fracture. This disease is a major public health threat currently estimated to affect 10 million people nationwide and may be partially prevented by factors operating during skeletal growth. The development of osteoporosis and related fractures in later life depends not only on the rate of bone loss in adulthood, but also on the amount of bone present at skeletal maturity. In general, three classes of factors are thought to influence the accumulation of and maintenance of bone: alterations in hormone concentration (reproductive, calciotropic, other), bone-loading (weight, strength, mobility), and lifestyle (nutrition, alcohol, tobacco). The present study explored the relationships between use of hormonal contraceptives (oral contraceptive pills) and isokinetic muscular strength training over the course of 32 weeks to determine any potential interactive effects of these two stimuli on the attainment of optimal peak bone mass in skeletally immature females. Targeting factors that affect bone response in this age group has vast implications in the primary prevention of osteoporosis in our aging population. While most research on the topic of hormonal contraception and exercise training present measures of BMD, this study incorporated not only the density of bone but also EI, a measure of long bone bending stiffness, measured by mechanical response tissue analysis (MRTA). Subjects were randomized into either concentric or eccentric isokinetic training groups for training of the nondominant limbs for the intervention period. This method of muscular strength training was undertaken to provide a unique stimulus to bone unlike that of conventional isotonic training presented in previous research on this topic, and to provide the researchers with a control limb for reference. Comparisons were made 
between OC use and non-use, trained and untrained limbs, concentric and eccentric training modes, and weight bearing and non-weight-bearing limbs. It is important to realize that BMD during old age is largely determined by factors operating during skeletal growth and that any treatment options that either maximize or hinder the deposition and structural integrity of bone, necessitate further research.

\section{Summary and Conclusions}

Subjects from the Trial in Bone Injury Abatement for Ladies (TiBIAL) were examined to determine if use of oral contraceptives modified the effects of isokinetic resistance training on BMD and EI. Although the original design of the TiBIAL study was not to directly assess the effects of OC use on bone health, results from this study were in agreement with previous research on this topic stating that use of OCs may limit the attainment of total body peak bone mass in young adult females. Ulnar BMD increased significantly from baseline regardless of training or OC status $(\mathrm{p}<0.01)$, as did total hip BMD in the trained leg regardless of OC status $(p<0.05)$. Changes in the ulna seem then, to be a factor of normal age related growth in this age

group, and remain unaffected by OC use, or isokinetic training. Remaining regions of interest did not change significantly from baseline and remained consistent between groups with the exception of significant increases in total body BMD, untrained tibial BMD, and trained ulnar EI in NOC subjects, and trained tibial EI in OC users. Although BMD changed significantly within each group, no between group comparisons reached significance at the $p<0.05$ level illustrating that site specific BMD was unaffected by use of OCs. Further, changes see in the tibia (a weightbearing bone) were not different from changes seen in the ulna (a non-weight-bearing bone), nor were there differences in BMD or EI that were significantly greater for the trained than the untrained limb. Significance found in values of ulnar and tibial EI from baseline, although 
inconsistent, warrant further studies that incorporate additional measures of bone strength and quality. Correlations between BMD and EI differences over time were weakly related and inconsistent in terms of direction, suggesting that the MRTA device requires improvements to various hardware and software components before it can be used as a reliable and valid assessment of bone quality. Issues of bone health in OC users are important to address so that we may formulate a set of recommendations for use, and guarantee that this form of contraception will not lead to serious skeletal consequences in later life.

\section{Practical and Clinical Implications}

The results of this study show that OC use by young adult females undergoing unilateral isokinetic resistance training may limit the attainment of total body peak bone mass. In the same population, use of OCs does not seem to have any consistent effects on various appendicular changes in BMD or EI. However, further studies need to be performed to draw any definitive conclusions. Lifestyle decisions made in adolescence, such as the decisions to strength train and use OCs, can have a major impact on the state of the skeleton in older age. By the time most women obtain enough knowledge about bone health to take control of matters, it is often too late. A better understanding of adolescent bone health that can be gained from well-designed future studies on this topic will help in the formation and implementation of guidelines for young females using OCs so that they may maintain skeletal growth up to the attainment of peak bone mass. The estimated 17 billion dollars spent annually on osteoporosis and related fractures could be drastically reduced with an enhanced understanding of the factors that help women reach their optimal peak bone mass. Further exploration of this topic, and investigation of new and better measures of bone integrity, will assist in understanding the mechanisms of osteoporotic fracture 
and will help to increase quality of life for the estimated 29.6 million women who presently suffer from osteoporosis and osteopenia. Unfortunately, there have been no studies to date that allow a definitive statement on the effect of low-dose OCs and exercise training on bone quality measures in young women. Such studies are urgently needed so that we are able to guarantee for young women that a popular form of contraception does not have to be paid for by a long-term risk for skeletal health.

\section{Recommendations for Future Research}

General Recommendations for future studies are listed below. Following these recommendations are three proposed research projects that may help to enhance the understanding of the potential skeletal effects of OC use and exercise.

1. Due to the small number of subjects in the current study, suppositions could be made regarding changes in $\mathrm{BMD}$ and $\mathrm{EI}_{\mathrm{MRTA}}$, but no definitive interactions between $\mathrm{OC}$ use and exercise training could be shown. A larger subject sample would allow for more powerful statistical analysis and greater certainty regarding potential interactive effects of these two interventions.

2. Because the current study was not originally designed to assess the interactive effects of OCs and isokinetic resistance training, there were no precautions taken to control for additional lifestyle factors such as dietary intake, family history of osteoporosis, alcohol and tobacco use, and so on. Thorough records of related lifestyle habits that could be controlled for in statistical analysis would help to avoid confounding.

3. Most OC studies have recruited subjects using differing OC prescriptions. Although this method helps in the application of generalizing the study results to all OC users, differing concentrations of estrogen and progesterone merely add another avenue for confounding. 
Conducting research where everyone uses one prescription for esteroid hormone contraception or a study comparing and contrasting multiple prescriptions, would help to avoid skepticism regarding results of the study and would allow results and conclusions to apply to specific brands and dosages of contraceptives.

4. Additional measures of bone metabolism and integrity should be incorporated into future studies. Using measures of BMD, bone metabolism (NTx, OPG), and a validated and reliable measure of bone geometry such as peripheral quantitative computed tomography (pQCT) would lend a more complete understanding of the mechanisms by which the skeleton is affected during this developmentally critical period of skeletal growth.

5. Incorporation of varying modes of exercise into contraceptive studies would enhance understanding of the differing forces and mechanisms of exercise that play a role in bone health. A shortcoming of the current study was the routine nature (consistent dose of 5 sets / 6 repetitions) of the isokinetic resistance training. If training demand had been increased throughout the duration of the training period, enhanced skeletal adaptation may have occurred. Isokinetic resistance training is also difficult to apply to the general population because of the expense and lack of availability of the equipment required. Weight-bearing cardiovascular exercise, concentric isokinetic strength training, eccentric isokinetic strength training, and untrained control groups would cover a wide range of physical activity patterns, and would give more insight into the potential applications of this research to the general population.

Proposed follow-up studies on these topics are briefly summarized below: 
STUDY 1: There is a shortage of prospective studies lasting greater than two years duration on the topic of OC-use, exercise, and measures of bone "strength." A research project involving college freshman on a university campus would be the easiest method of recruiting young adult females for a follow-up period of 36 months. Due to ethical restrictions, it would be difficult to randomize young female subjects into a contraceptive, or no contraceptive group. However, it may be possible to post subject recruitment flyers in freshman orientation packets, student gymnasiums, and gynecological and obstetrics offices to inform subjects of a study that would provide free contraception to women who are willing to be randomized into an OC or barrier contraception group. The oral contraceptive prescription will be the same for all subjects involved. The purpose of this study would be to assess the effects of OC use and a structured weight-bearing cardiovascular + weight training exercise program on young women over 36 months. Four groups: exercise/OC, exercise/no-OC, no-exercise/OC, and no-exercise/no-OC would be assessed. Bone measures will be assessed by DXA, and pQCT at 6 month intervals over a period of 36 months.

STUDY 2: Collegiate athletics remain an untapped resource for OC studies. It would be of great benefit to examine differential effects of women on the swim team (non-weight bearing sport), distance event athletes on the track team (weight bearing sport), basketball team (sport involving intermittent bursts of activity), and sedentary age-matched controls on bone health with or without the use of OCs. Measures of BMD and structural integrity are to be collected during the peak of the athletic season, and questionnaires to assess dietary intake, type and duration of OCuse, smoking and alcohol consumption will be administered. Information regarding the athletic training involved with each respective sport will be collected. 
STUDY 3: To date, no studies have contrasted the different hormonal concentrations of OC prescriptions available. A study comparing skeletal health in women using triphasic, monophasic, progestin only, and no oral contraceptives combined with varying levels of exercise training would be useful in investigating hormonal concentrations and regimens that may have differential effects on measures of bone "strength." This study may be conducted prospectively on a subset of women obtaining new OC prescriptions from a gynecologist. Bone measures will be assessed by DXA, and pQCT at 6 month intervals over a period of 36 months. Detailed physical activity questionnaires will be administered to classify subjects as "highly active," "moderately active," or inactive at all time points.

Information collected from long-term randomized prospective studies, studies using elite female athletes in a variety of sports, and females using monophasic, triphasic, progestin only, or no-OC prescriptions, will help offer further information regarding the interactive effects of OCuse and exercise training on measures of BMD and structural integrity in women. This area of research is still fairly new, and needs to be continually reevaluated as prescriptions for OCs, new measurement devices for assessment of BMD and bone quality, knowledge and modes of exercise training, and knowledge of bone physiology continue to change and adapt. 


\section{BIBLIOGRAPHY}

National Institutes of Health Consensus Statement, (2000). Osteoporosis Prevention, Diagnosis, and Therapy. NIH Consensus Statement. 17: 1-45.

Abma, J. C., A. Chandra, et al. (1997). "Fertility, family planning, and women's health: new data from the 1995 National Survey of Family Growth. National Center for Health Statistics." Vital Health Statistics 23(19).

Anonymous (1993). "Consensus development conference: diagnosis, prophylaxis and treatment of osteoporosis." Am J Med 94: 646-50.

Arnaud, S. B., C. R. Steele, et al. (1991). "A Direct Non-Invasive Measure of Long Bone Strength." Annual International Conference of the IEEE Engineering in Medicine and Biology Society 13(5): 1984-1985.

Berenson, A. B., C. M. Radecki, et al. (2001). "A prospective, controlled study of the effects of hormonal contraception on bone mineral density." Obstet Gynecol 98(4): 576-82.

Bikle, D. D., B. P. Halloran, et al. (1997). "Space flight and the skeleton: lessons for the earthbound." Endocrinologist 7(1): 10-22.

Burkman, R. (1995). "The role of oral contraceptives in the treatment of hyperandrogenic disorders." Am J Med 98(Supp1 1A): 130S-6S.

Burr, D. B., T. Yoshikawa, et al. (2000). "Exercise and oral contraceptive use suppress the normal age-related increase in bone mass and strength of the femoral neck in women 1831 years of age." Bone 27(6): 855-63.

Callaghan, C. E. (2003). Reliability of Tibial Measurement with Mechanical Response Tissue Analysis. Human Nutrition, Foods and Exercise. Blacksburg, Virginia Polytechnic Institute and State University: 123.

Cobb, K. L., J. L. Kelsey, et al. (2002). "Oral contraceptives and bone mineral density in white and black women in CARDIA. Coronary Risk Development in Young Adults." Osteoporos Int 13(11): 893-900.

Collins, K. S., C. Schoen, et al. (1999). "Health Concerns Across A Woman's Lifespan: The Commonwealth Fund 1998 Survey Of Women's Health."

Cooper, C., P. Hannaford, et al. (1993). "Oral contraceptive pill use and fractures in women: a prospective study." Bone 14(1): 41-5.

Cromer, B. A., J. M. Blair, et al. (1996). "A prospective comparison of bone density in adolescent girls receiving depot medroxyprogesterone acetate (Depo-Provera), levonorgestrel (Norplant), or oral contraceptives." J Pediatr 129(5): 671-6.

Cundy, T., J. Cornish, et al. (1998). "Spinal Bone Density in Women Using Depot Medroxyprogesterone Contraception." Obstet Gynecol 92: 569-573.

Cundy, T., C. M. Farquhar, et al. (1996). "Short-term effects of high dose oral medroxyprogesterone acetate on bone density in premenopausal women." J Clin Endocrinol Metab 81(3): 1014-7.

Cussler, E. C., T. G. Lohman, et al. (2003). "Weight Lifted in Strength Training Predicts Bone Change in Postmenopausal Women." Med Sci Sports Exerc 35(1): 10-17.

de Bruin, E. D., R. Herzog, et al. (2000). "Estimation of geometric properties of cortical bone in spinal cord injury." Arch Phys Med Rehabil 81(2): 150-6.

Drinkwater, B., K. Nilson, et al. (1984). "Bone mineral content of amenorrheic and eumenorrheic athletes." N Engl J Med 311: 277-281. 
Fait, T., A. Novakova, et al. (2001). "[Osteoporosis and hormonal contraception]." Ceska Gynekol 66(5): 309-13.

Farthing, J. and P. Chilibeck (2003). "The effect of eccentric training at different velocities on cross-education." Eur J Appl Physiol 89(6): 570-7.

Fortney, J. A., P. J. Feldblum, et al. (1994). "Bone mineral density and history of oral contraceptive use." J Reprod Med 39(2): 105-9.

Frisch, R. E., A. V. Gotz-Welbergen, et al. (1981). "Delayed menarche and amenorrhea of college athletes in relation to to age of onset of training." JAMA 246: 1559-1563.

Gambacciani, M., M. Ciaponi, et al. (2000). " Longitudinal Evaluation of Perimenopausal Femoral Bone Loss: Effects of a Low-Dose Oral Contraceptive Preparation on Bone Mineral Density and Metabolism." Osteopor Int 11: 544-548.

Genant, H., C. Cooper, et al. (1999). "Interim report and recommendations of the World Health Organization Task Force for Osteoporosis." Osteoporos Int 10: 259-64.

Golden, N., L. Lanzkowsky, et al. (2002). "The Effect of Estrogen-Progestin Treatment on Bone Mineral Density in Anorexia Nervosa." J Pediatr Adolesc Gynecol 15: 135-143.

Greenspan, F. S. and D. G. Gardner (2001). Basic and Clinical Endocrinology. New York, NY, Lange Medical Books/McGraw-Hill.

Hartard, M., P. Bottermann, et al. (1997). "Effects on bone mineral density of low-dosed oral contraceptives compared to and combined with physical activity." Contraception 55(2): 87-90.

Hawker, G. A., S. Forsmo, et al. (2002). "Correlates of Forearm Bone Mineral Density in Young Norwegian Women, The Nord-Trondelag Health Study." Am J Epidemiol 156: 418-427.

Hawkins, S. A., E. T. Schroeder, et al. (1999). "Eccentric muscle action increases site-specific osteogenic response." Med Sci Sports Exerc 31(9): 1287-92.

Hergenroeder, A. C., E. O. Smith, et al. (1997). "Bone mineral changes in young women with hypothalamic amenorrhea treated with oral contraceptives, medroxyprogesterone, or placebo over 12 months." Am J Obstet Gynecol 176(5): 1017-25.

Hiliard-Robertson, P., S. Schneider, et al. (2003). "Strength gains following different combined concentric and eccentric exercise regimens." Aviat Space Environ Med 74(4): 342-7.

Hortobagyi, T., P. Devita, et al. (2001). "Effects of standard and eccentric overload strength training in young women." Med Sci Sports Exerc 33(7): 1206-12.

Housh, D. and T. Housh (1993). "The effects of unilateral velocity-specific concentric strength training." J Orthop Sports Phys Ther 17(5): 252-6.

Housh, T., D. Housh, et al. (1996). "Effects of eccentric-only resistance training and detraining." Int J Sports Med 17(2): 145-8.

Housh, T., D. Housh, et al. (1996). "Effects of unilateral concentric-only dynamic constant external resistance training." Int J Sports Med 17(5): 338-43.

Jones, H. H., J. D. Priest, et al. (1977). "Humeral hypertrophy in response to exercise." J Bone Joint Surg 59-A: 204-208.

Kannus, P., H. Haapasalo, et al. (1995). "Effect of starting age of physical activity on bone mass in the dominant arm of tennis and squash players." Ann Intern Med 123: 27-31.

Karck, U. and M. Breckwoldt (2001). "[Low-dose oral contraception and bone density]." Ther Umsch 58(9): 547-51.

Kaunitz, A. M. (2001). "Oral contraceptive use in perimenopause." Am J Obstet Gynecol 185(2 Suppl): S32-7. 
Kaunitz, A. M. (2002). "Noncontraceptive Health Benefits of Oral Contraceptives." Reviews in Endocrine and Metabolic Disorders 3: 277-283.

Kontulainen, S., H. Sievanen, et al. (2003). "Effect of Long-Term Impact-Loading on Mass, Size, and Estimated Strength of Humerus and Radius of Female Racquet-Sports Players:

A Peripheral Quantitative Computed Tomography Study Between Young and Old Starters and Controls." Journal of Bone and Mineral Research 18(2): 352-359.

Kritz-Silverstein, D. and E. Barrett-Connor (1993). "Bone mineral density in postmenopausal women as determined by prior oral contraceptive use." Am J Public Health 83(1): 100-2.

Kuohung, W., L. Borgatta, et al. (2000). "Low-dose oral contraceptives and bone mineral density: an evidence- based analysis." Contraception 61(2): 77-82.

Lloyd, T., D. S. Taylor, et al. (2000). "Oral contraceptive use by teenage women does not affect peak bone mass: a longitudinal study." Fertil Steril 74(4): 734-8.

MacDougall, J., M. C. Davies, et al. (1999). "Bone density in a population of long term oral contraceptive pill users does not differ from that in menstruating women." Br J Fam Plann 25(3): 96-100.

Marcus, R. (2002). Mechanisms of Exercise Effects on Bone. Principles of Bone Biology, Academic Press. 2: 1477-1488.

Mazess, R. B. (1983). "The noninvasive measurement of skeletal mass." In: Bone and Mineral Research Annual 1, W.A. Peck (Ed.). Amsterdam: Excerpta Medica: 223-279.

McCabe, F., L. J. Zhou, et al. (1991). "Noninvasive assessment of ulnar bending stiffness in women." J Bone Miner Res 6(1): 53-9.

McCabe Frances, Z. L.-J., Steele Charles R, Marcus Robert (1991). "Noninvasive Assessment of Ulnar Bending Stiffness in Women." Journal of Bone and Mineral Research 6(1): 53-59.

Miller, L. E. (2003). Reliability and Validity of

Mechanical Response Tissue Analysis in

Composite and Human Tibia. Human Nutrition, Foods and Exercise. Blacksburg, Virginia Polytechnic Institute and State University: 164.

Myburgh Kathryn H, C. S., Zhou Linjun, Steele Charles R, Arnaud Sara, Marcus Robert (1993). "Influence of Recreational Activity and Muscle Strength on Ulnar Bending Stiffness in Men." Medicine and Science in Sports and Exercise 25(5): 592-596.

Myburgh Kathryn, Z. L.-J., Steele Charles R, Arnaud Sara, Marcus Robert (1992). "In Vivo Assessment of Forearm Bone Mass and Ulnar Bending Stiffness in Healthy Men." Journal of Bone and Mineral Research 7(11): 1345-1350.

Myburgh, K. H., S. Charette, et al. (1993). "Influence of recreational activity and muscle strength on ulnar bending stiffness in men." Med Sci Sports Exerc 25(5): 592-6.

Myburgh, K. H., L. J. Zhou, et al. (1992). "In vivo assessment of forearm bone mass and ulnar bending stiffness in healthy men." J Bone Miner Res 7(11): 1345-50.

Nand, S. L., B. G. Wren, et al. (1999). "Bone density effects of continuous estrone sulfate and varying doses of medroxyprogesterone acetate. Ogen/Provera Study Group." Obstet Gynecol 93(6): 1009-1013.

Nelson, H. D., J. Rizzo, et al. (2002). "Osteoporosis and Fractures in Postmenopausal Women Using Estrogen." Archives of Internal Medicine 162: 2278-2284.

NOF (2000). America's Bone Health: The State of Osteoporosis and Low Bone Mass in Our Nation. National Osteoporosis Foundation.

Ott, S. M., D. Scholes, et al. (2001). "Effects of contraceptive use on bone biochemical markers in young women." J Clin Endocrinol Metab 86(1): 179-85. 
Perrotti, M., L. Bahamondes, et al. (2001). "Forearm bone density in long-term users of oral combined contraceptives and depot medroxyprogesterone acetate." Fertil Steril 76(3): 469-73.

Petitti, D. B., G. Piaggio, et al. (2000). "Steroid hormone contraception and bone mineral density: a cross- sectional study in an international population. The WHO Study of Hormonal Contraception and Bone Health." Obstet Gynecol 95(5): 736-44.

Polatti, F., F. Perotti, et al. (1995). "Bone mass and long-term monophasic oral contraceptive treatment in young women." Contraception 51(4): 221-4.

Prior, J. C., S. A. Kirkland, et al. (2001). "Oral contraceptive use and bone mineral density in premenopausal women: cross-sectional, population-based data from the Canadian Multicentre Osteoporosis Study." Cmaj 165(8): 1023-9.

Prior, J. C., Y. M. Vigna, et al. (1997). "Premenopausal ovariectomy-related bone loss: a randomized, double- blind, one-year trial of conjugated estrogen or medroxyprogesterone acetate." J Bone Miner Res 12(11): 1851-63.

Proctor, K. L., W. C. Adams, et al. (2002). "Upper-limb bone mineral density of female collegiate gymnasts versus controls." Med Sci Sports Exerc 34(11): 1830-1835.

Recker, R. R., K. M. Davies, et al. (1992). "Bone gain in young adult women." Jama 268(17): 2403-8.

Reed, S. D., D. Scholes, et al. (2003). "Longitudinal changes in bone density in relation to oral contraceptive use." Contraception 68(3): 177-82.

Register, T. C., M. J. Jayo, et al. (1997). "Oral contraceptive treatment inhibits the normal acquisition of bone mineral in skeletally immature young adult female monkeys." Osteoporos Int 7(4): 348-53.

Rickard, D., S. Harris, et al. (2002). Estrogens and Progestins. Principles of Bone Biology. G. Rodan. San Diego, CA, Academic Press. 1: 655-675.

Riggs, B., S. Hodgson, et al. (1990). "Effect of flouride treatment on the fracture rate of postmenopausal women with osteoporosis." N Engl J Med(322): 802-809.

Roberts S. G., H. T. M., Arnaud S. B., Kiratli B. J., Martin R. B., Steele C. R. (1995). "Noninvasive Determination of Bone Mechanical Properties Using Vibration Response: A Refined Model and Validation In Vivo." Journal of Biomechanics 29(1): 91-98.

Roberts, S. G., T. M. Hutchinson, et al. (1996). "Noninvasive determination of bone mechanical properties using vibration response: a refined model and validation in vivo." J Biomech 29(1): 91-8.

Scerpella, T. A., M. Davenport, et al. (2003). "Dose Related Association of Impact Activity and Bone Mineral Density in Pre-pubertal Girls." Calcif Tissue Int 72: 24-31.

Steele, C. R., L. J. Zhou, et al. (1988). "Noninvasive determination of ulnar stiffness from mechanical response-- in vivo comparison of stiffness and bone mineral content in humans." J Biomech Eng 110(2): 87-96.

Steele CR, Z. L.-J., Guido D, Marcus R, Heinrichs, Cheema C (1988). "Noninvasive determination of ulnar stiffness from mechanical response--in vivo comparison of stiffness and bone mineral content in humans." Journal of biomechanical engineering 110(3): 87-96.

Taechakraichana, N., K. Limpaphayom, et al. (2000). "A randomized trial of oral contraceptive and hormone replacement therapy on bone mineral density and coronary heart disease risk factors in postmenopausal women." Obstet Gynecol 95(1): 87-94. 
Tharnprisarn, W. and S. Taneepanichskul (2002). "Bone mineral density in adolescent and young Thai girls receiving oral contraceptives compared with depot medroxyprogesterone acetate: a cross- sectional study in young Thai women." Contraception 66(2): 101-3.

Turner, C. H. and A. G. Robling (2003). "Designing Exercise Regimens to Increase Bone Strength." Exercise and Sport Sciences Reviews 31(1): 45-50.

Turner, R. T. (2000). "Invited review: what do we know about the effects of spaceflight on bone?" J Appl Physiol 89(2): 840-7.

Vessey, M., J. Mant, et al. (1998). "Oral contraception and other factors in relation to hospital referral for fracture. Findings in a large cohort study." Contraception 57(4): 231-5.

Wanichsetakul, P., A. Kamudhamas, et al. (2002). "Bone mineral density at various anatomic bone sites in women receiving combined oral contraceptives and depotmedroxyprogesterone acetate for contraception." Contraception 65(6): 407-10.

Wasnich, R. D., P. D. Ross, et al. (1985). "Prediction of postmenopausal fracture risk with use of bone mineral measurements." Am J Obstet Gynecol 153: 745-751.

Weaver, C. M., D. Teegarden, et al. (2001). "Impact of exercise on bone health and contraindication of oral contraceptive use in young women." Med Sci Sports Exerc 33(6): 873-80.

Weir, J., D. Housh, et al. (1997). "The effect of unilateral concentric weight training and detraining on joint angle specificity, cross-training, and the bilateral deficit." J Orthop Sports Phys Ther 25(4): 264-70.

Zerath, E., M. Grynpas, et al. (2002). "Spaceflight affects bone formation in rhesus monkeys: a histological and cell culture study." J Appl Physiol 93(3): 1047-56. 
APPENDICES 
RAW DATA 


\begin{tabular}{|c|c|c|c|c|c|c|c|c|}
\hline $\begin{array}{c}\text { subject } \\
\text { number }\end{array}$ & $\begin{array}{c}\text { OC user } \\
\text { status }\end{array}$ & $\begin{array}{c}\text { Duration of } \\
\text { OC use at } \\
\text { baseline } \\
\text { (months) }\end{array}$ & $\begin{array}{c}\text { Duration of } \\
\text { OC use at } \\
32 \text { weeks } \\
\text { (months) }\end{array}$ & $\begin{array}{c}\text { Mode of isokinetic } \\
\text { training }\end{array}$ & $\begin{array}{c}\text { Age } \\
\text { (years) at } \\
\text { baseline }\end{array}$ & $\begin{array}{c}\text { Height } \\
\text { (cm) at } \\
\text { baseline }\end{array}$ & $\begin{array}{c}\text { Weight } \\
\text { (kg) at } \\
\text { baseline }\end{array}$ & $\begin{array}{c}\text { Weight } \\
(\mathrm{kg}) \text { at 32 } \\
\text { weeks }\end{array}$ \\
\hline 2 & YES & 18 & 26 & Concentric & 24 & 170.2 & 63.3 & 64.2 \\
\hline 3 & YES & 4 & 12 & Concentric & 20 & 153 & 50.2 & 51.5 \\
\hline 36 & YES & 24 & 32 & Concentric & 19 & 160 & 68.1 & 72.8 \\
\hline 42 & YES & 18 & 27 & Concentric & 20 & 164.5 & 63.1 & 65 \\
\hline 52 & YES & 24 & 32 & Concentric & 20 & 168.3 & 70.7 & 67.2 \\
\hline 81 & YES & 9 & 18 & Concentric & 19 & 158.1 & 47.4 & 50.5 \\
\hline 83 & YES & 6 & 14 & Concentric & 19 & 163.2 & 57.4 & 59.7 \\
\hline 91 & YES & 7 & 15 & Concentric & 19 & 159.4 & 60.6 & no data \\
\hline 324 & YES & 48 & 57 & Concentric & 20 & 169.6 & 71.2 & 71 \\
\hline 347 & YES & 12 & 19 & Concentric & 20 & 172.1 & 59.6 & 60 \\
\hline 363 & YES & 13 & 18 & Concentric & 20 & 160 & 53.5 & 56.4 \\
\hline 365 & YES & 30 & 37 & Concentric & 20 & 172.1 & 71.7 & 74.5 \\
\hline 5 & YES & 24 & 33 & Eccentric & 20 & 168.3 & 85.4 & 90.6 \\
\hline 14 & YES & 18 & 27 & Eccentric & 18 & 163.2 & 54.6 & 52.9 \\
\hline 25 & YES & 36 & 44 & Eccentric & 21 & 173.4 & 68.3 & 69 \\
\hline 27 & YES & 36 & 52 & Eccentric & 21 & 165.1 & 54.5 & 60 \\
\hline 38 & YES & 20 & 23 & Eccentric & 19 & 166.4 & 54 & 52.2 \\
\hline 49 & YES & 8 & 15 & Eccentric & 20 & 162.6 & 54.7 & 55 \\
\hline 62 & YES & 12 & 21 & Eccentric & 19 & 165.1 & 54.2 & 57.2 \\
\hline 323 & YES & 48 & 55 & Eccentric & 21 & 152.4 & 47.8 & 49.2 \\
\hline 326 & YES & 36 & 42 & Eccentric & 21 & 177.8 & 63 & 65.3 \\
\hline 341 & YES & 18 & 25 & Eccentric & 21 & 161.3 & 46.7 & 57.5 \\
\hline mean & NA & 21.3 & 29.3 & 12 CON/10 ECC & 20.0 & 164.8 & 60.0 & 62.0 \\
\hline
\end{tabular}

\begin{tabular}{|c|c|c|c|c|c|c|c|c|}
\hline $\begin{array}{c}\text { subject } \\
\text { number }\end{array}$ & $\begin{array}{c}\text { OC user } \\
\text { status }\end{array}$ & $\begin{array}{c}\text { Duration of } \\
\text { OC use at } \\
\text { baseline } \\
\text { (months) }\end{array}$ & $\begin{array}{c}\text { Duration of } \\
\text { OC use at } \\
32 \text { weeks } \\
\text { (months) }\end{array}$ & $\begin{array}{c}\text { Mode of isokinetic } \\
\text { training }\end{array}$ & $\begin{array}{c}\text { Age } \\
\text { (years) at } \\
\text { baseline }\end{array}$ & $\begin{array}{c}\text { Height } \\
\text { (cm) at } \\
\text { baseline }\end{array}$ & $\begin{array}{c}\text { Weight } \\
\text { (kg) at } \\
\text { baseline }\end{array}$ & $\begin{array}{c}\text { Weight } \\
\text { (kg) at 32 } \\
\text { weeks }\end{array}$ \\
\hline 1 & NO & 0 & 0 & Concentric & 21 & 167 & 59.3 & 59.7 \\
\hline 13 & NO & 0 & 0 & Concentric & 19 & 160.7 & 49.6 & 53.6 \\
\hline 16 & NO & 0 & 0 & Concentric & 19 & 161.8 & 54.7 & 55.9 \\
\hline 32 & NO & 0 & 0 & Concentric & 19 & 160.7 & 47.2 & 48.1 \\
\hline 33 & NO & 0 & 0 & Concentric & 19 & 165.7 & 50.9 & 50 \\
\hline 50 & NO & 0 & 0 & Concentric & 20 & 163.8 & 54.6 & 55.3 \\
\hline 64 & NO & 0 & 0 & Concentric & 18 & 160.3 & 52.5 & 56 \\
\hline 87 & NO & 0 & 0 & Concentric & 20 & 156.2 & 50.7 & 51 \\
\hline 94 & NO & 0 & 0 & Concentric & 20 & 165.7 & 81.2 & no data \\
\hline 330 & NO & 0 & 0 & Concentric & 20 & 154.9 & 55.7 & 54.7 \\
\hline 335 & NO & 0 & 0 & Concentric & 19 & 156.8 & 67.4 & 68 \\
\hline 352 & NO & 0 & 0 & Concentric & 22 & 172.1 & 63.8 & 65.6 \\
\hline 354 & NO & 0 & 0 & Concentric & 25 & 159.4 & 51.6 & 51.6 \\
\hline 359 & NO & 0 & 0 & Concentric & 19 & 173.4 & 63.3 & 65.6 \\
\hline 11 & NO & 0 & 0 & Eccentric & 19 & 172.1 & 61.5 & 62.7 \\
\hline 15 & NO & 0 & 0 & Eccentric & 20 & 165.7 & 56.4 & 59 \\
\hline 39 & NO & 0 & 0 & Eccentric & 20 & 158.1 & 55.4 & 55.6 \\
\hline 41 & NO & 0 & 0 & Eccentric & 23 & 162.6 & 59 & 62.2 \\
\hline 63 & NO & 0 & 0 & Eccentric & 20 & 158.8 & 52.4 & 53.3 \\
\hline 66 & NO & 0 & 0 & Eccentric & 19 & 168.9 & 54.4 & 59.6 \\
\hline 72 & NO & 0 & 0 & Eccentric & 19 & 148.6 & 64.8 & 65.4 \\
\hline 79 & NO & 0 & 0 & Eccentric & 20 & 165.7 & 54.5 & 54.2 \\
\hline 314 & NO & 0 & 0 & Eccentric & 19 & 165.1 & 60.5 & 63.5 \\
\hline 332 & NO & 0 & 0 & Eccentric & 20 & 165.7 & 68.5 & 68 \\
\hline mean & NA & 0 & 0 & 14 CON/ 10 ECC & 20.0 & 162.9 & 57.9 & 58.2 \\
\hline
\end{tabular}




\begin{tabular}{|c|c|c|c|c|c|c|}
\hline \multirow{2}{*}{$\begin{array}{c}(\mathrm{OC}) \\
\text { subject } \\
\text { number }\end{array}$} & \multicolumn{2}{|c|}{$\underline{\text { Ulnar El at baseline }}$} & \multicolumn{2}{|c|}{$\underline{\text { Ulnar El at } 32 \text { weeks }}$} & \multicolumn{2}{|c|}{$\begin{array}{c}\text { Ulnar El } \\
\text { (32 weeks - baseline) }\end{array}$} \\
\hline & Untrained limb & Trained limb & Untrained limb & Trained limb & Untrained limb & Trained limb \\
\hline 2 & 23.6 & 12.5 & 20.9 & 22.3 & -2.7 & 9.8 \\
\hline 3 & 8.7 & 0 & 6.6 & 10.1 & -2.1 & 10.1 \\
\hline 36 & 0 & 14.1 & 21.1 & 16.5 & 21.1 & 2.4 \\
\hline 42 & 10.9 & 15.9 & 14.6 & 13.4 & 3.7 & -2.5 \\
\hline 52 & 9.8 & 30.1 & 13.7 & 24.2 & 3.9 & -5.9 \\
\hline 81 & 2.7 & 7.3 & 12.7 & 17.7 & 10 & 10.4 \\
\hline 83 & 27.1 & 16.6 & 18.2 & 29.6 & -8.9 & 13 \\
\hline 91 & no data & no data & no data & no data & no data & no data \\
\hline 324 & 56.3 & 31.9 & 0 & 38.6 & -56.3 & 6.7 \\
\hline 347 & 58.5 & 47.6 & no data & 19.7 & no data & -27.9 \\
\hline 363 & 14.8 & 14.2 & no data & no data & no data & no data \\
\hline 365 & 18.5 & no data & 35.1 & 26.5 & 16.6 & no data \\
\hline 5 & 18.8 & 0 & 22.6 & 32.2 & 3.8 & 32.2 \\
\hline 14 & 17.7 & 18.2 & 18.3 & 12.4 & 0.6 & -5.8 \\
\hline 25 & 21.9 & 20 & 21.1 & 24 & -0.8 & 4 \\
\hline 27 & 0 & 0 & no data & no data & no data & no data \\
\hline 38 & 0 & 0 & 22.5 & 18.8 & 22.5 & 18.8 \\
\hline 49 & 26.2 & 25.1 & 26.3 & 19.9 & 0.1 & -5.2 \\
\hline 62 & 27.8 & 30.8 & 44.7 & 39.5 & 16.9 & 8.7 \\
\hline 323 & 0 & no data & 0 & 14.4 & 0 & no data \\
\hline 326 & 29.1 & 35.3 & 39.8 & 33.9 & 10.7 & -1.4 \\
\hline 341 & 24.6 & 14.7 & 35 & 21 & 10.4 & 6.3 \\
\hline mean & 18.9 & 17.6 & 20.7 & 22.9 & 2.8 & 4.3 \\
\hline
\end{tabular}

\begin{tabular}{|c|c|c|c|c|c|c|}
\hline \multirow{2}{*}{$\begin{array}{l}\text { (NOC) } \\
\text { subject } \\
\text { number }\end{array}$} & \multicolumn{2}{|c|}{ UInar EI at baseline } & \multicolumn{2}{|c|}{ Ulnar El at 32 weeks } & \multicolumn{2}{|c|}{$\begin{array}{c}\text { Ulnar El } \\
\text { (32 weeks - baseline) }\end{array}$} \\
\hline & Untrained limb & Trained limb & Untrained limb & Trained limb & Untrained limb & Trained limb \\
\hline 1 & 24.1 & 25.1 & 25.9 & 34.3 & 1.8 & 9.2 \\
\hline 13 & 21.5 & 10 & 23.8 & 24.8 & 2.3 & 14.8 \\
\hline 16 & 27 & 52.8 & 35.2 & 42.1 & 8.2 & -10.7 \\
\hline 32 & 12.8 & 0 & 13.5 & 16.8 & 0.7 & 16.8 \\
\hline 33 & 40.4 & 14 & 22.8 & 14.5 & -17.6 & 0.5 \\
\hline 50 & 32.7 & 0 & 25 & 21.4 & -7.7 & 21.4 \\
\hline 64 & 25.4 & 23.5 & 28 & 16 & 2.6 & -7.5 \\
\hline 87 & 24.2 & 44.5 & 26.3 & 26.5 & 2.1 & -18 \\
\hline 94 & 22.5 & 14.2 & 10 & 39.7 & -12.5 & 25.5 \\
\hline 330 & 0 & 11.6 & 21.1 & 12.1 & 21.1 & 0.5 \\
\hline 335 & 10.7 & 21.7 & 18.8 & 14.2 & 8.1 & -7.5 \\
\hline 352 & 18.3 & 17.2 & 26.4 & 34.1 & 8.1 & 16.9 \\
\hline 354 & 21.7 & 26.3 & 23.1 & 34.5 & 1.4 & 8.2 \\
\hline 359 & 17.6 & 24.6 & 58.1 & 19.5 & 40.5 & -5.1 \\
\hline 11 & 16.9 & 10.1 & 17.6 & 18 & 0.7 & 7.9 \\
\hline 15 & 0 & 12.8 & 22.3 & 15.6 & 22.3 & 2.8 \\
\hline 39 & 18.5 & 3.3 & 16 & 25.6 & -2.5 & 22.3 \\
\hline 41 & 0 & 5.3 & 14.8 & 8 & 14.8 & 2.7 \\
\hline 63 & 19.9 & 22.5 & 12.8 & 13 & -7.1 & -9.5 \\
\hline 66 & 0 & 0 & 0 & 18.6 & 0 & 18.6 \\
\hline 72 & 18.7 & 17.6 & 21.1 & 21 & 2.4 & 3.4 \\
\hline 79 & 15.9 & 0 & 17.7 & no data & 1.8 & no data \\
\hline 314 & 0 & 13.5 & 11.6 & 19 & 11.6 & 5.5 \\
\hline 332 & no data & no data & no data & no data & no data & no data \\
\hline mean & 16.9 & 16.1 & 21.4 & 22.2 & 4.5 & 5.4 \\
\hline
\end{tabular}




\begin{tabular}{|c|c|c|c|c|c|c|}
\hline \multirow{2}{*}{$\begin{array}{c}(\mathrm{OC}) \\
\text { subject } \\
\text { number }\end{array}$} & \multicolumn{2}{|c|}{ Tibial El at baseline } & \multicolumn{2}{|c|}{ Tibial El at 32 weeks } & \multicolumn{2}{|c|}{$\begin{array}{c}\text { Tibial El } \\
\text { (32 weeks - baseline) }\end{array}$} \\
\hline & Untrained limb & Trained limb & Untrained limb & Trained limb & Untrained limb & Trained limb \\
\hline 2 & 109 & 142 & 105 & 124 & -4 & -18 \\
\hline 3 & 77.3 & 85.6 & 74.9 & 79.6 & -2.4 & -6 \\
\hline 36 & 77.1 & 99 & no data & 77.5 & no data & -21.5 \\
\hline 42 & 70.8 & 41.4 & 47 & 98 & -23.8 & 56.6 \\
\hline 52 & 133 & 178 & 161 & 190 & 28 & 12 \\
\hline 81 & 0 & 86.5 & 118 & 162 & 118 & 75.5 \\
\hline 83 & 180 & 37.7 & 137 & 138 & -43 & 100.3 \\
\hline 91 & no data & no data & no data & no data & no data & no data \\
\hline 324 & 163 & 158 & 235 & 283 & 72 & 125 \\
\hline 347 & 127 & 101 & 145 & 151 & 18 & 50 \\
\hline 363 & 153 & 75 & no data & no data & no data & no data \\
\hline 365 & 153 & 148 & 148 & 328 & -5 & 180 \\
\hline 5 & 113 & 116 & 77.5 & 63.9 & -35.5 & -52.1 \\
\hline 14 & 90.7 & 113 & no data & 106 & no data & -7 \\
\hline 25 & 107 & 218 & 170 & 221 & 63 & 3 \\
\hline 27 & 146 & 129 & no data & no data & no data & no data \\
\hline 38 & 47.6 & 24.7 & 128 & 0 & 80.4 & -24.7 \\
\hline 49 & 97.7 & 50 & 154 & 94.4 & 56.3 & 44.4 \\
\hline 62 & no data & no data & no data & no data & no data & no data \\
\hline 323 & 91.3 & 63.9 & 73.4 & 59.9 & -17.9 & -4 \\
\hline 326 & 142 & 146 & 133.9 & 238.6 & -8.1 & 92.6 \\
\hline 341 & 118 & 119 & 102 & 86.2 & -16 & -32.8 \\
\hline mean & 109.8 & 106.6 & 125.6 & 139.0 & 17.5 & 31.9 \\
\hline \multirow{2}{*}{$\begin{array}{l}\text { (NOC) } \\
\text { subject } \\
\text { number }\end{array}$} & \multicolumn{2}{|c|}{$\underline{\text { Tibial El at baseline }}$} & \multicolumn{2}{|c|}{ Tibial El at 32 weeks } & \multicolumn{2}{|c|}{$\begin{array}{c}\text { Tibial El } \\
\text { (32 weeks - baseline) }\end{array}$} \\
\hline & Untrained limb & Trained limb & Untrained limb & Trained limb & Untrained limb & Trained limb \\
\hline 1 & 216 & 82.4 & 218 & 168 & 2 & 85.6 \\
\hline 13 & 70.3 & 124 & 116 & 105 & 45.7 & -19 \\
\hline 16 & 75.4 & 84.4 & 138.8 & 82.1 & 63.4 & -2.3 \\
\hline 32 & 91.9 & 53.5 & 86.3 & 158 & -5.6 & 104.5 \\
\hline 33 & 151 & 104 & 149 & 70.8 & -2 & -33.2 \\
\hline 50 & 120 & 167 & 140 & 121 & 20 & -46 \\
\hline 64 & 173 & 92.7 & 160.6 & 144.7 & -12.4 & 52 \\
\hline 87 & 75 & 152 & 130.5 & 59 & 55.5 & -93 \\
\hline 94 & 187 & $\overline{75.9}$ & 136.6 & 88 & -50.4 & 12.1 \\
\hline 330 & 81.1 & $\begin{array}{l}79.4 \\
\end{array}$ & 104 & 83.8 & 22.9 & 4.4 \\
\hline 335 & 156 & 44.7 & 78.8 & 62.7 & $\begin{array}{l}-77.2 \\
\end{array}$ & 18 \\
\hline 352 & 141 & 271 & 172 & 128 & 31 & $\begin{array}{l}-143 \\
\end{array}$ \\
\hline 354 & 99.4 & 122 & 137 & 131 & 37.6 & 9 \\
\hline 359 & 130 & 168 & 176 & 204 & 46 & 36 \\
\hline 11 & no data & no data & no data & no data & no data & no data \\
\hline 15 & 0 & 0 & 220.8 & 182 & 220.8 & 182 \\
\hline 39 & 164 & 206 & 92.3 & 82.6 & -71.7 & -123.4 \\
\hline 41 & 88.6 & 215 & 281 & 67.2 & 192.4 & -147.8 \\
\hline 63 & 139 & 137 & 74.9 & 183 & -64.1 & 46 \\
\hline 66 & 0 & 0 & 130 & 129 & 130 & 129 \\
\hline 72 & 132 & 189 & 170 & 184 & 38 & $2-5$ \\
\hline 79 & 22.7 & 60.5 & 120 & 83.7 & 97.3 & 23.2 \\
\hline 314 & 101 & 33.7 & 88.7 & 121 & -12.3 & 87.3 \\
\hline 332 & no data & no data & no data & no data & no data & no data \\
\hline mean & 109.7 & 111.9 & 141.9 & 119.9 & 32.1 & 8.0 \\
\hline
\end{tabular}




\begin{tabular}{|c|c|c|c|c|}
\hline $\begin{array}{c}\text { (OC) } \\
\text { subject } \\
\text { number }\end{array}$ & $\begin{array}{c}\% \text { body fat at } \\
\text { baseline }\end{array}$ & $\begin{array}{c}\text { TBBMD at } \\
\text { baseline }\end{array}$ & $\begin{array}{c}\text { TBBMD at } \\
\text { baseline }\end{array}$ & $\begin{array}{c}\text { Total body BMD } \\
\text { (32 weeks - baseline) }\end{array}$ \\
\hline 2 & 29 & 1.05 & 1.024 & -0.026 \\
\hline 3 & 31.2 & 1.047 & 1.044 & -0.003 \\
\hline 36 & 35.9 & 1.074 & 1.055 & -0.019 \\
\hline 42 & 34.1 & 1.109 & 1.092 & -0.017 \\
\hline 52 & 35.6 & 1.022 & 1.054 & 0.032 \\
\hline 81 & 26.1 & 0.99 & 0.987 & -0.003 \\
\hline 83 & 22.5 & 1.185 & 1.186 & 0.001 \\
\hline 91 & 30.3 & 1.194 & 1.183 & -0.011 \\
\hline 324 & 33.7 & 1.162 & 1.164 & 0.002 \\
\hline 347 & 27.8 & 1.038 & 1.037 & -0.001 \\
\hline 363 & 26.7 & 1.034 & 1.045 & 0.011 \\
\hline 365 & 29.7 & 1.235 & 1.245 & 0.01 \\
\hline 5 & 36.1 & 1.094 & 1.103 & 0.009 \\
\hline 14 & 24.5 & 1.214 & 1.225 & 0.011 \\
\hline 25 & 35.9 & 1.072 & 1.064 & -0.008 \\
\hline 27 & 26.3 & 1.157 & 1.149 & -0.008 \\
\hline 38 & 30.4 & 0.938 & 0.945 & 0.007 \\
\hline 49 & 23.4 & 1.104 & 1.115 & 0.011 \\
\hline 62 & 26.5 & 1.107 & 1.102 & -0.005 \\
\hline 323 & 22.6 & 1.159 & 1.124 & -0.035 \\
\hline 326 & 20.7 & 1.313 & 1.322 & 0.009 \\
\hline 341 & 33.2 & 1.092 & 1.098 & 0.006 \\
\hline mean & 29.19 & 1.11 & 1.11 & 0.00 \\
\hline
\end{tabular}

\begin{tabular}{|c|c|c|c|c|}
\hline $\begin{array}{l}\text { (NOC) } \\
\text { subject } \\
\text { number }\end{array}$ & $\begin{array}{c}\% \text { body fat at } \\
\text { baseline }\end{array}$ & $\begin{array}{c}\text { TBBMD at } \\
\text { baseline }\end{array}$ & $\begin{array}{c}\text { TBBMD at } \\
\text { baseline }\end{array}$ & $\begin{array}{c}\text { Total body BMD } \\
\text { (32 weeks - baseline) }\end{array}$ \\
\hline 1 & 27 & 1.173 & 1.181 & 0.008 \\
\hline 13 & 23.7 & 1.038 & 1.051 & 0.013 \\
\hline 16 & 24.5 & 1.09 & 1.099 & 0.009 \\
\hline 32 & 26.1 & 1.068 & 1.08 & 0.012 \\
\hline 33 & 24.5 & 1.072 & 1.068 & -0.004 \\
\hline 50 & 25.7 & 1.128 & 1.129 & 0.001 \\
\hline 64 & 22.6 & 1.146 & 1.138 & -0.008 \\
\hline 87 & 27 & 1.08 & 1.097 & 0.017 \\
\hline 94 & 35.4 & 1.172 & 1.174 & 0.002 \\
\hline 330 & 32.5 & 1.055 & 1.07 & 0.015 \\
\hline 335 & 35.5 & 1.142 & 1.151 & 0.009 \\
\hline 352 & 24.3 & 1.226 & 1.231 & 0.005 \\
\hline 354 & 23.3 & 1.108 & 1.133 & 0.025 \\
\hline 359 & 20.8 & 1.257 & 1.255 & -0.002 \\
\hline 11 & 21.7 & 1.261 & 1.267 & 0.006 \\
\hline 15 & 25.5 & 1.076 & 1.069 & -0.007 \\
\hline 39 & 28.2 & 1.125 & 1.104 & -0.021 \\
\hline 41 & 27.1 & 1.096 & 1.11 & 0.014 \\
\hline 63 & 25.3 & 1.039 & 1.043 & 0.004 \\
\hline 66 & 28.1 & 1.062 & 1.059 & -0.003 \\
\hline 72 & 23 & 1.158 & 1.169 & 0.011 \\
\hline 79 & 21.9 & 1.017 & 1.018 & 0.001 \\
\hline 314 & 33.6 & 0.999 & 1.003 & 0.004 \\
\hline 332 & 35.3 & 1.159 & 1.166 & 0.007 \\
\hline mean & 26.78 & 1.11 & 1.12 & 0.00 \\
\hline
\end{tabular}




\begin{tabular}{|c|c|c|c|c|c|c|}
\hline $\begin{array}{c}(\mathrm{OC}) \\
\text { subject } \\
\text { number }\end{array}$ & \multicolumn{2}{c}{$\begin{array}{c}\text { Femoral neck BMD (baseline) } \\
\text { Untrained limb }\end{array}$} & \multicolumn{2}{c|}{$\begin{array}{c}\text { Temoral neck BMD } \\
\text { (32 weeks) }\end{array}$} & \multicolumn{3}{c|}{$\begin{array}{c}\text { Femoral Neck BMD } \\
\text { (32 weeks - baseline) }\end{array}$} \\
\hline 2 & 0.789 & 0.732 & 0.746 & 0.707 & -0.043 & -0.025 \\
\hline 3 & 0.774 & 0.777 & 0.705 & 0.786 & -0.069 & 0.009 \\
\hline 36 & 0.939 & 0.965 & 0.957 & 0.965 & 0.018 & 0 \\
\hline 42 & 0.82 & 0.78 & 0.812 & 0.782 & -0.008 & 0.002 \\
\hline 52 & 0.796 & 0.819 & 0.843 & 0.793 & 0.047 & -0.026 \\
\hline 81 & 0.742 & 0.7 & 0.708 & 0.692 & -0.034 & -0.008 \\
\hline 83 & 1.087 & 1.054 & 1.078 & 1.075 & -0.009 & 0.021 \\
\hline 91 & 0.984 & 0.955 & 1.024 & 0.963 & 0.04 & 0.008 \\
\hline 324 & 0.972 & 0.955 & 0.975 & 0.909 & 0.003 & -0.046 \\
\hline 347 & 0.823 & 0.877 & 0.866 & 0.862 & 0.043 & -0.015 \\
\hline 363 & 0.786 & 0.805 & 0.834 & 0.795 & 0.048 & -0.01 \\
\hline 365 & 1.082 & 1.155 & 1.075 & 1.152 & -0.007 & -0.003 \\
\hline 5 & 0.807 & 0.879 & 0.905 & 0.914 & 0.098 & 0.035 \\
\hline 14 & 0.805 & 0.799 & 0.789 & 0.815 & -0.016 & 0.016 \\
\hline 25 & 0.802 & 0.827 & 0.847 & 0.86 & 0.045 & 0.033 \\
\hline 27 & 0.945 & 0.955 & 0.918 & 0.95 & -0.027 & -0.005 \\
\hline 38 & 0.602 & 0.607 & 0.599 & 0.618 & -0.003 & 0.011 \\
\hline 49 & 0.785 & 0.754 & 0.795 & 0.779 & 0.01 & 0.025 \\
\hline 62 & 0.964 & 0.944 & 0.966 & 0.987 & 0.002 & 0.043 \\
\hline 323 & 0.927 & 0.922 & 0.877 & 0.918 & -0.05 & -0.004 \\
\hline 326 & 0.938 & 0.974 & 0.989 & 0.982 & 0.051 & 0.008 \\
\hline 341 & 0.724 & 0.724 & 0.749 & 0.752 & 0.025 & 0.028 \\
\hline mean & 0.86 & 0.86 & 0.87 & 0.87 & 0.01 & 0.00 \\
\hline
\end{tabular}

\begin{tabular}{|c|c|c|c|c|c|c|}
\hline \multirow{2}{*}{$\begin{array}{l}\text { (NOC) } \\
\text { subject } \\
\text { number }\end{array}$} & \multicolumn{2}{|c|}{ Femoral neck BMD (baseline) } & \multicolumn{2}{|c|}{$\begin{array}{c}\text { Femoral neck BMD } \\
\text { (32 weeks) }\end{array}$} & \multicolumn{2}{|c|}{$\begin{array}{l}\text { Femoral Neck BMD } \\
\text { (32 weeks - baseline) }\end{array}$} \\
\hline & Untrained limb & Trained limb & Untrained limk & Trained limb & Untrained limb & Trained limb \\
\hline 1 & 0.922 & 0.933 & 0.959 & 0.922 & 0.037 & -0.011 \\
\hline 13 & 0.671 & 0.675 & 0.709 & 0.715 & 0.038 & 0.04 \\
\hline 16 & 0.849 & 0.767 & 1.03 & 0.761 & 0.181 & -0.006 \\
\hline 32 & 0.804 & 0.792 & 0.825 & 0.826 & 0.021 & 0.034 \\
\hline 33 & 0.757 & 0.743 & 0.789 & 0.734 & 0.032 & -0.009 \\
\hline 50 & 0.842 & 0.853 & 0.861 & 0.85 & 0.019 & -0.003 \\
\hline 64 & 0.806 & 0.798 & 0.82 & 0.791 & 0.014 & -0.007 \\
\hline 87 & 0.771 & 0.822 & 0.827 & 0.813 & 0.056 & -0.009 \\
\hline 94 & 0.982 & 0.93 & 1.01 & 0.938 & 0.028 & 0.008 \\
\hline 330 & 0.891 & 0.832 & 0.891 & 0.834 & 0 & 0.002 \\
\hline 335 & 0.877 & 0.84 & 0.825 & 0.823 & -0.052 & -0.017 \\
\hline 352 & 0.938 & 1.005 & 0.908 & 0.986 & -0.03 & -0.019 \\
\hline 354 & 0.786 & 0.823 & 0.773 & 0.797 & -0.013 & -0.026 \\
\hline 359 & 1.056 & 1.053 & 1.031 & 1.024 & -0.025 & -0.029 \\
\hline 11 & 0.769 & 0.773 & 0.742 & 0.771 & -0.027 & -0.002 \\
\hline 15 & 0.844 & 0.822 & 0.826 & 0.825 & -0.018 & 0.003 \\
\hline 39 & 0.875 & 0.878 & 0.866 & 0.901 & -0.009 & 0.023 \\
\hline 41 & 0.837 & 0.82 & 0.855 & 0.836 & 0.018 & 0.016 \\
\hline 63 & 0.742 & 0.717 & 0.798 & 0.721 & 0.056 & 0.004 \\
\hline 66 & 0.767 & 0.753 & 0.765 & 0.774 & -0.002 & 0.021 \\
\hline 72 & 0.975 & 0.937 & 0.983 & 0.966 & 0.008 & 0.029 \\
\hline 79 & 0.75 & 0.812 & 0.734 & 0.789 & -0.016 & -0.023 \\
\hline 314 & 0.787 & 0.792 & 0.81 & 0.797 & 0.023 & 0.005 \\
\hline 332 & 0.796 & 0.808 & 0.827 & 0.815 & 0.031 & 0.007 \\
\hline mean & 0.84 & 0.83 & 0.85 & 0.83 & 0.02 & 0.00 \\
\hline
\end{tabular}




\begin{tabular}{|c|c|c|c|c|c|c|c|}
\hline $\begin{array}{c}(\mathrm{OC}) \\
\text { subject } \\
\text { number }\end{array}$ & \multicolumn{2}{c}{ Total Hip BMD (baseline) } & \multicolumn{2}{c}{$\begin{array}{c}\text { Total Hip BMD } \\
\text { (32 weeks) }\end{array}$} \\
\hline 2 & 0.907 & 0.876 & 0.885 & 0.875 & -0.022 & -0.001 \\
\hline 3 & 0.87 & 0.895 & 0.829 & 0.903 & -0.041 & 0.008 \\
\hline 36 & 1.066 & 1.057 & 1.076 & 1.074 & 0.01 & 0.017 \\
\hline 42 & 0.97 & 0.94 & 0.992 & 0.951 & 0.022 & 0.011 \\
\hline 52 & 0.855 & 0.844 & 0.884 & 0.865 & 0.029 & 0.021 \\
\hline 81 & 0.811 & 0.777 & 0.81 & 0.82 & -0.001 & 0.043 \\
\hline 83 & 1.21 & 1.194 & 1.194 & 1.193 & -0.016 & -0.001 \\
\hline 91 & 1.146 & 1.141 & 1.14 & 1.146 & -0.006 & 0.005 \\
\hline 324 & 1.063 & 1.055 & 1.086 & 1.055 & 0.023 & 0 \\
\hline 347 & 0.897 & 0.908 & 0.926 & 0.922 & 0.029 & 0.014 \\
\hline 363 & 0.871 & 0.848 & 0.873 & 0.847 & 0.002 & -0.001 \\
\hline 365 & 1.189 & 1.254 & 1.206 & 1.272 & 0.017 & 0.018 \\
\hline 5 & 0.95 & 1.008 & 0.973 & 1.069 & 0.023 & 0.061 \\
\hline 14 & 0.957 & 0.931 & 0.942 & 0.935 & -0.015 & 0.004 \\
\hline 25 & 0.936 & 0.931 & 0.954 & 0.96 & 0.018 & 0.029 \\
\hline 27 & 1.029 & 1.049 & 1.015 & 1.057 & -0.014 & 0.008 \\
\hline 38 & 0.659 & 0.667 & 0.651 & 0.668 & -0.008 & 0.001 \\
\hline 49 & 0.843 & 0.837 & 0.837 & 0.855 & -0.006 & 0.018 \\
\hline 62 & 0.96 & 0.965 & 0.977 & 0.988 & 0.017 & 0.023 \\
\hline 323 & 0.951 & 1.029 & 0.967 & 1.022 & 0.016 & -0.007 \\
\hline 326 & 1.053 & 1.02 & 1.071 & 1.047 & 0.018 & 0.027 \\
\hline 341 & 0.821 & 0.808 & 0.895 & 0.855 & 0.074 & 0.047 \\
\hline mean & 0.96 & 0.96 & 0.96 & 0.97 & 0.01 & 0.02 \\
\hline
\end{tabular}

\begin{tabular}{|c|c|c|c|c|c|c|}
\hline \multirow{2}{*}{$\begin{array}{l}\text { (NOC) } \\
\text { subject } \\
\text { number }\end{array}$} & \multicolumn{2}{|c|}{$\underline{\text { Total Hip BMD (baseline) }}$} & \multicolumn{2}{|c|}{$\begin{array}{c}\text { Total Hip BMD } \\
\text { (32 weeks) }\end{array}$} & \multicolumn{2}{|c|}{$\begin{array}{c}\text { Total Hip BMD } \\
\text { (32 weeks - baseline) }\end{array}$} \\
\hline & Untrained limb & Trained limb & Untrained limb & Trained limb & Untrained limb & Trained limb \\
\hline 1 & 0.967 & 0.973 & 0.979 & 0.975 & 0.012 & 0.002 \\
\hline 13 & 0.818 & 0.821 & 0.828 & 0.832 & 0.01 & 0.011 \\
\hline 16 & 0.923 & 0.919 & 0.964 & 0.92 & 0.041 & 0.001 \\
\hline 32 & 0.866 & 0.889 & 0.865 & 0.904 & -0.001 & 0.015 \\
\hline 33 & 0.829 & 0.804 & 0.809 & 0.807 & -0.02 & 0.003 \\
\hline 50 & 0.979 & 0.98 & 0.98 & 0.989 & 0.001 & 0.009 \\
\hline 64 & 0.952 & 0.945 & 0.94 & 0.941 & -0.012 & -0.004 \\
\hline 87 & 0.874 & 0.941 & 0.89 & 0.936 & 0.016 & -0.005 \\
\hline 94 & 1.022 & 1.016 & 1.051 & 1.049 & 0.029 & 0.033 \\
\hline 330 & 0.92 & 0.913 & 0.927 & 0.922 & 0.007 & 0.009 \\
\hline 335 & 0.95 & 0.964 & 0.945 & 0.946 & -0.005 & -0.018 \\
\hline 352 & 1.05 & 1.039 & 1.049 & 1.046 & -0.001 & 0.007 \\
\hline 354 & 0.879 & 0.912 & 0.879 & 0.911 & 0 & -0.001 \\
\hline 359 & 1.099 & 1.079 & 1.117 & 1.105 & 0.018 & 0.026 \\
\hline 11 & 0.878 & 0.944 & 0.839 & 0.943 & -0.039 & -0.001 \\
\hline 15 & 0.895 & 0.948 & 0.893 & 0.934 & -0.002 & -0.014 \\
\hline 39 & 0.906 & 0.922 & 0.893 & 0.945 & -0.013 & 0.023 \\
\hline 41 & 0.94 & 0.894 & 0.956 & 0.897 & 0.016 & 0.003 \\
\hline 63 & 0.875 & 0.877 & 0.887 & 0.882 & 0.012 & 0.005 \\
\hline 66 & 0.755 & 0.786 & 0.756 & 0.794 & 0.001 & 0.008 \\
\hline 72 & 1.055 & 1.039 & 1.063 & 1.07 & 0.008 & 0.031 \\
\hline 79 & 0.825 & 0.878 & 0.815 & 0.868 & -0.01 & -0.01 \\
\hline 314 & 0.851 & 0.861 & 0.866 & 0.873 & 0.015 & 0.012 \\
\hline 332 & 0.911 & 0.944 & 0.94 & 0.953 & 0.029 & 0.009 \\
\hline mean & 0.92 & 0.93 & 0.92 & 0.94 & 0.00 & 0.01 \\
\hline
\end{tabular}




\begin{tabular}{|c|c|c|c|c|c|c|}
\hline \multirow{2}{*}{$\begin{array}{c}(\mathrm{OC}) \\
\text { subject } \\
\text { lumber }\end{array}$} & \multicolumn{2}{|c|}{ Total Tibia BMD (baseline) } & \multicolumn{2}{|c|}{$\begin{array}{l}\text { Total Tibia BMD } \\
\text { (32 weeks) }\end{array}$} & \multicolumn{2}{|c|}{$\begin{array}{c}\text { Total Tibial BMD } \\
\text { (32 weeks - baseline) } \\
\end{array}$} \\
\hline & Untrained limb & Trained limb & Untrained limb & Trained limb & Untrained limb & Trained limb \\
\hline 2 & no data & no data & 0.958 & 0.976 & no data & no data \\
\hline 3 & 0.846 & 0.791 & 0.866 & 0.817 & 0.02 & 0.026 \\
\hline 36 & 0.978 & 0.996 & 0.978 & 1.009 & 0 & 0.013 \\
\hline 42 & 0.91 & 0.95 & 0.915 & 0.908 & 0.005 & -0.042 \\
\hline 52 & 1.058 & 0.973 & 1.073 & 0.971 & 0.015 & -0.002 \\
\hline 81 & 0.97 & 0.931 & 0.909 & 0.932 & -0.061 & 0.001 \\
\hline 83 & 0.95 & 0.879 & 1.058 & 0.952 & 0.108 & 0.073 \\
\hline 91 & 1.256 & 1.249 & 1.246 & 1.232 & -0.01 & -0.017 \\
\hline 324 & 1.098 & 1.09 & 1.122 & 1.076 & 0.024 & -0.014 \\
\hline 347 & 0.876 & 0.842 & 0.831 & 0.831 & -0.045 & -0.011 \\
\hline 363 & 0.941 & 0.926 & 0.922 & 0.924 & -0.019 & -0.002 \\
\hline 365 & 1.157 & 1.104 & 1.171 & 1.19 & 0.014 & 0.086 \\
\hline 5 & 1.029 & no data & 1.071 & 1.013 & 0.042 & no data \\
\hline 14 & 1.06 & 1.032 & 1.014 & 1.02 & -0.046 & -0.012 \\
\hline 25 & 0.938 & 0.94 & 0.972 & 0.944 & 0.034 & 0.004 \\
\hline 27 & 1.078 & 1.087 & 1.092 & 1.101 & 0.014 & 0.014 \\
\hline 38 & 0.83 & 0.8 & 0.815 & 0.82 & -0.015 & 0.02 \\
\hline 49 & 1.071 & 1.034 & 1.026 & 1.019 & -0.045 & -0.015 \\
\hline 62 & 0.819 & 0.897 & 0.894 & 0.901 & 0.075 & 0.004 \\
\hline 323 & 1.036 & 1.028 & 1.091 & 1.062 & 0.055 & 0.034 \\
\hline 326 & 1.069 & 1.019 & 1.089 & 0.987 & 0.02 & -0.032 \\
\hline 341 & 0.904 & 0.866 & 0.917 & 0.887 & 0.013 & 0.021 \\
\hline mean & 0.99 & 0.97 & 1.00 & 0.98 & 0.01 & 0.01 \\
\hline \multirow{2}{*}{$\begin{array}{l}\text { (NOC) } \\
\text { subject } \\
\text { number }\end{array}$} & \multicolumn{2}{|c|}{ Total Tibia BMD (baseline) } & \multicolumn{2}{|c|}{$\begin{array}{c}\text { Total Tibia BMD } \\
\text { (32 weeks) }\end{array}$} & \multicolumn{2}{|c|}{$\begin{array}{c}\text { Total Tibial BMD } \\
\text { (32 weeks - baseline) }\end{array}$} \\
\hline & Untrained limb & Trained limb & Untrained limb & Trained limb & Untrained limb & Trained limb \\
\hline 1 & 1.067 & 1.101 & 1.066 & 1.082 & -0.001 & -0.019 \\
\hline 13 & 0.912 & 0.919 & 0.909 & 0.928 & -0.003 & 0.009 \\
\hline 16 & 0.948 & 0.941 & 0.953 & 0.954 & 0.005 & 0.013 \\
\hline 32 & 0.932 & 0.921 & 0.922 & 0.918 & -0.01 & -0.003 \\
\hline 33 & 1.051 & 1.005 & 1.077 & 1.018 & 0.026 & 0.013 \\
\hline 50 & 0.971 & 0.978 & 0.988 & 0.967 & 0.017 & -0.011 \\
\hline 64 & 0.982 & 0.964 & 0.984 & 0.964 & 0.002 & 0 \\
\hline 87 & 1.156 & 1.136 & 1.175 & 1.15 & 0.019 & 0.014 \\
\hline 94 & 1.035 & 1.002 & 1.065 & 0.978 & 0.03 & -0.024 \\
\hline 330 & 0.907 & 0.865 & 0.913 & 0.876 & 0.006 & 0.011 \\
\hline 335 & 0.863 & 0.872 & 0.886 & 0.883 & 0.023 & 0.011 \\
\hline 352 & 1.124 & 1.137 & 1.164 & 1.16 & 0.04 & 0.023 \\
\hline 354 & 1.033 & 1.02 & 1.059 & 1.07 & 0.026 & 0.05 \\
\hline 359 & 1.038 & 1.011 & 1.05 & 1.023 & 0.012 & 0.012 \\
\hline 11 & 1.026 & 1.058 & 1.057 & 1.065 & 0.031 & 0.007 \\
\hline 15 & 1.061 & 1.08 & 1.079 & 1.066 & 0.018 & -0.014 \\
\hline 39 & 0.958 & 1.001 & 0.982 & 1.025 & 0.024 & 0.024 \\
\hline 41 & 1.017 & 0.985 & 1.009 & 0.978 & -0.008 & -0.007 \\
\hline 63 & 1.108 & 1.2 & 1.113 & 1.204 & 0.005 & 0.004 \\
\hline 66 & 0.871 & 0.863 & 0.901 & 0.858 & 0.03 & -0.005 \\
\hline 72 & 0.977 & 0.985 & 1.02 & 1.047 & 0.043 & 0.062 \\
\hline 79 & 0.96 & 0.951 & 0.933 & 0.921 & -0.027 & -0.03 \\
\hline 314 & 0.881 & 0.93 & 0.925 & 0.949 & 0.044 & 0.019 \\
\hline 332 & 1.068 & 1.111 & 1.048 & 1.105 & -0.02 & -0.006 \\
\hline mean & 1.00 & 1.00 & 1.01 & 1.01 & 0.01 & 0.01 \\
\hline
\end{tabular}




\begin{tabular}{|c|c|c|c|c|c|c|}
\hline \multirow{2}{*}{$\begin{array}{c}(\mathrm{OC}) \\
\text { subject } \\
\text { number }\end{array}$} & \multicolumn{2}{|c|}{ Total UInar BMD (baseline) } & \multicolumn{2}{|c|}{$\begin{array}{l}\text { Total UInar BMD } \\
\text { (32 weeks) }\end{array}$} & \multicolumn{2}{|c|}{$\begin{array}{c}\text { Total Ulnar BMD } \\
\text { (32 weeks - baseline) }\end{array}$} \\
\hline & Untrained limb & Trained limb & Untrained limb & Trained limb & Untrained limb & Trained limb \\
\hline 2 & 0.482 & 0.501 & 0.481 & 0.492 & -0.001 & -0.009 \\
\hline 3 & 0.482 & 0.464 & 0.486 & 0.466 & 0.004 & 0.002 \\
\hline 36 & 0.498 & 0.516 & 0.502 & 0.507 & 0.004 & -0.009 \\
\hline 42 & 0.46 & 0.44 & 0.462 & 0.471 & 0.002 & 0.031 \\
\hline 52 & 0.513 & 0.511 & 0.519 & 0.518 & 0.006 & 0.007 \\
\hline 81 & 0.542 & 0.494 & 0.54 & 0.524 & -0.002 & 0.03 \\
\hline 83 & 0.554 & 0.547 & 0.557 & 0.568 & 0.003 & 0.021 \\
\hline 91 & 0.542 & 0.52 & 0.554 & 0.532 & 0.012 & 0.012 \\
\hline 324 & 0.498 & 0.489 & 0.526 & 0.519 & 0.028 & 0.03 \\
\hline 347 & 0.515 & 0.521 & 0.536 & 0.534 & 0.021 & 0.013 \\
\hline 363 & 0.537 & 0.535 & 0.533 & 0.544 & -0.004 & 0.009 \\
\hline 365 & 0.584 & 0.56 & 0.592 & 0.583 & 0.008 & 0.023 \\
\hline 5 & 0.54 & 0.526 & 0.542 & 0.55 & 0.002 & 0.024 \\
\hline 14 & 0.578 & 0.554 & 0.613 & 0.588 & 0.035 & 0.034 \\
\hline 25 & 0.544 & 0.547 & 0.551 & 0.55 & 0.007 & 0.003 \\
\hline 27 & 0.569 & 0.573 & 0.576 & 0.578 & 0.007 & 0.005 \\
\hline 38 & 0.484 & 0.551 & 0.482 & 0.547 & -0.002 & -0.004 \\
\hline 49 & 0.572 & 0.56 & 0.582 & 0.592 & 0.01 & 0.032 \\
\hline 62 & 0.516 & 0.493 & 0.507 & 0.492 & -0.009 & -0.001 \\
\hline 323 & 0.578 & 0.598 & 0.621 & 0.61 & 0.043 & 0.012 \\
\hline 326 & 0.674 & 0.626 & 0.704 & 0.647 & 0.03 & 0.021 \\
\hline 341 & 0.471 & 0.472 & 0.477 & 0.473 & 0.006 & 0.001 \\
\hline mean & 0.53 & 0.53 & 0.54 & 0.54 & 0.01 & 0.01 \\
\hline
\end{tabular}

\begin{tabular}{|c|c|c|c|c|c|c|}
\hline \multirow{2}{*}{$\begin{array}{l}\text { (NOC) } \\
\text { subject } \\
\text { number }\end{array}$} & \multicolumn{2}{|c|}{ Total UInar BMD (baseline) } & \multicolumn{2}{|c|}{$\begin{array}{c}\text { Total UInar BMD } \\
\text { (32 weeks) }\end{array}$} & \multicolumn{2}{|c|}{$\begin{array}{c}\text { Total Ulnar BMD } \\
\text { (32 weeks - baseline) }\end{array}$} \\
\hline & Untrained limb & Trained limb & Untrained limb & Trained limb & Untrained limb & Trained limb \\
\hline 1 & 0.552 & 0.528 & 0.547 & 0.547 & -0.005 & 0.019 \\
\hline 13 & 0.544 & 0.525 & 0.566 & 0.529 & 0.022 & 0.004 \\
\hline 16 & 0.543 & 0.531 & 0.542 & 0.535 & -0.001 & 0.004 \\
\hline 32 & 0.549 & 0.547 & 0.563 & 0.577 & 0.014 & 0.03 \\
\hline 33 & 0.495 & 0.476 & 0.514 & 0.495 & 0.019 & 0.019 \\
\hline 50 & 0.498 & 0.501 & 0.5 & 0.505 & 0.002 & 0.004 \\
\hline 64 & 0.556 & 0.546 & 0.553 & 0.563 & -0.003 & 0.017 \\
\hline 87 & 0.521 & 0.524 & 0.526 & 0.523 & 0.005 & -0.001 \\
\hline$\overline{94}$ & 0.567 & 0.528 & 0.559 & 0.543 & -0.008 & 0.015 \\
\hline 330 & 0.517 & 0.484 & 0.522 & 0.506 & 0.005 & 0.022 \\
\hline 335 & 0.518 & 0.503 & 0.524 & 0.531 & 0.006 & 0.028 \\
\hline 352 & 0.605 & 0.564 & 0.614 & 0.583 & 0.009 & 0.019 \\
\hline 354 & 0.579 & 0.552 & 0.616 & 0.591 & 0.037 & 0.039 \\
\hline 359 & 0.51 & 0.501 & 0.533 & 0.499 & 0.023 & -0.002 \\
\hline 11 & 0.554 & 0.523 & 0.555 & 0.53 & 0.001 & 0.007 \\
\hline 15 & 0.531 & 0.509 & 0.528 & 0.515 & -0.003 & 0.006 \\
\hline 39 & 0.579 & 0.564 & 0.636 & 0.575 & 0.057 & 0.011 \\
\hline 41 & 0.549 & 0.534 & 0.567 & 0.542 & 0.018 & 0.008 \\
\hline 63 & 0.471 & 0.484 & 0.48 & 0.485 & 0.009 & 0.001 \\
\hline 66 & 0.513 & 0.521 & 0.522 & 0.524 & 0.009 & 0.003 \\
\hline 72 & 0.58 & 0.542 & 0.568 & 0.542 & -0.012 & 0 \\
\hline 79 & no data & 0.47 & 0.497 & 0.472 & no data & 0.002 \\
\hline 314 & 0.509 & 0.502 & 0.522 & 0.523 & 0.013 & 0.021 \\
\hline 332 & 0.588 & 0.572 & 0.617 & 0.579 & 0.029 & 0.007 \\
\hline mean & 0.54 & 0.52 & 0.55 & 0.53 & 0.01 & 0.01 \\
\hline
\end{tabular}




\begin{tabular}{|c|c|c|c|c|c|c|c|c|}
\hline \multirow{2}{*}{$\begin{array}{c}(\mathrm{OC}) \\
\text { subject } \\
\text { number }\end{array}$} & \multicolumn{2}{|c|}{$\begin{array}{c}\text { Elbow Extensor Strength } \\
\text { (baseline) }\end{array}$} & \multicolumn{2}{|c|}{$\begin{array}{c}\text { Elbow Extensor Strength } \\
\text { (32-weeks) }\end{array}$} & \multicolumn{2}{|c|}{$\begin{array}{l}\text { Elbow Flexor Strength } \\
\text { (baseline) }\end{array}$} & \multicolumn{2}{|c|}{$\begin{array}{c}\text { Elbow Flexor Strength (32 } \\
\text { weeks) }\end{array}$} \\
\hline & $\begin{array}{l}\text { Untrained } \\
\operatorname{limb}(\mathrm{Nm})\end{array}$ & $\begin{array}{l}\text { Trained limb } \\
(\mathrm{Nm})\end{array}$ & $\begin{array}{l}\text { Untrained } \\
\operatorname{limb}(\mathrm{Nm})\end{array}$ & $\begin{array}{l}\text { Trained limb } \\
(\mathrm{Nm})\end{array}$ & $\begin{array}{l}\text { Untrained } \\
\operatorname{limb}(\mathrm{Nm})\end{array}$ & $\begin{array}{l}\text { Trained limb } \\
(\mathrm{Nm})\end{array}$ & $\begin{array}{l}\text { Untrained } \\
\operatorname{limb}(\mathrm{Nm})\end{array}$ & $\begin{array}{l}\text { Trained limb } \\
(\mathrm{Nm})\end{array}$ \\
\hline 2 & 70.5 & 64.6 & 70.4 & \begin{tabular}{l|l}
70.7 \\
\end{tabular} & 57.4 & 56.3 & 52.6 & 59.8 \\
\hline 3 & 34 & 36.3 & 53.3 & 58.9 & 28.7 & 30.2 & 34.5 & 36 \\
\hline 36 & 57.5 & 57 & 62.6 & 64.3 & 40.9 & 47.7 & 39.1 & 45.7 \\
\hline 42 & 50.5 & 57.9 & 55.6 & 63.7 & 44.2 & 42.3 & 47.8 & 41.9 \\
\hline 52 & 59.4 & 54.6 & 59.9 & 63 & 44.4 & 37.6 & 49.6 & 47.3 \\
\hline 81 & 48.3 & 53.5 & 53.8 & 58.5 & 31.7 & 29.9 & 31.6 & 55.7 \\
\hline 83 & 74.6 & 68.5 & 68.7 & 80.1 & 47.5 & 42 & 43.9 & 48.8 \\
\hline 91 & 74.6 & 70.6 & 96.6 & 105.8 & 52.1 & 52.3 & 59.8 & 63 \\
\hline 324 & 63 & 68.5 & 37 & 55.8 & 34.3 & 46.8 & 30.7 & 35.8 \\
\hline 347 & 66.4 & 66.9 & 66.9 & 60.3 & 49.6 & 51.4 & 50.6 & 47.9 \\
\hline 363 & 63.8 & 61.8 & 57 & 55 & 41.7 & 41.1 & 47 & 47.3 \\
\hline 365 & 62.2 & 58.5 & 67.6 & 70 & 44.9 & 40.6 & 52.9 & 47.1 \\
\hline 5 & 89.5 & 110.3 & 92.7 & 101.5 & 77.4 & 74.4 & 69.4 & 61.9 \\
\hline 14 & 63.7 & 54.8 & 64.4 & 63.2 & 48.5 & 46 & 54 & 48.1 \\
\hline 25 & 57.3 & 61.3 & 86.1 & 80.4 & 43.8 & 45.8 & 58.8 & 54.8 \\
\hline 27 & 81.5 & 72.1 & 87.2 & 105.7 & 67.2 & 50.9 & 46.6 & 53.3 \\
\hline 38 & 54.4 & 53.1 & 52.4 & 65.8 & 42.8 & 42.5 & 37.4 & 42.6 \\
\hline 49 & 57.7 & 64.2 & 87.4 & 100.8 & 49.2 & 44.4 & 47.6 & 63.3 \\
\hline 62 & 70.8 & 74.6 & no data & no data & 53.7 & 55.1 & no data & no data \\
\hline 323 & 95.7 & 102 & 99.3 & $\begin{array}{l}101.8 \\
\end{array}$ & 61.8 & 63.3 & 72.1 & $\begin{array}{l}64.9 \\
\end{array}$ \\
\hline 326 & 59.8 & 51.2 & 92.9 & 73.6 & 54.8 & 51.8 & 60.3 & 58.9 \\
\hline 341 & 45 & 38.1 & 55.8 & 65.1 & 35.1 & 34.4 & 39.9 & 42.4 \\
\hline mean & 63.6 & 63.7 & 69.9 & 74.5 & 47.8 & 46.7 & 48.9 & 50.8 \\
\hline
\end{tabular}

\begin{tabular}{|c|c|c|c|c|c|c|c|c|}
\hline \multirow{2}{*}{$\begin{array}{l}\text { (NOC) } \\
\text { subject } \\
\text { number }\end{array}$} & \multicolumn{2}{|c|}{$\begin{array}{l}\text { Elbow Extensor Strength } \\
\text { (baseline) }\end{array}$} & \multicolumn{2}{|c|}{$\begin{array}{c}\text { Elbow Extensor Strength } \\
\text { (32-weeks) }\end{array}$} & \multicolumn{2}{|c|}{$\begin{array}{l}\text { Elbow Flexor Strength } \\
\text { (baseline) }\end{array}$} & \multicolumn{2}{|c|}{$\begin{array}{c}\text { Elbow Flexor Strength (32 } \\
\text { weeks) }\end{array}$} \\
\hline & $\begin{array}{l}\text { Untrained } \\
\operatorname{limb}(\mathrm{Nm})\end{array}$ & $\begin{array}{l}\text { Trained limb } \\
(\mathrm{Nm})\end{array}$ & $\begin{array}{l}\text { Untrained } \\
\operatorname{limb}(\mathrm{Nm})\end{array}$ & $\begin{array}{l}\text { Trained limb } \\
(\mathrm{Nm})\end{array}$ & $\begin{array}{l}\text { Untrained } \\
\operatorname{limb}(\mathrm{Nm})\end{array}$ & $\begin{array}{l}\text { Trained limb } \\
(\mathrm{Nm})\end{array}$ & $\begin{array}{l}\text { Untrained } \\
\operatorname{limb}(\mathrm{Nm})\end{array}$ & $\begin{array}{l}\text { Trained limb } \\
(\mathrm{Nm})\end{array}$ \\
\hline 1 & 68.6 & 62.6 & 77.4 & 84.6 & 41.5 & 36 & 47.2 & 50.1 \\
\hline 13 & 53.4 & 57.1 & 63.6 & 80.2 & 29.2 & 31.3 & 43.3 & 41.3 \\
\hline 16 & 63.4 & 54.7 & 59.6 & 66.4 & 40.2 & 41.7 & 34.7 & 37.4 \\
\hline 32 & 63.1 & 48.2 & 65.6 & 71.5 & 49.5 & 36 & 40.8 & 48.5 \\
\hline 33 & 61.5 & 60 & 69.8 & 71.1 & 48.5 & 44.3 & 44.8 & 46.8 \\
\hline 50 & 46.8 & 53.6 & no data & no data & 44.2 & 44.1 & no data & no data \\
\hline 64 & 54.9 & 49.7 & 81.7 & 87.7 & 37.8 & 41.9 & 49.3 & 56.1 \\
\hline 87 & 60.5 & 64.1 & 66.3 & 59.9 & 42.8 & 56.6 & 60.3 & 50.3 \\
\hline 94 & 73.2 & 69.5 & 59.1 & 78.4 & 43.7 & 39.9 & 49.2 & 47.4 \\
\hline 330 & 50.6 & 49.6 & 51.8 & 59 & 33.8 & 40.8 & 40.7 & 36.7 \\
\hline 335 & 79.4 & 71.4 & 57.6 & 52.9 & 42.2 & 58.6 & 47.9 & 50.8 \\
\hline 352 & 55.5 & 48.5 & 60.9 & 59.2 & 54.6 & 51.9 & 53.2 & 51.2 \\
\hline 354 & 68.5 & 66 & 58.7 & 56.5 & 49.4 & 46.4 & 41.2 & 38.3 \\
\hline 359 & 60.1 & 67.9 & 60.2 & 59.4 & 57 & 47.9 & 45.3 & 59.5 \\
\hline 11 & 76.2 & 61.8 & 110.4 & 140.6 & 51.7 & 50.6 & 61.8 & 66.3 \\
\hline 15 & 50.5 & 52.2 & 81.9 & 93.8 & 46.4 & 41.9 & 49.8 & 45.8 \\
\hline 39 & 69.4 & 49.5 & 69.1 & 85.7 & 51 & 40.7 & 47.3 & 50.3 \\
\hline 41 & 74.7 & 58.9 & 58.8 & 53.6 & 63 & 47.5 & 42.6 & 57.5 \\
\hline 63 & 56.8 & 59.7 & 91.5 & 117 & 36.5 & 41 & 43.5 & 40.5 \\
\hline 66 & 37.3 & 39.4 & 57.4 & 64.8 & 37.4 & 29.8 & 41.8 & 42 \\
\hline 72 & 69.9 & 69.3 & 103.7 & 118.9 & 55.9 & 54.2 & 61.6 & 67.5 \\
\hline 79 & 69 & 69.2 & 80.1 & 96.3 & 60.4 & 48.9 & 50.7 & 55.4 \\
\hline 314 & 46.9 & 46.7 & 48.2 & 48.3 & 40.2 & 32.7 & 39.1 & 45.1 \\
\hline 332 & 59.6 & 52.6 & 58.5 & 67.4 & 44.7 & 50 & 57.9 & 56 \\
\hline mean & 61.2 & 57.6 & 69.2 & 77.1 & 45.9 & 43.9 & 47.6 & 49.6 \\
\hline
\end{tabular}




\begin{tabular}{|c|c|c|c|c|c|c|c|c|}
\hline \multirow{2}{*}{$\begin{array}{c}\text { (OC) } \\
\text { subject } \\
\text { number }\end{array}$} & \multicolumn{2}{|c|}{$\begin{array}{l}\text { Knee Extensor Strength } \\
\text { (baseline) }\end{array}$} & \multicolumn{2}{|c|}{$\begin{array}{l}\text { Knee Extensor Strength } \\
\text { (32-weeks) }\end{array}$} & \multicolumn{2}{|c|}{$\begin{array}{l}\text { Knee Flexor Strength } \\
\text { (baseline) }\end{array}$} & \multicolumn{2}{|c|}{$\begin{array}{l}\text { Knee Flexor Strength } \\
\text { (32-weeks) }\end{array}$} \\
\hline & $\begin{array}{l}\text { Untrained } \\
\operatorname{limb}(\mathrm{Nm})\end{array}$ & $\begin{array}{l}\text { Trained limb } \\
(\mathrm{Nm})\end{array}$ & $\begin{array}{l}\text { Untrained } \\
\operatorname{limb}(\mathrm{Nm})\end{array}$ & $\begin{array}{l}\text { Trained limb } \\
(\mathrm{Nm})\end{array}$ & $\begin{array}{l}\text { Untrained } \\
\text { limb }(\mathrm{Nm})\end{array}$ & $\begin{array}{l}\text { Trained limb } \\
(\mathrm{Nm})\end{array}$ & $\begin{array}{l}\text { Untrained } \\
\operatorname{limb}(\mathrm{Nm})\end{array}$ & $\begin{array}{l}\text { Trained limb } \\
(\mathrm{Nm})\end{array}$ \\
\hline 2 & 232.1 & 212.2 & 219.6 & 233.1 & 183.6 & 153.5 & 155.5 & 148.1 \\
\hline 3 & 113 & 114 & 151.8 & 142.2 & 92.2 & 70.7 & 100 & 96.9 \\
\hline 36 & 158.7 & 170.5 & 243.8 & 258.6 & 119.7 & 126.6 & 143.5 & 147.6 \\
\hline 42 & 132.9 & 161 & 200.6 & 179.1 & 102.6 & 109.3 & 128 & 131.7 \\
\hline 52 & 183.6 & 195.1 & 209.3 & 270.5 & 111.9 & 125.9 & 122.4 & 141.3 \\
\hline 81 & 223.1 & 187.6 & 188.4 & 197 & 118.1 & 109.4 & 96.1 & 97.9 \\
\hline 83 & 284.6 & 263.6 & 276 & 310.7 & 163.2 & 149.3 & 132.1 & 148.8 \\
\hline 91 & 259.8 & 186 & 300.4 & 344.4 & 201.8 & 195.8 & 153.7 & 144.4 \\
\hline 324 & 239.7 & 235.8 & 223.6 & 259.4 & 153.4 & 123.2 & 115 & 119.1 \\
\hline 347 & 214.8 & 218 & 199.2 & 232.3 & 132.9 & 125.4 & 146.6 & 137.5 \\
\hline 363 & 199.8 & 219.6 & 163.7 & 209.1 & 120.3 & 112.2 & 111.6 & 121.4 \\
\hline 365 & 299.1 & 293.5 & 291.1 & 349.5 & 160.4 & 139.4 & 171.6 & 187.7 \\
\hline 5 & 336.8 & 338.1 & 310.8 & 383.7 & 212.3 & 216.4 & 226 & 244.3 \\
\hline 14 & 197.4 & 187.2 & 242 & 266.3 & 133.4 & 123.3 & 126.4 & 129.5 \\
\hline 25 & 215.7 & 188.2 & 255.9 & 321.3 & 125.3 & 96.9 & 145.7 & 153.2 \\
\hline 27 & 249.7 & 232.9 & 259.3 & 283.1 & 133.5 & 122.2 & 140.1 & 151 \\
\hline 38 & 198.3 & 187.6 & 184.9 & 212.8 & 114.5 & 111.1 & 125.4 & 142.4 \\
\hline 49 & 249.5 & 234.3 & 263.7 & 284.7 & 205.1 & 146 & 129.8 & 198.3 \\
\hline 62 & 210.5 & 187.3 & 240.8 & 264.6 & 139 & 123.9 & 114.6 & 143.7 \\
\hline 323 & 278.2 & 239.2 & 249.8 & 168.1 & 110.2 & 115 & 129.3 & 125 \\
\hline 326 & 288.5 & 258.6 & 339.2 & 313.8 & 165.5 & 154.1 & 164 & 180.8 \\
\hline 341 & 212 & 177.7 & 217.9 & 267.1 & 126.2 & 111.2 & 125 & 143.4 \\
\hline mean & 226.3 & 213.1 & 237.8 & 261.4 & 142.1 & 130.0 & 136.5 & 147.0 \\
\hline
\end{tabular}

\begin{tabular}{|c|c|c|c|c|c|c|c|c|}
\hline \multirow{2}{*}{$\begin{array}{l}\text { (NOC) } \\
\text { subject } \\
\text { number }\end{array}$} & \multicolumn{2}{|c|}{$\begin{array}{l}\text { Knee Extensor Strength } \\
\text { (baseline) }\end{array}$} & \multicolumn{2}{|c|}{$\begin{array}{c}\text { Knee Extensor Strength } \\
\text { (32-weeks) }\end{array}$} & \multicolumn{2}{|c|}{$\begin{array}{l}\text { Knee Flexor Strength } \\
\text { (baseline) }\end{array}$} & \multicolumn{2}{|c|}{$\begin{array}{c}\text { Knee Flexor Strength } \\
\text { (32-weeks) }\end{array}$} \\
\hline & $\begin{array}{l}\text { Untrained } \\
\operatorname{limb}(\mathrm{Nm})\end{array}$ & $\begin{array}{c}\text { Trained limb } \\
(\mathrm{Nm})\end{array}$ & $\begin{array}{l}\text { Untrained } \\
\operatorname{limb}(\mathrm{Nm})\end{array}$ & $\begin{array}{l}\text { Trained limb } \\
(\mathrm{Nm})\end{array}$ & $\begin{array}{l}\text { Untrained } \\
\text { limb (Nm) }\end{array}$ & $\begin{array}{c}\text { Trained limb } \\
(\mathrm{Nm})\end{array}$ & $\begin{array}{l}\text { Untrained } \\
\operatorname{limb}(\mathrm{Nm})\end{array}$ & $\begin{array}{l}\text { Trained limb } \\
(\mathrm{Nm})\end{array}$ \\
\hline 1 & 216.2 & 218.6 & 251.2 & 295.6 & 136.5 & 165.1 & 165.2 & 137.5 \\
\hline 13 & 164.6 & 142.3 & 192.4 & 204.6 & 100 & 99 & 121.8 & 124.8 \\
\hline 16 & 135.6 & 136.6 & 151.4 & 175 & 106.2 & 95.3 & 101.1 & 110 \\
\hline 32 & 187 & 170 & 237 & 247.9 & 81.7 & 82.6 & 106.1 & 123.3 \\
\hline 33 & 218.5 & 224 & 247.3 & 282.7 & 121.2 & 131.1 & 130.1 & 146.5 \\
\hline 50 & 137.6 & 156.8 & no data & no data & 96.9 & 124.8 & no data & no data \\
\hline 64 & 158.6 & 145.9 & 275.1 & 296.8 & 96.6 & 96.1 & 151.2 & 160.5 \\
\hline 87 & 252 & 236.7 & 232.3 & 259 & 126.6 & 127.3 & 127.4 & 131.8 \\
\hline 94 & 209.8 & 206.7 & 250 & 257.1 & 137 & 138.8 & 150.5 & 154.6 \\
\hline 330 & 128.5 & 127.2 & 153 & 171.5 & 77.6 & 80.4 & 89.8 & 97.7 \\
\hline 335 & 269.2 & 274.6 & 286.7 & 276.8 & 104.6 & 117.5 & 117 & 132.6 \\
\hline 352 & 234.7 & 218.8 & 245 & 221.7 & 142.1 & 131.6 & 150.6 & 137.4 \\
\hline 354 & 218.5 & 207.4 & 196.6 & 194 & 98.5 & 95.4 & 97.3 & 98.6 \\
\hline 359 & 261.7 & 275.3 & 269.2 & 294.1 & 151.3 & 137.1 & 165.2 & 146.7 \\
\hline 11 & 194.6 & 200.4 & 287.9 & 366.2 & 127.3 & 140 & 176.7 & 218.2 \\
\hline 15 & 253.1 & 235.7 & 286.1 & 329.6 & 162.4 & 145.8 & 156.8 & 173.1 \\
\hline 39 & 215.9 & 183 & 213.3 & 277.6 & 118.9 & 120.8 & 126.1 & 137.7 \\
\hline 41 & 214.2 & 204.2 & 169.6 & 237.9 & 135.7 & 126.9 & 107.6 & 155 \\
\hline 63 & 229.3 & 211.5 & 282.1 & 258.8 & 152.2 & 138.4 & 141.2 & 111 \\
\hline 66 & 163.6 & 156.8 & 173.1 & 232.2 & 111.6 & 97.2 & 145.1 & 156 \\
\hline 72 & 225.9 & 245.3 & 344.9 & 364.2 & 159.6 & 121.1 & 186.6 & 189.1 \\
\hline 79 & 207.6 & 211.3 & 236.3 & 292.8 & 98.4 & 107.3 & 128.6 & 133.1 \\
\hline 314 & 194.7 & 187.4 & 177.5 & 206.2 & 101.2 & 116.6 & 102.5 & 116.8 \\
\hline 332 & 172.3 & 200 & 186.5 & 263.2 & 104.9 & 110.7 & 107.8 & 149 \\
\hline mean & 202.7 & 199.0 & 232.4 & 261.1 & 118.7 & 118.6 & 132.7 & 140.9 \\
\hline
\end{tabular}


Figure 5: Subject Inclusion Criteria for the TiBIAL study

\begin{tabular}{l} 
Subject Inclusion Criteria \\
\hline 1) Women, aged $18-26$ \\
2) Willing to give informed consent \\
3) Body Mass Index $18 \leq 25$ \\
4) Have not participated in any structured exercise program or \\
athletic training during the previous 12 months \\
5) No diagnosed or self-reported cardiovascular, pulmonary, \\
metabolic, or orthopedic medical conditions that medically would \\
contraindicate participation in maximal exercise \\
6) No self-reported menstrual disfunction during the past year (no \\
oligomenorrhea or amenorrhea \\
7) No bone disorders or diseases such as phenylketonuria or \\
diabetes, or other chronic deficiencies Crohn's disease, cancer, \\
ulcerative colitis, lactase deficiency, malabsorption, asthma, renal \\
disease, and thyroid diseases that may affect bone metabolism and \\
status \\
8) No use of oral contraceptives prescribed specifically to treat \\
menstrual irregularities, or other medications (prescription or \\
nonprescription) known to affect bone metabolism and status \\
9) Non-pregnant
\end{tabular}


TABLES AND FIGURES 


\section{TABLE 1:}

Table 1: Hormonal Contraceptive Concentrations - Use at Baseline

\begin{tabular}{|c|c|c|c|}
\hline & Estrogen (mg) & Progestin (mg)2 & Subjects \\
\hline Ortho-Tri-Cyclen & & & 11 \\
\hline days $1-7$ & Ethinyl estradiol 35 & Norgestimate 0.18 & \\
\hline days $8-14$ & Ethinyl estradiol 35 & Norgestimate 0.215 & \\
\hline Days $15-21$ & Ethinyl estradiol 35 & Norgestimate 0.25 & \\
\hline Ortho-Cyclen & Ethinyl estradiol 35 & Norgestimate 0.25 & 2 \\
\hline Desogen & Ethinyl estradiol 30 & Desogestrel 0.15 & 3 \\
\hline Triphasil & & & 2 \\
\hline days 1-6 & Ethinyl estradiol 30 & L-Norgestrel 0.05 & \\
\hline days $7-11$ & Ethinyl estradiol 40 & L-Norgestrel 0.075 & \\
\hline Days12-21 & Ethinyl estradiol 30 & L-Norgestrel 0.125 & \\
\hline Demulen 1/35 & Ethinyl estradiol 35 & Ethynodiol Diacetate 1.0 & 1 \\
\hline Loestrin $1.5 / 30$ & Ethinyl estradiol 30 & Norethindrone acetate 1.5 & 1 \\
\hline Nordette & Ethinyl estradiol 30 & L-Norgestrel 0.15 & 1 \\
\hline Ortho-Novum 1/35 & Ethinyl estradiol 35 & Norethindrone 1.0 & 1 \\
\hline None & 0 & 0 & 24 \\
\hline
\end{tabular}


TABLE 2:

Table 2: Baseline characteristics for oral contraceptive users and non-users

\begin{tabular}{|c|c|c|c|c|c|c|c|c|}
\hline \multirow[b]{2}{*}{ Measure } & \multirow[b]{2}{*}{ Unit } & \multicolumn{3}{|c|}{$\mathrm{NC}$} & \multicolumn{3}{|c|}{$\mathrm{OC}$} & \multirow[b]{2}{*}{$\mathbf{P}$} \\
\hline & & Mean & & SD & Mean & & SD & \\
\hline Age & $\mathrm{yr}$ & 20.0 & \pm & 1.5 & 20.1 & \pm & 1.2 & 0.83 \\
\hline Height & $\mathrm{m}$ & 1.6 & \pm & 5.9 & 1.6 & \pm & 6.4 & 0.30 \\
\hline Weight & $\mathrm{kg}$ & 57.9 & \pm & 7.6 & 60.0 & \pm & 9.7 & 0.42 \\
\hline Total Body Fat & $\%$ & 26.8 & \pm & 4.5 & 29.2 & \pm & 4.9 & 0.09 \\
\hline Total Body BMD & $\mathrm{g} / \mathrm{cm}^{2}$ & 1.114 & \pm & 0.070 & 1.109 & \pm & 0.090 & 0.81 \\
\hline \multicolumn{9}{|l|}{ Femoral Neck BMD } \\
\hline trained & $\mathrm{g} / \mathrm{cm}^{2}$ & 0.832 & \pm & 0.090 & 0.862 & \pm & 0.130 & 0.37 \\
\hline untrained & $\mathrm{g} / \mathrm{cm}^{2}$ & 0.837 & \pm & 0.090 & 0.859 & \pm & 0.120 & 0.49 \\
\hline \multicolumn{9}{|l|}{ Total Hip BMD } \\
\hline trained & $\mathrm{g} / \mathrm{cm}^{2}$ & 0.929 & \pm & 0.090 & 0.956 & \pm & 0.140 & 0.40 \\
\hline untrained & $\mathrm{g} / \mathrm{cm}^{2}$ & 0.917 & \pm & 0.080 & 0.955 & \pm & 0.130 & 0.25 \\
\hline \multicolumn{9}{|l|}{ Tibial BMD } \\
\hline trained & $\mathrm{g} / \mathrm{cm}^{2}$ & 1.002 & \pm & 0.090 & 0.917 & \pm & 0.110 & 0.34 \\
\hline untrained & $\mathrm{g} / \mathrm{cm}^{2}$ & 0.998 & \pm & 0.080 & 0.994 & \pm & 0.110 & 0.90 \\
\hline \multicolumn{9}{|l|}{ Tibial EI } \\
\hline trained & $\mathrm{N} \cdot \mathrm{m}^{2}$ & 111.9 & \pm & 70.9 & 106.6 & \pm & 50.3 & 0.78 \\
\hline untrained & $\mathrm{N} \cdot \mathrm{m}^{2}$ & 109.7 & \pm & 57.0 & 109.8 & \pm & 43.0 & 1.00 \\
\hline \multicolumn{9}{|l|}{ Ulnar BMD } \\
\hline trained & $\mathrm{g} / \mathrm{cm}^{2}$ & 0.522 & \pm & 0.030 & 0.527 & \pm & 0.050 & 0.64 \\
\hline untrained & $\mathrm{g} / \mathrm{cm}^{2}$ & 0.540 & \pm & 0.030 & 0.533 & \pm & 0.050 & 0.58 \\
\hline \multicolumn{9}{|l|}{ Ulnar EI } \\
\hline trained & $\mathrm{N} \cdot \mathrm{m}^{2}$ & 16.1 & \pm & 13.4 & 17.6 & \pm & 13.4 & 0.72 \\
\hline untrained & $\mathrm{N} \cdot \mathrm{m}^{2}$ & 16.9 & \pm & 11.0 & 18.9 & \pm & 16.3 & 0.63 \\
\hline
\end{tabular}




\section{TABLE 3:}

Table 3: Changes in strength over time for oral contraceptive users compared with non-users

\begin{tabular}{rrrrrr}
\multicolumn{3}{c}{ OC } & & \multicolumn{3}{c}{ NOC } \\
\hline \hline 0 & 32 & $\mathrm{P}$ & 0 & 32 & $\mathrm{p}$
\end{tabular}

\begin{tabular}{|c|c|c|c|c|c|c|}
\hline \multicolumn{7}{|l|}{ Arm } \\
\hline \multirow{2}{*}{$\begin{array}{l}\text { flexors } \\
(\mathrm{Nm})\end{array}$} & Trained & 46.3 & 50.80 .026 * & 43.94 & 49.60 & 0.002 * \\
\hline & untrained & 47.5 & $48.9 \quad 0.432$ & 45.97 & 47.57 & 0.428 \\
\hline \multirow{2}{*}{$\begin{array}{l}\text { extensors } \\
(\mathrm{Nm})\end{array}$} & Trained & 63.3 & 69.90 .041 * & 57.77 & 77.10 & 0.001 * \\
\hline & untrained & 63.1 & 74.50 .002 * & 61.87 & 69.21 & 0.042 * \\
\hline \multicolumn{7}{|l|}{ Leg } \\
\hline \multirow{2}{*}{$\begin{array}{l}\text { flexors } \\
(\mathrm{Nm})\end{array}$} & Trained & 130.0 & 147.00 .003 * & 118.35 & 140.91 & 0.001 * \\
\hline & untrained & 142.1 & 136.50 .332 & 119.66 & 132.71 & 0.003 * \\
\hline \multirow{2}{*}{$\begin{array}{l}\text { extensors } \\
(\mathrm{Nm})\end{array}$} & Trained & 213.1 & 261.40 .000 * & 200.86 & 261.11 & 0.000 * \\
\hline & untrained & 226.3 & 237.80 .132 & 205.48 & 232.37 & 0.004 * \\
\hline
\end{tabular}


TABLE 4:

Table 4: Changes in BMD and EI from baseline to post-training for $\mathrm{OC}$ users and nonusers

\begin{tabular}{|c|c|c|c|c|c|c|c|c|c|}
\hline \multirow[b]{2}{*}{ Reqion } & \multirow[b]{2}{*}{ Measure } & \multirow[b]{2}{*}{ Status } & \multirow[b]{2}{*}{ Units } & \multicolumn{3}{|c|}{ OC } & \multicolumn{3}{|c|}{ NOC } \\
\hline & & & & 0 & 32 & $\mathrm{p}$ & 0 & 32 & $\mathrm{p}$ \\
\hline Total Body & BMD & & $\mathrm{g} / \mathrm{cm}^{2}$ & 1.109 & 1.107 & 0.700 & 1.114 & 1.119 & $0.020^{*}$ \\
\hline \multirow{2}{*}{ Total Hip } & \multirow{2}{*}{ BMD } & trained & $\mathrm{g} / \mathrm{cm}^{2}$ & 0.956 & 0.972 & $0.000^{*}$ & 0.929 & 0.935 & $0.023^{*}$ \\
\hline & & untrained & $\mathrm{g} / \mathrm{cm}^{2}$ & 0.862 & 0.866 & 0.355 & 0.832 & 0.832 & 0.738 \\
\hline \multirow{2}{*}{ Femoral Neck } & \multirow{2}{*}{ BMD } & trained & $\mathrm{g} / \mathrm{cm}^{2}$ & 0.859 & 0.866 & 0.391 & 0.837 & 0.853 & 0.107 \\
\hline & & untrained & $\mathrm{g} / \mathrm{cm}^{2}$ & 0.955 & 0.963 & 0.146 & 0.917 & 0.922 & 0.196 \\
\hline \multirow{4}{*}{ Ulna } & \multirow{2}{*}{ BMD } & trained & $\mathrm{g} / \mathrm{cm}^{2}$ & 0.527 & 0.540 & $0.000^{*}$ & 0.522 & 0.534 & $0.000^{*}$ \\
\hline & & untrained & $\mathrm{g} / \mathrm{cm}^{2}$ & 0.53 & 0.54 & $0.003^{*}$ & 0.54 & 0.55 & $0.004^{*}$ \\
\hline & \multirow{2}{*}{$\mathrm{EI}$} & trained & $\mathrm{N} \cdot \mathrm{m}^{2}$ & 18.8 & 23.2 & 0.181 & 16.8 & 22.2 & $0.048^{*}$ \\
\hline & & untrained & $\mathrm{N} \cdot \mathrm{m}^{2}$ & 18.0 & 20.7 & 0.506 & 16.9 & 21.4 & 0.092 \\
\hline \multirow{4}{*}{ Tibia } & \multirow{2}{*}{ BMD } & trained & $\mathrm{g} / \mathrm{cm}^{2}$ & 0.972 & 0.979 & 0.298 & 1.002 & 1.008 & 0.151 \\
\hline & & untrained & $\mathrm{g} / \mathrm{cm}^{2}$ & 0.994 & 1.003 & 0.308 & 0.998 & 1.012 & $0.002^{*}$ \\
\hline & \multirow{2}{*}{ El } & trained & $\mathrm{N} \cdot \mathrm{m}^{2}$ & 107.1 & 139.0 & $0.046^{*}$ & 111.9 & 119.9 & 0.662 \\
\hline & & untrained & $\mathrm{N} \cdot \mathrm{m}^{2}$ & 108.1 & 125.6 & 0.158 & 109.7 & 141.9 & 0.063 \\
\hline
\end{tabular}

* statistically significant at $p<0.05$, no significance was found for time by group interactions, significant values reflect only time effects within groups 
Figure 1: Total body, and site specific increases in BMD seen in NOC and OC subjects

\section{OC Subjects}

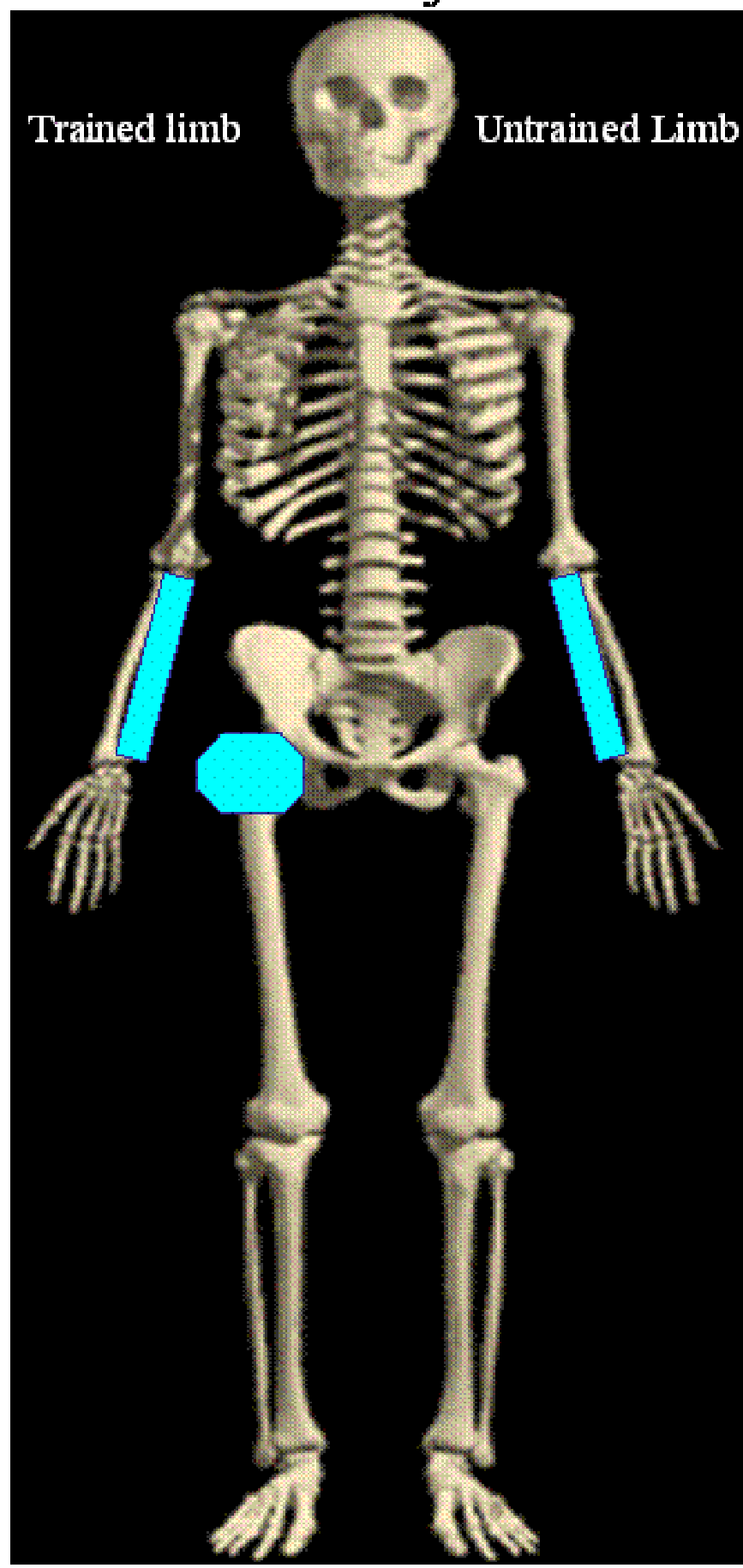

Total Ulna (Both limbs, p <0.01), Total Hip $\uparrow$ (Untrained limb, $\mathrm{p}<0.01$ )

\section{NOC Subjects}

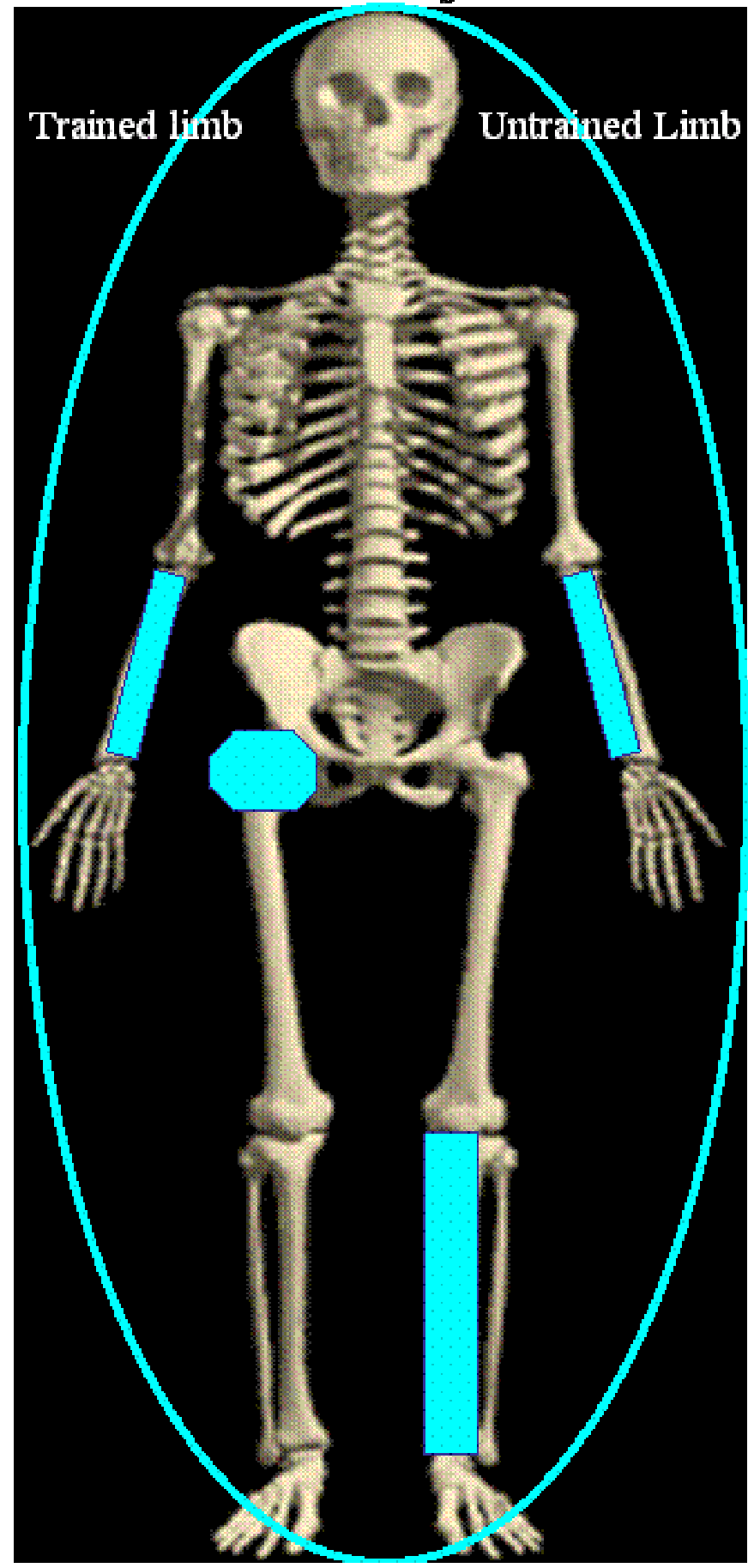

Total Body $\uparrow(p<005)$, Total Ulna $\uparrow$ (Both limbs, $\mathrm{p}<0.01$ ) Total Hip $\uparrow$ (Untraned limb, $\mathrm{p}<005$ ), Total Tibia (Traned limb, $\mathrm{p}<001$ ) 
Figure 2: Site specific changes in BMD over time for OC and NOC groups

\section{Changes in BMD over time (OC)}

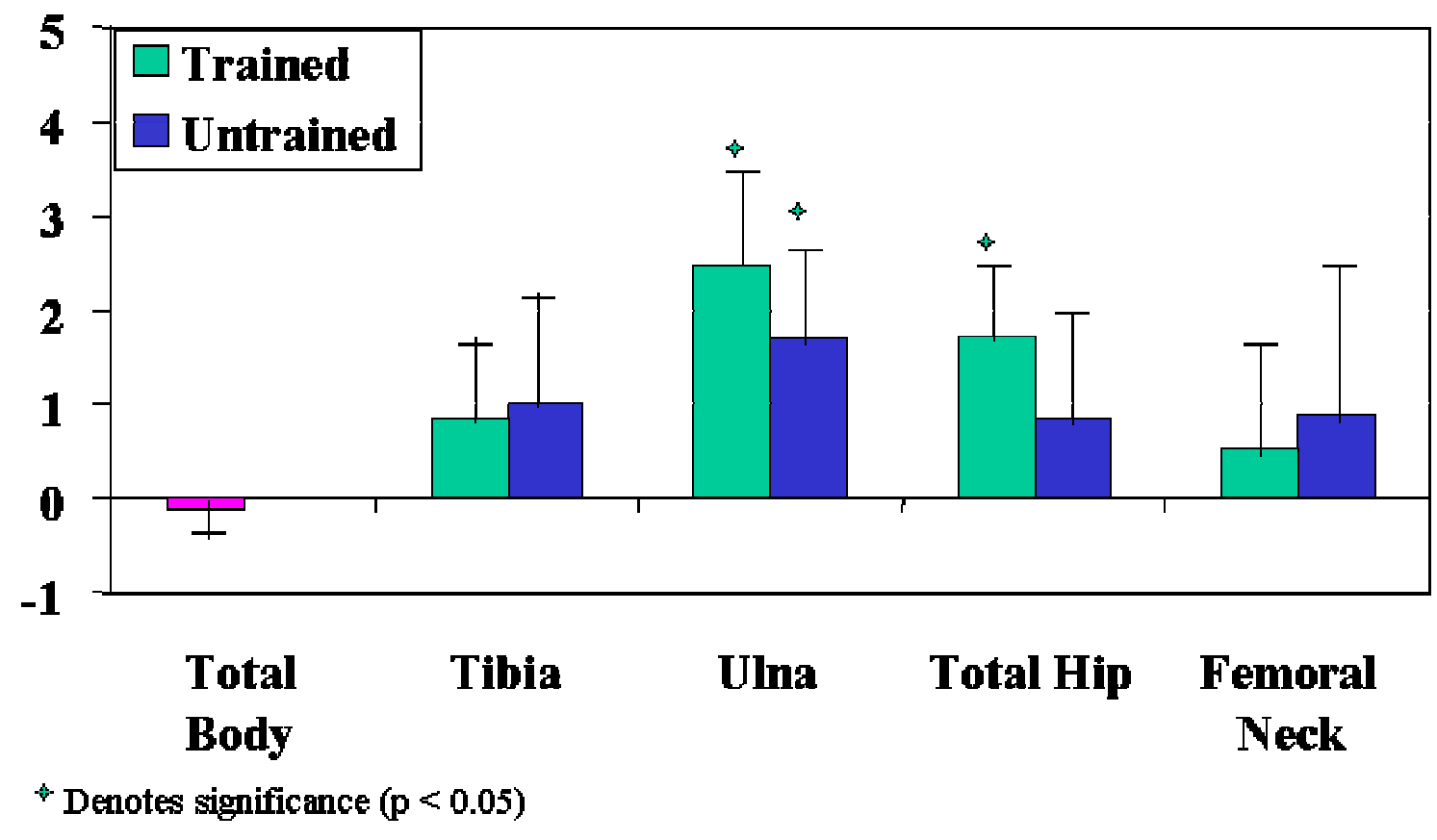

Changes in BMD over time (NOC)

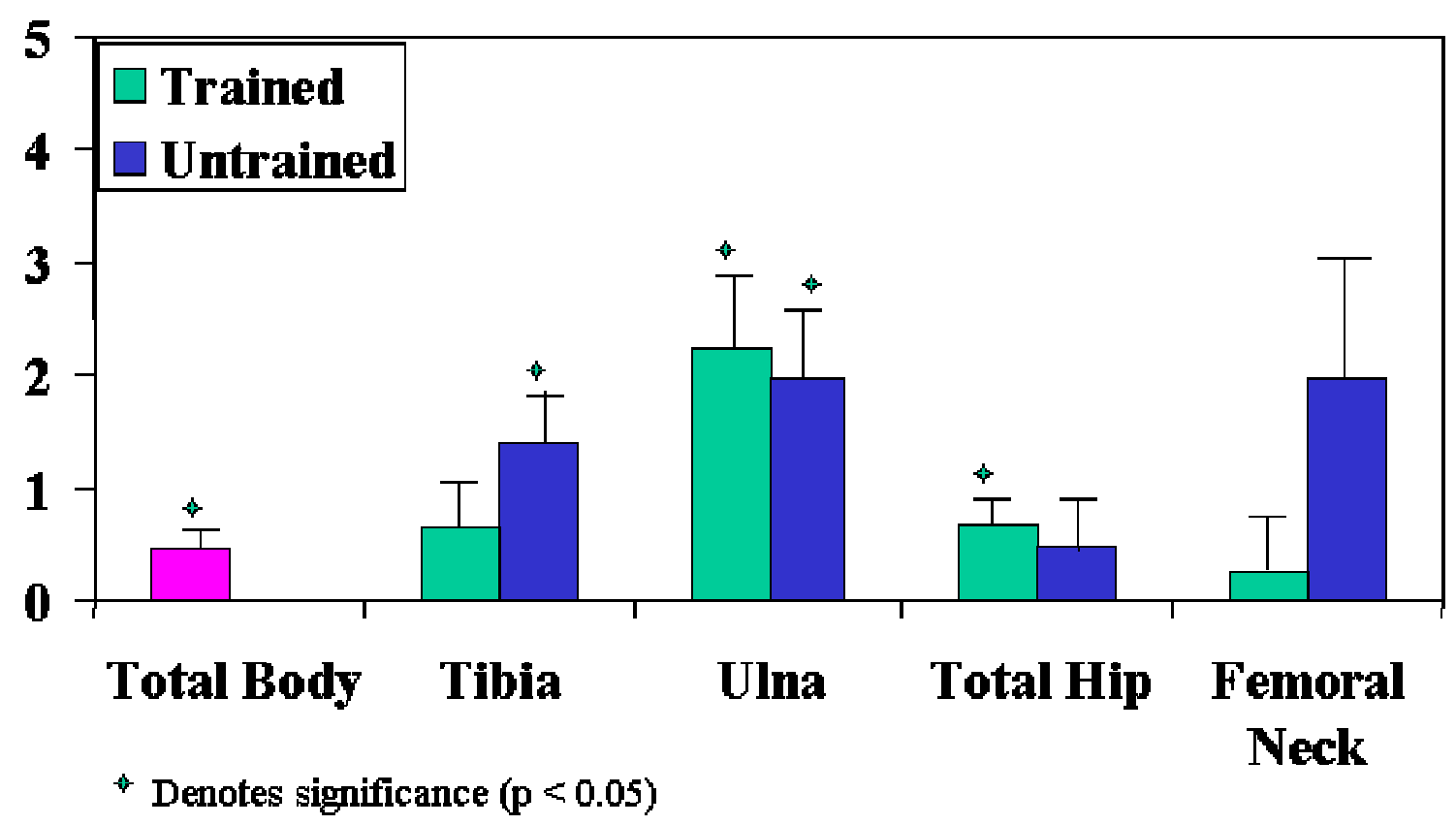


Figure 3- Trends seen in total body BMD (OC vs. NOC)

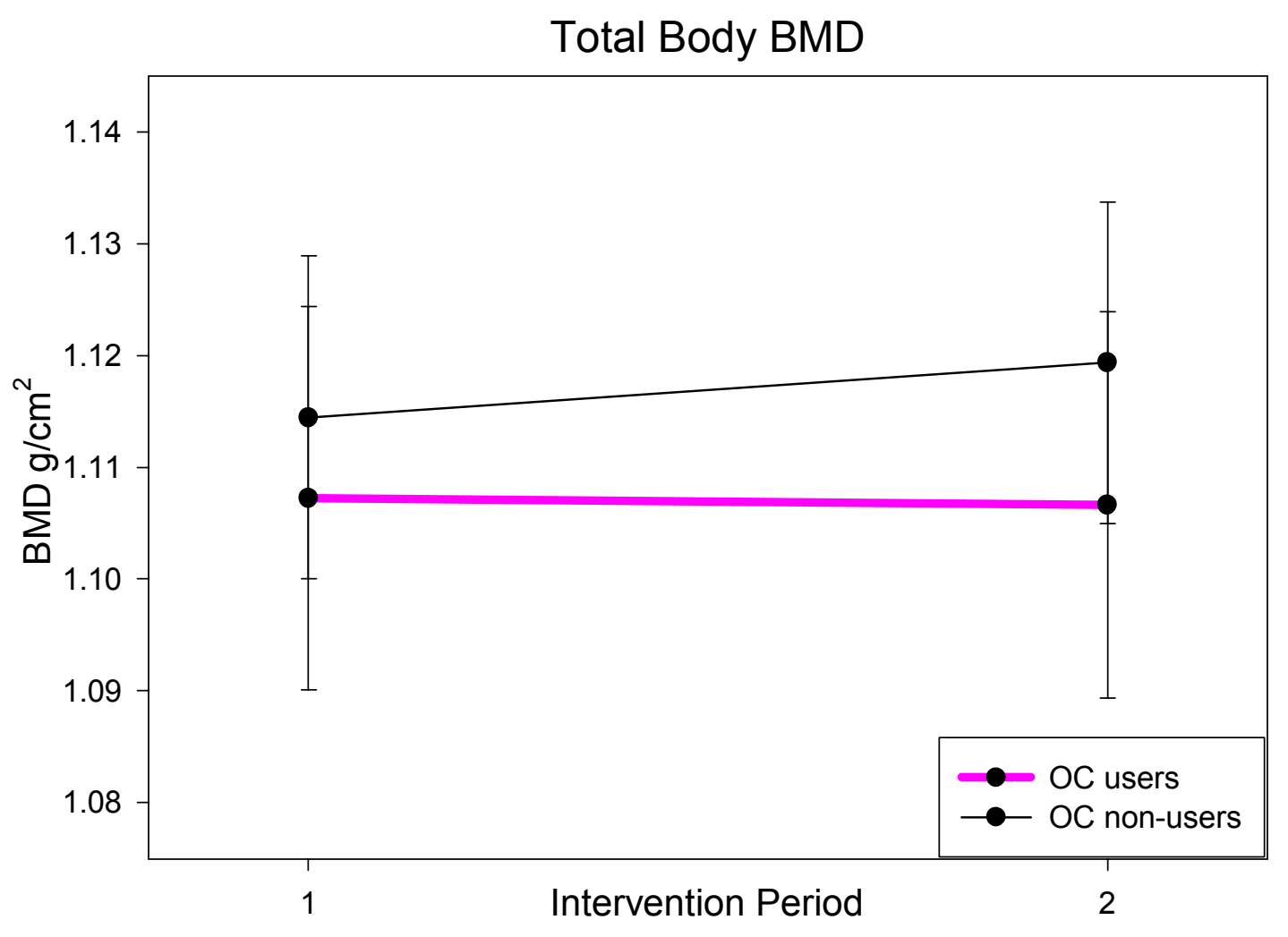


FIGURE 4: Diagram of skeletal maturation occurring in the ulna irrespective of exercise training, or oral contraceptive status

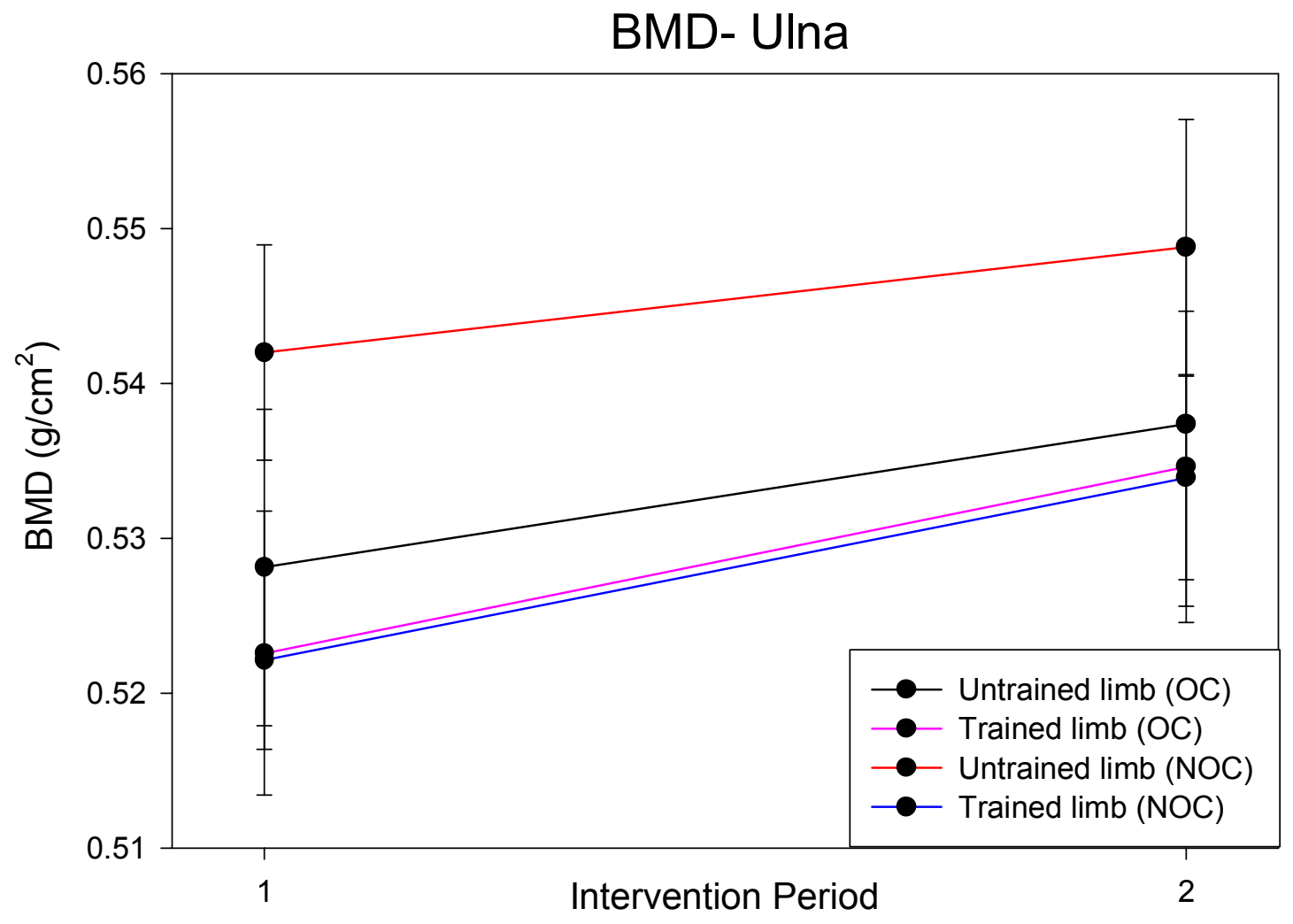




\section{CURRICULUM VITAE \\ Serah Elizabeth Selmon}

\section{ACADEMIC TRAINING}

Master of Science, Clinical Exercise Physiology, Virginia Polytechnic Institute and State University, Blacksburg, VA, 2003

Thesis topic: Influence of Oral Contraceptives on Bone Adaptations to Isokinetic Strength

Training in Young Women

-Advisor: Dr. William G. Herbert

Bachelor of Science, Human Nutrition, Foods and Exercise, Virginia Polytechnic Institute and State University, Blacksburg, VA, 2001

-Advisor: Dr. Kathleen C. Poole

\section{RESEARCH EXPERIENCE}

2001 - 2003 Laboratory Assistant; Laboratory for Health and Exercise Science, Virginia Polytechnic Institute and State University, Blacksburg, VA

\section{ACADEMIC/TEACHING EXPERIENCE}

2001 - 2003 Teaching Assistant; Virginia Polytechnic Institute and State University, Blacksburg, VA 
Courses taught: Health Counseling; Selected lectures in the Aerobics Instructor Certification, and Personal Training Certification courses; Clinical Applications of Therapeutic Exercise and Community Health

2002 - 2003 Weight Training Instructor; Virginia Polytechnic Institute and State University, Blacksburg, VA

\section{RELATED PROFESSIONAL EXPERIENCE}

2001 - 2002 Fitness Coordinator; New Town Fitness LLC, Blacksburg, VA

2000 - 2002 Personal Trainer; New Town Fitness LLC, Blacksburg, VA

2000-present Group Fitness Instructor; Virginia Polytechnic Institute and State University

(2000-2002), New Town Fitness, LLC (2001-2002), The Weight Club (2003-present)

\section{LICENSES AND CERTIFICATIONS}

ACSM Exercise Specialist ${ }^{\circledR}$

AFAA Group Exercise Instructor ${ }^{\circledR}$

ACE Personal Trainer ${ }^{\circledR}$

\section{ACADEMIC HONORS AND AWARDS}

Excellence Award for Graduate Health-Fitness Intern, Department of Human Nutrition, Foods and Exercise, Virginia Polytechnic Institute and State University 2001-2002

Excellence Award for Graduate Health-Fitness Intern, Department of Human Nutrition, Foods and Exercise, Virginia Polytechnic Institute and State University 2002-2003 


\title{
PROFESSIONAL AFFILIATIONS
}

American College of Sports Medicine (ACSM)

Aerobic Fitness Association of America (AFAA)

American Council on Exercise (ACE)

\section{MANUSCRIPTS}

Miller LE, Pierson LM, Selmon SE, Wootten DF, Nickols-Richardson SM, Ramp WK, and Herbert WG. Knee extensor and flexor torque development with concentric and eccentric isokinetic training. Submitted to: Research Quarterly for Exercise and Sport, September 2003.

\begin{abstract}
S AND PRESENTATIONS
Wootten DF, Thorne R, Ramp WK, Miller LE, Nickols-Richardson SM, Cross LH, Mott S, Guill S, Herbert WG. Tibial measurement reliability of refined mechanical response tissue analysis. J Bone Miner Res 2001; 16: SU344.
\end{abstract}

Mott S, Williams B, Wootten DF, Ramp WK, Kelso T, Herbert WG, FACSM. Do arm muscular strength variables influence ulnar bending stiffness? Med Sci Sport Exer 2002;34(5):S147.

Selmon SE, Zeff KD, Nickols-Richardson SM, Miller LE, Pierson LM, Wootten DF, Ramp WK, and Herbert WG. Leg strength and bone-free lean mass adaptations with concentric vs eccentric isokinetic strength training in young women. Medicine and Science in Sports and Exercise 35: S290, 2003. 
Selmon S.E., Herbert W.G., Nickols-Richardson S.M., Ramp W.K. Influence of Oral Contraceptives on Bone Adaptations to Isokinetic Strength Training in Young Women. Abstract Submitted to: Medicine and Science in Sports and Exercise for 2004 Annual Meeting.

Poole KP, Leiferman JA, Poole JR, Selmon SE. Examination of the physiological demands of officiating in the National Football League. Abstract Submitted to: Medicine and Science in Sports and Exercise for 2004 Annual Meeting. 